Portland State University

PDXScholar

$5-31-1994$

\title{
Modeling Music with Grammars: Some Examples from Balinese Kotekan
}

Janet Tom Cowal

Portland State University

Follow this and additional works at: https://pdxscholar.library.pdx.edu/open_access_etds

Part of the Applied Linguistics Commons, and the First and Second Language Acquisition Commons Let us know how access to this document benefits you.

\section{Recommended Citation}

Cowal, Janet Tom, "Modeling Music with Grammars: Some Examples from Balinese Kotekan" (1994). Dissertations and Theses. Paper 2933.

https://doi.org/10.15760/etd.2929

This Thesis is brought to you for free and open access. It has been accepted for inclusion in Dissertations and Theses by an authorized administrator of PDXScholar. Please contact us if we can make this document more accessible: pdxscholar@pdx.edu. 


\section{THESIS APPROVAL}

The abstract and thesis of Janet Tom Cowal for the Master of Arts in TESOL were presented May 31, 1994, and accepted by the thesis committee and the department.

COMMITTEE APPROVALS:

thames R. Nattinger, Chair

Beatrice T. Oshika

Stephen H. Martin

Representative of the Office of Graduate Studies

DEPARTMENT APPROVAL:

andes R. Nattinger, Chair

Department of Applied Linguistics

ACCEPTED FOR PORTLAND STATE UNIVERSITY BY THE LIBRARY

byl

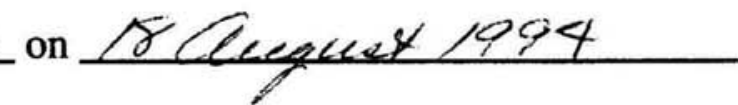




\begin{abstract}
,
An abstract of the thesis of Janet Tom Cowal for the Master of Arts in TESOL presented May 31, 1994.
\end{abstract}

Title: Modeling Music with Grammars: Some Examples from Balinese Kotekan

What is the relationship of music and language? Analogies and comparisons of music and language are plentiful in various types of literature. For researchers in the cognitive sciences, the importance of organization, patterning, and structuring of sounds is a common theme in analyzing both language and music. With the success of generative grammars for languages, a number of researchers have used similar kinds of grammars to describe or model particular aspects of music. In addition, researchers are interested in possible universals in musical grammars. However, while grammars of non-Western musics have been written, most of the work has been based on Western tonal systems.

The purpose of this research is to analyze, in an information processing, linguistic framework, a non-Western musical system for which there is currently no formal grammar in the literature, and to describe an aspect of it in the form of a grammar. Kotekan, the system of interlocking parts in Balinese gamelan music, is examined in this study.

This study is based on library research, scores, tapes, and communication with experts in Balinese music. A number of previously written grammars for musical systems are examined, as well as literature concerning various types of formal grammars. Balinese kotekan data is collected, in the form of literature, scores, and tapes. Portions of the data are described in the form of a grammar. The rules are then tested on new data, that is, portions of other Balinese pieces. 
The natures of and the relationship between music and language can be examined more closely through the use of an information processing, linguistic framework. Grammars are a precise and formal way of describing structure and regularities in linguistic and musical systems, and of describing aspects of competence. Linguistic and musical grammars share some features and differ in others.

The grammar for Balinese kotekan presented in this study exhibits features that are similar to other musical grammars. The system can be described as a hierarchy of constraints from global tendencies to specific rules for various types of kotekan. In addition, there are deep and surface structures, variation related to structure, ranked or preference rules, spatio-motor considerations, and the need for context-sensitive rules. The structure of polos and sangsih (the interlocking parts of kotekan) as individual lines is described by context-free phrase structure rules. The relationship between polos and sangsih is described by transformations. The grammar presented is a starting point for a complete grammar of Balinese kotekan. 


\title{
MODELING MUSIC WITH GRAMMARS: SOME EXAMPLES FROM BALINESE KOTEKAN
}

\author{
by \\ JANET TOM COWAL
}

A thesis submitted in partial fulfillment of the requirements for the degree of

\section{MASTER OF ARTS}

in

TESOL

\section{Portland State University}

1994 


\section{TABLE OF CONTENTS}

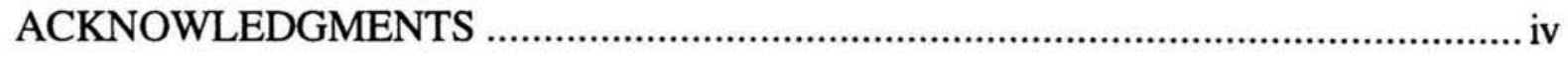

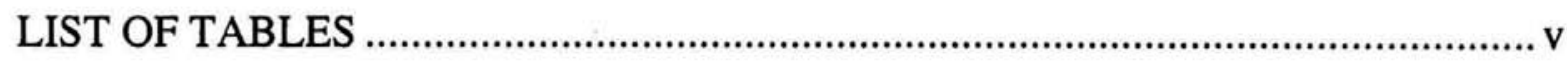

LIST OF FIGURES ........................................................................................ vi

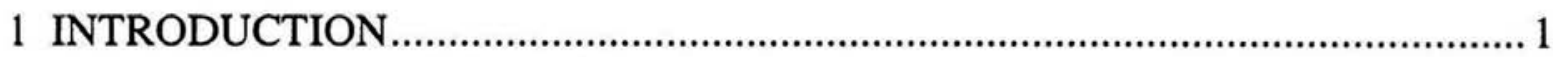

1.1 Statement of the Problem ........................................................................ 1

1.2 Language and Music Analogies ....................................................... 1

1.2.1 Structure.................................................................................. 4

1.2.2 Systems of Rules.................................................................. 5

1.2.3 Levels of Abstraction and Representation................................. 5

1.2.4 Information Processing Framework....................................... 6

1.2.5 Grammars and Competence ................................................. 6

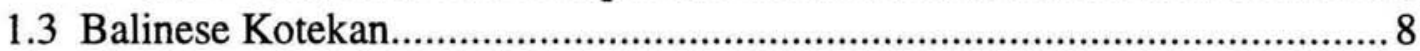

1.4 Research Questions ............................................................................ 10

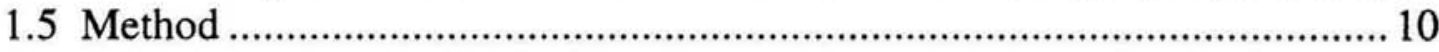

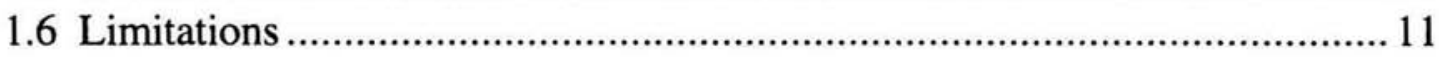

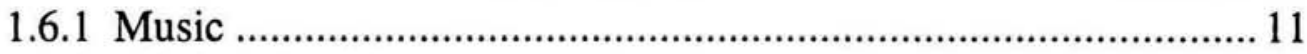

1.6 .2 (Native) Intuition ............................................................... 11

1.6.3 Experienced Listener........................................................... 13

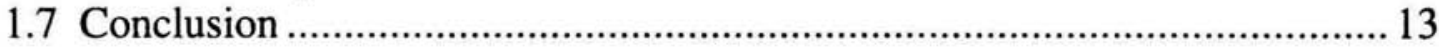

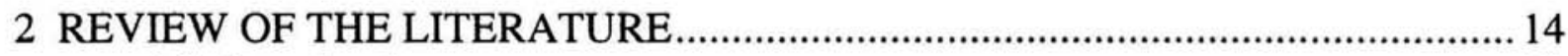

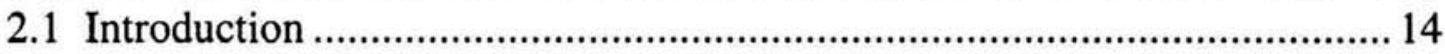

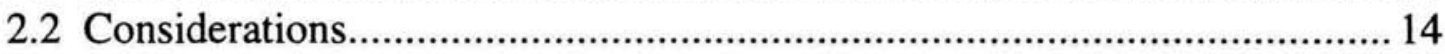

2.2.1 Well-formedness and Grammaticality ................................... 14

2.2.2 Motivation for Rules........................................................... 16

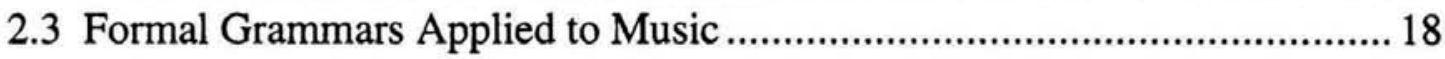

2.3.1 Background .................................................................... 18

2.3.2 Regular Grammar, Finite-State (Type 3) .................................. 20

2.3.3 Context-Free Grammar (Type 2) .......................................... 21

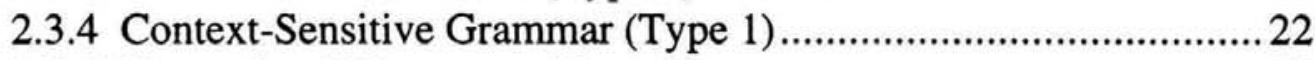

2.3.5 Unrestricted Grammars (Type 0) ............................................. 24

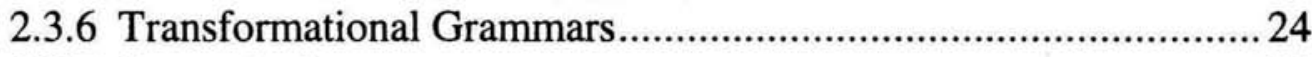

2.3.7 Systemic Grammars ............................................................. 25

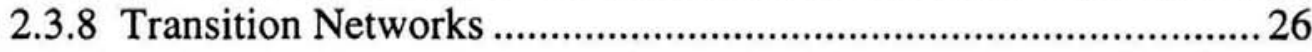

2.3.9 Multidimensional Grammars................................................... 27

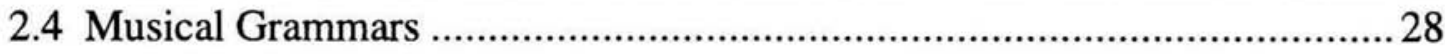

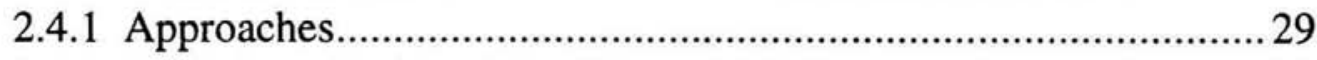

2.4.2 A Listing of Selected Studies ................................................ 30 
2.5 Selected Features of Musical Grammars ……............................................. 32

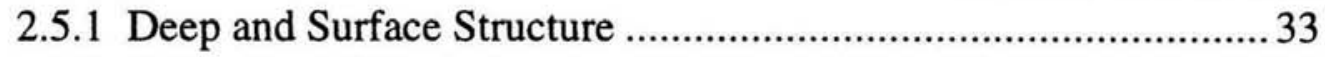

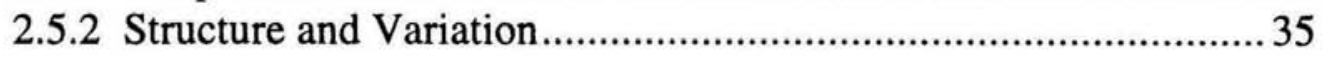

2.5.3 Hierarchy of Rules -- Precedence, Conflicts, Variation ................. 36

2.5.4 Preference Rules ........................................................................ 38

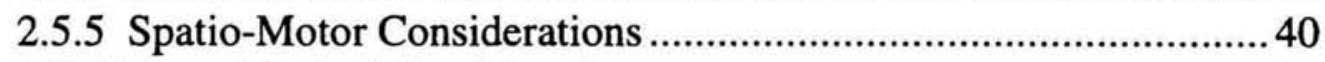

2.5.6 Extra-Musical Considerations ...................................................... 42

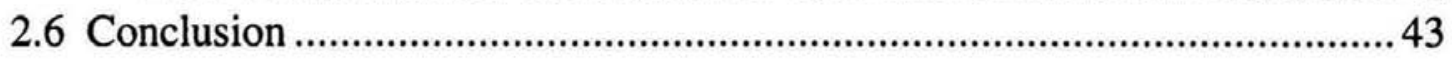

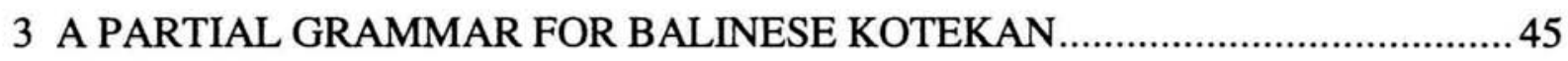

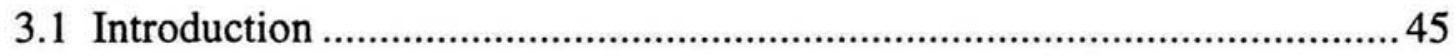

3.2 Balinese Gamelan Music - Background.......................................................45

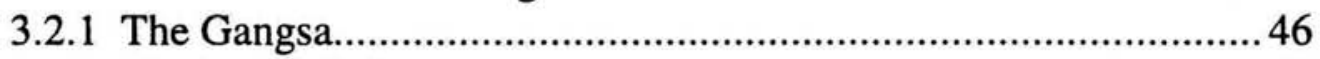

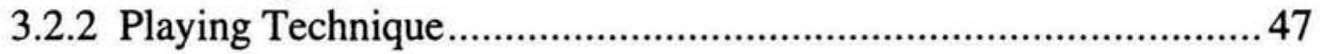

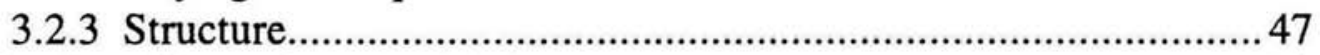

3.3 Rules in Balinese Gamelan Music ................................................................ 49

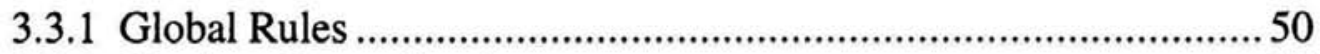

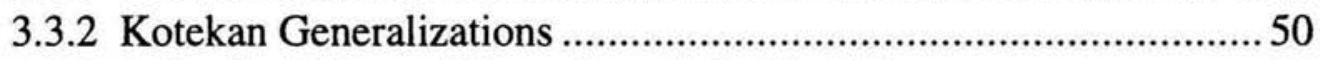

3.3.3 Rules for Polos and Sangsih as Individual Lines. .........................52

3.3.4 Rules for Generating Sangsih from Polos. ..................................55

3.3.4.1 Oncang-Oncangan ........................................................5 56

3.3.4.2 Kotekan Norot ............................................................59

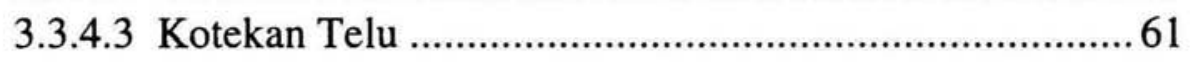

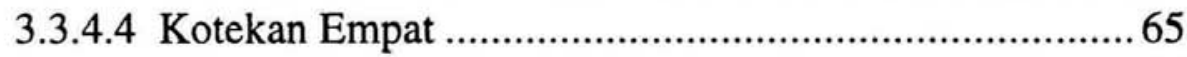

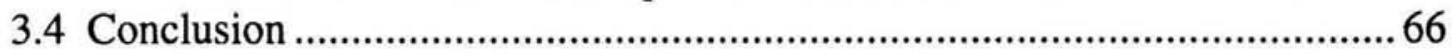

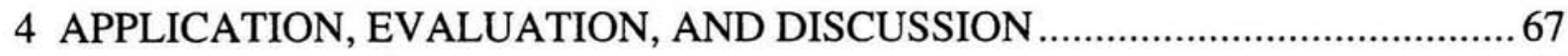

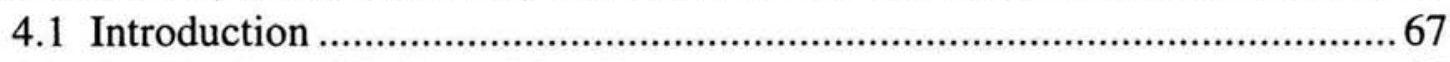

4.2 Application of Rules to New Data ..........................................................67

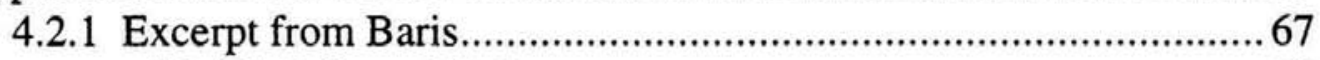

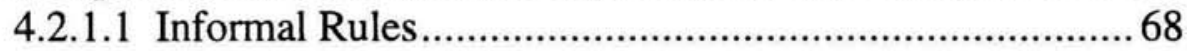

4.2.1.2 Phrase Structure Rules for Polos and Sangsih as Individual Lines ............................................................ 68

4.2.1.3 Polos-to-Sangsih Transformational Rules (Kotekan Empat) ........................................................................ 70

4.2.2 Excerpt from Legong Keraton ................................................. 71

4.2.2.1 Informal Rules............................................................ 71

4.2.2.2 Phrase Structure Rules for Polos and Sangsih as Individual Lines ............................................................ 72

4.2.2.3 Polos-to-Sangsih Transformational Rules (Kotekan Empat) .................................................................... 74

4.2.3 Excerpt from Gora Merdawa …………......................................... 77

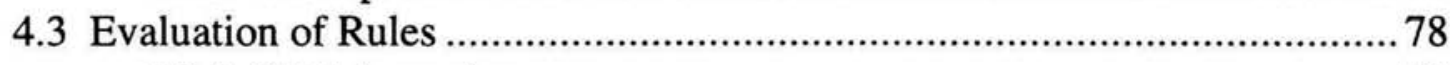

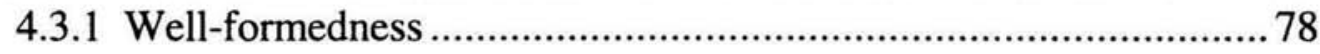




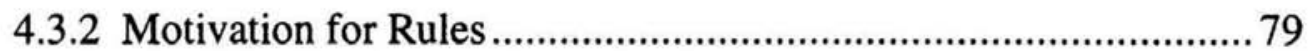

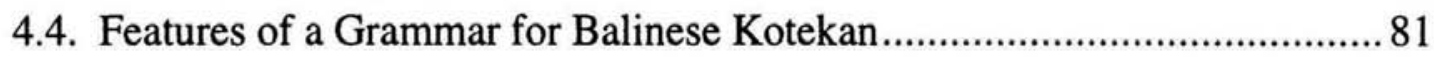

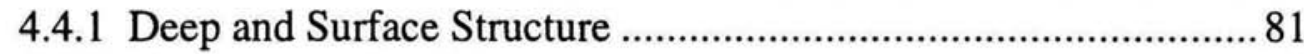

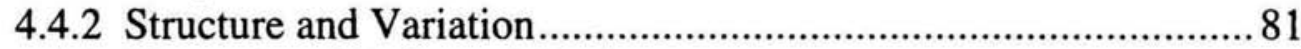

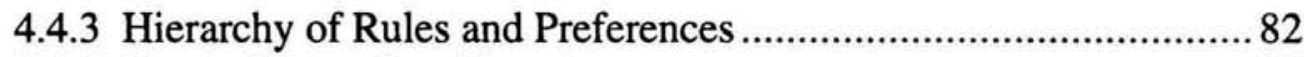

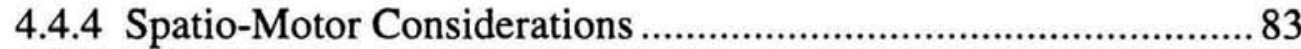

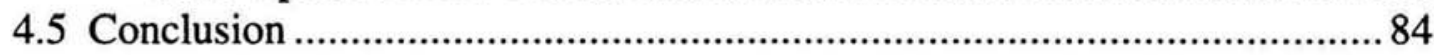

5 CONCLUSION

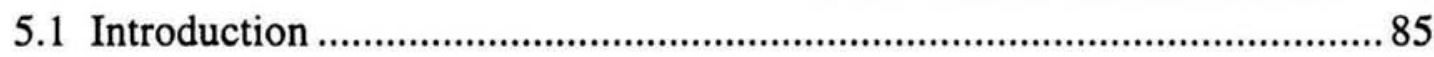

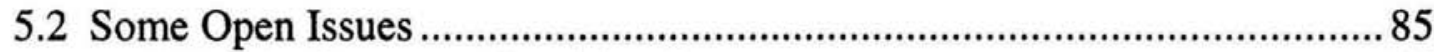

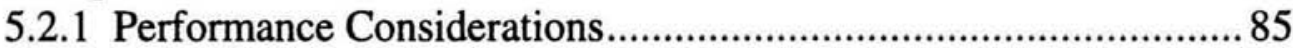

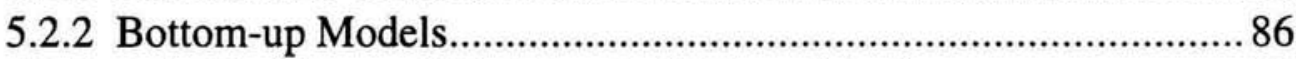

5.2.3 Rule Conflicts and Variation in Balinese Music .......................... 86

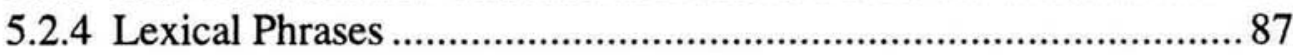

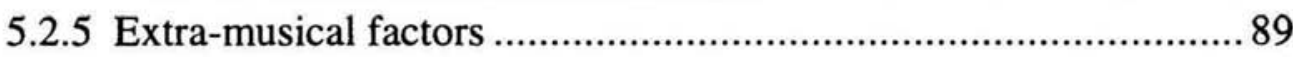

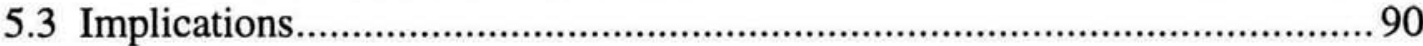

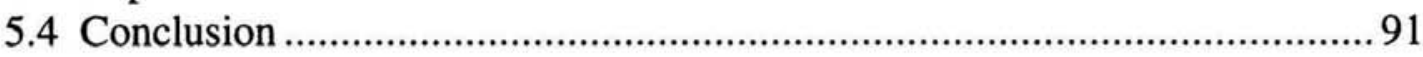

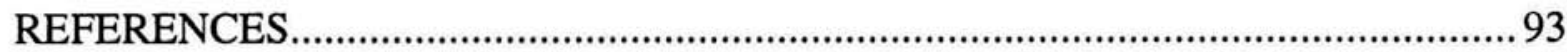

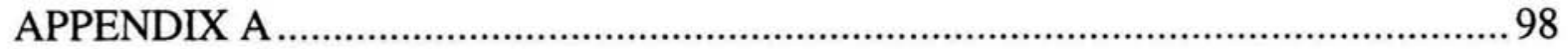

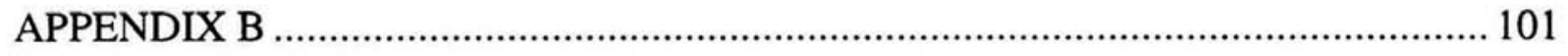

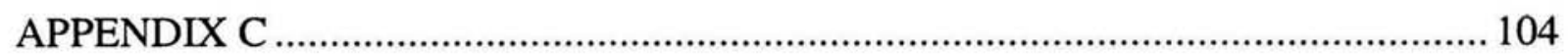




\section{ACKNOWLEDGMENTS}

I am very grateful for the following support:

The members of the thesis committee, James Nattinger, Beatrice Oshika, and Stephen Martin, provided guidance, encouragement, comments, and interesting discussion.

Wayne Vitale provided Balinese music expertise, information, scores, tapes, many hours of discussion, and comments. He also demonstrated kotekan on the gangsas with the assistance of I Nyoman Windha and Sarah Willner.

Al Kato provided a keyboard instrument that substituted for a gangsa.

Jay Peterson provided comments, discussion, and alternative views.

Vincent Cowal provided computer expertise, comments, and a wonderful sense of humor. 


\section{LIST OF TABLES}

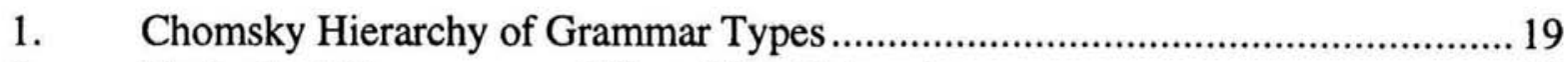

2. Equivalent Grammars and Transition Networks...............................................22

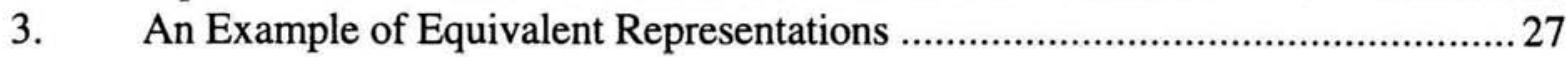

4. Selected Studies of Musical Grammars …….................................................... 31

5. Correspondence between Polos in Figure 23 and Line (1) ................................5 54

6. Example Sequences of Notes Described by Line (1) .......................................55

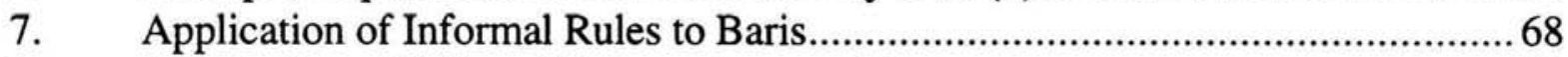

8. Application of Informal Rules to Legong Keraton ...........................................71

9. Descriptions of Broken Rules in Gora Merdawa .............................................. 77 


\section{LIST OF FIGURES}

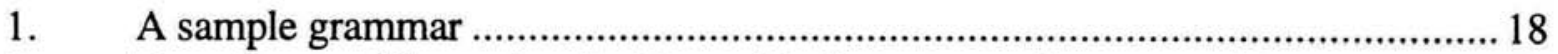

2. Tree diagram illustrating the hierarchical structure of sequence (a) ....................22

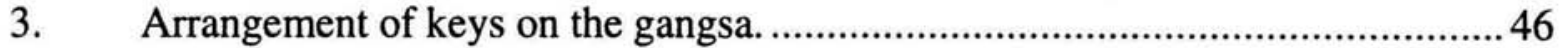

4. Gangsas and assignments of polos and sangsih parts.......................................4 47

5. Hierarchical phrasing structure of Balinese gamelan music................................48

6. Display of a typical layering of instrumental parts in an 8-beat phrase. ...............49

7. Transition network for generating polos and sangsih lines................................53

8. Patterns generated by the NP phrase structure rule and corresponding note

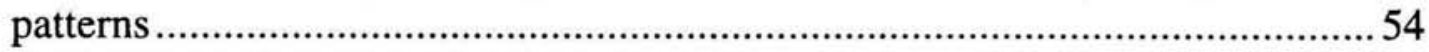

9. An example of a graphical representation of line (1) .....................................5

10. Process of generating sangsih from polos ...................................................58

11. Tree structure illustrating the derivation of polos and sangsih from the core......60 60

12. Generation of sangsih from the polos and ultimately, from the pokok. ..............61

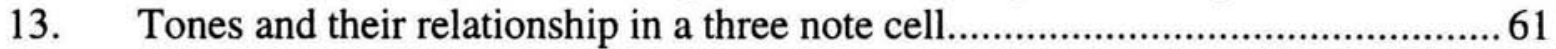

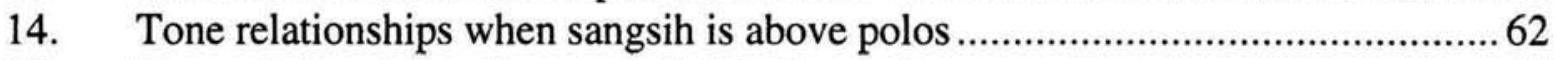

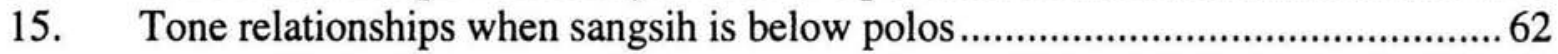

16. Three note cell when polos alternates between $\mathrm{E}$ and $\mathrm{G}$...................................63

17. Generation of sangsih from the polos in Appendix A - Figure 28 ........................64

18. Relationship of tones to a 4 note cell and the kotekan parts ...............................65

19. Correspondence between Baris and the lines generated by the phrase

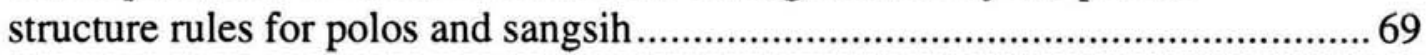

20. Generation of sangsih from the polos in Baris ................................................. 70

21. Correspondence between Legong Keraton and lines generated by phrase structure rules for polos and sangsih ................................................................73

22. Generation of sangsih from the polos in Legong Keraton................................76

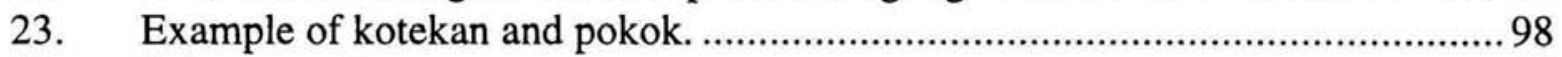

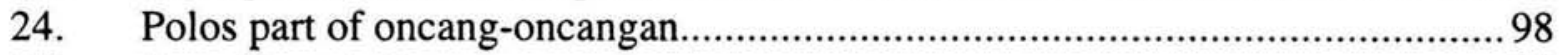

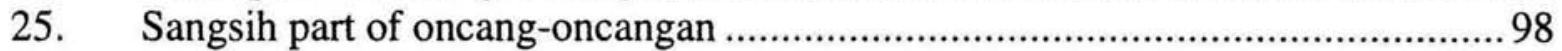

26. Composite of polos and sangsih in oncang-oncangan ......................................... 98

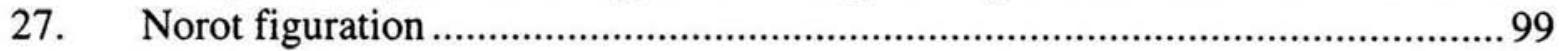

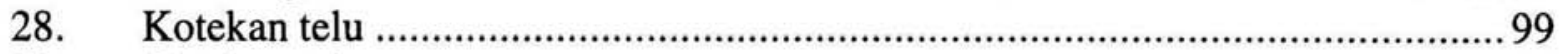

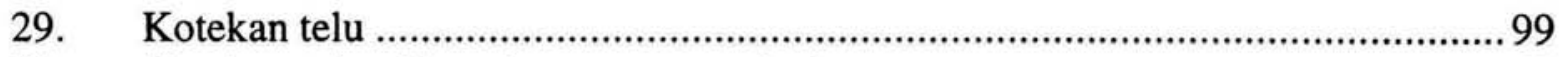

30. Kotekan telu. Shared notes are marked......................................................... 99

31. Kotekan telu with sangsih below polos........................................................ 100

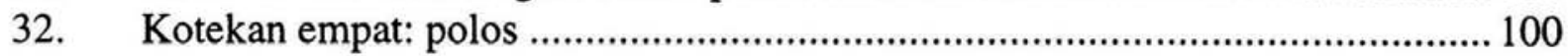

33. Kotekan empat: application of $\mathrm{R}->\mathrm{c}$ rule for generating sangsih from polos ...... 100

34. Kotekan empat: complete figuration that results by applying $b->R$ and

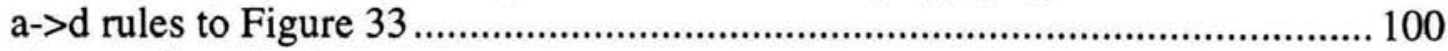

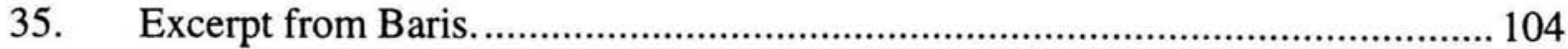

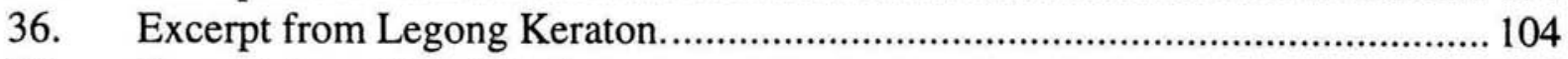

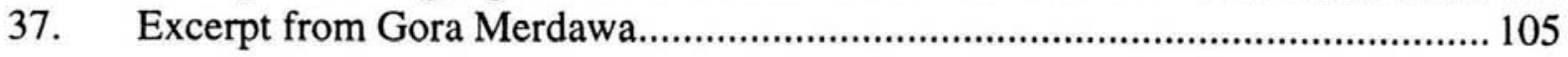




\section{CHAPTER 1}

\section{INTRODUCTION}

\subsection{Statement of the Problem}

What is the relationship of music and language? Analogies and comparisons of music and language are plentiful in various types of literature. For researchers in the cognitive sciences, the importance of organization, patterning, and structuring of sounds is a common theme in analyzing both language and music. With the success of generative grammars for languages, a number of researchers have used similar kinds of grammars to describe or model particular aspects of music. In addition, researchers are interested in possible universals in musical grammars. However, while grammars of non-Western musics $^{1}$ have been written, most of the work has been based on Western tonal systems.

The purpose of this research is to analyze, in the tradition of linguistics, a nonWestern musical system for which there is currently no formal grammar in the literature, and to describe an aspect of it in the form of a grammar. Kotekan, the system of interlocking parts in Balinese gamelan music, will be examined in this study.

\subsection{Language and Music Analogies}

A current research topic in Artificial Intelligence (AI) is finding ways to model and represent music (Dannenberg, 1993). Since there are any number of ways to model music, one might ask why linguistic models of music are worthwhile to pursue. People have been making connections between language and music for as long as there have been theories of music. Perhaps this is one reason to assume that there is some type of connection even if it has not yet been clearly articulated. Keiler (1981) reports:

\footnotetext{
${ }^{1}$ Hughes (1991) notes problems with use of terms such as "Western music" and "non-Western music." In this study, these terms are used in the conventional manner.
} 
Comparisons between language and music are not hard to find in most periods of musical scholarship. Indeed analogies of this kind occur already in the earliest periods of Sanskrit literature. Some of these earliest concerns with language and music reflect the Indian scholars' particular attitude toward universals. (p. 138)

Powers (1980) notes "the fullest early articulation of the language-music parallel in the Western tradition occurs (as far as I know) in the anonymous 9th century Musica Enchiriadis" (p. 49). In this treatise, comparisons are made between Latin grammarians' punctuation in speech and regularities in the melodies of chants.

Comparisons in the literature focus on different aspects of language and music. Analogies range from broad notions of language and music as systems of communication and expressions of culture (Becker \& Becker, 1981; Blacking, 1981; Nettl, 1992) to more narrow concepts such as units of language corresponding to units of music (Bernstein, 1976). The rhythm and meter of poetry are compared to music (Nord, Kruckenberg, \& Fant, 1990). Similarities in the skills utilized in both the teaching and learning of languages and music are observed (Giauque, 1985). The question of the origins of language and music and their possible relationship is still a topic of research and discussion (Levman, 1992). Another analogy concerns notions of language and music as systems that can be expressed with grammars (Becker \& Becker, 1979; Hughes, 1988; Kippen \& Bel, 1992; Lerdahl \& Jackendoff, 1983; Perlman \& Greenblatt, 1981; Sundberg \& Lindblom, 1976; Winograd, 1968).

In the midst of the excitement of using linguistic techniques to analyze music, researchers such as Feld (1974), Becker \& Becker (1979), Lerdahl \& Jackendoff (1983) and Keiler (1978) warn against trying to superficially force one type of analysis on top of another discipline (i.e., one should not force a linguistic analysis on top of music just because one thinks a priori they should be related). Rather, they suggest that a type of analysis be used for music because it works well for music. Then comparisons between music and language as systems can be made and any parallels found are perhaps more significant. Analyses of music based in the linguistic traditions have, in fact, turned out to 
be useful because there are aspects of musical data that lend themselves to a linguisticallybased analysis. But researchers stress that there is no reason to expect models of music and language to be isomorphic. In a survey of language models for music, Powers (1980) warns against hasty and misguided metaphors, but concludes:

Language models for musical analysis used circumspectly can contribute fundamentally and not superficially to the musical disciplines, as they have more than once over the past millennium or so. (p. 55)

Lerdahl \& Jackendoff (1983), Kippen \& Bel (1992), Hughes (1988) and others who have modeled music in the linguistic tradition (with grammars) emphasize that they use a linguistic framework because it is well suited to their musical data. What are some of the characteristics of music that make linguistic-based analyses possible? The following are important characteristics that music and language share:

1. They have structure (often hierarchical) (Becker \& Becker, 1979; Cross, 1985; Dannenberg, 1993; Dowling \& Harwood, 1986; Lerdahl \& Jackendoff, 1983; Longuet-Higgins, 1993; Vitale, 1990).

2. They have underlying systems of rules (Baroni, Dalmonte, \& Jacoboni, 1992; Becker \& Becker, 1979; Lerdahl \& Jackendoff, 1983; Perlman \& Greenblatt, 1981).

3. They can be analyzed at different levels of abstraction ( Dannenberg, 1993; Dowling \& Harwood, 1986; Gardner, 1993; Lerdahl \& Jackendoff, 1983; Longuet-Higgins, 1993).

Systems with these characteristics lend themselves to an information processing framework. 


\subsubsection{Structure}

Language and music both involve the patterning and structuring of sound (Becker \& Becker, 1979; Howell, Cross \& West, 1985).

In music there are two kinds of structural relations (among many other structural relations) based on natural facts about sounds -- paradigmatic relations and syntagmatic relations. This definition is based upon the temporal nature of both language and music: both are manifested as a temporal sequence. Hence, any unit in either is related to units before and after it (which are its syntagmatic relations) and also to other units in the set (the scale, chord, row, etc.) from which it was chosen (which are its paradigmatic relations). (Becker \& Becker, 1979, pp. 6-7)

Paradigmatic and syntagmatic relations in language can be illustrated by a phrase such as "a ___ of milk." The word pint has "paradigmatic relations with words such as glass, bottle, cup, and syntagmatic relations with $a$, of, and milk" (Lyons, 1968, p. 74). In music, paradigmatic and syntagmatic relations refer to, for example, a note and its relation to other notes in a chord (paradigmatic) and its relation to the notes that precede and follow it (syntagmatic).

The structure of language is hierarchical (Chomsky, 1965; Radford, 1988). Units of language (e.g., words) are grouped into larger phrases or constituents (e.g., noun phrases or verb phrases), which are grouped into still larger structures (e.g., sentences). The structure of music is also hierarchical (Becker \& Becker, 1979; Lerdahl \& Jackendoff, 1983; Sundberg \& Lindblom, 1991). For example, Western music

is more than sets of notes, i.e., chords, melodies or themes and their variations, movements, songs, etc...The way a theme relates to its variations is not just the sum of the note-for-note relations of the theme and its variations: contours and groupings are also part of the structure. (Becker \& Becker, 1979, p. 7)

Notes are grouped into larger phrases that are grouped into still larger sections. 


\subsubsection{Systems of Rules}

Language and music are social activities (Cross, 1985; Nettl, 1992; Wardhaugh, 1986). Cross (1985) proposes "any social activity -- particularly when it takes the form of the transmission or communication of skills, ideas, and values -- requires rules for its conduct, together with a means of ordering and systematising its constituents" (p. 1).

People can produce new sentences and understand sentences they have never heard before. Chomsky (1965; 1972, cited in Radford, 1988) argues that this creative aspect of language is possible because language is rule-governed. Language "can (in Humboldt's words) 'make infinite use of finite means'" (Chomsky, 1965, p. 8). This finite means is a set of rules that enables speakers of languages to produce an infinite number of new sentences that are understood by other speakers.

Similarly, in music there are rules or a "set of constraints on the selection and sequencing of musical elements (notes, contours, patterns, harmonies)" (Becker \& Becker, 1979, pp. 4-5). This finite set of rules enables producers of music to generate an infinite number of songs or pieces in a particular musical idiom and enables listeners familiar with the idiom to find coherence in the new pieces (Lerdahl \& Jackendoff, 1983; Sagi \& Vitanyi, 1988; Sundberg \& Lindblom, 1991).

\subsubsection{Levels of Abstraction and Representation}

Language can be analyzed and represented at different levels of abstraction: from the level of sound -- physical waveforms, to other layers of organization, such as the phonological level, morphological level, etc. (Fromkin \& Rodman, 1988; Gardner, 1993; Lyons, 1968). Similarly, music can be viewed at different levels of abstraction: from waveforms, to rhythmic structure, grouping structure (Lerdahl \& Jackendoff, 1983), harmonic structure, etc. (Dannenberg, 1993; Gardner, 1993). People can examine abstract levels without reference to the physical. For example, a discussion of the syntax of 
language, or the rhythmic structure of music, can take place without reference to the waveforms of sound.

\subsubsection{Information Processing Framework}

In an information processing (cognitive science) framework, the human mind is viewed as "a complex system that receives, stores, retrieves, transforms, and transmits information" (Stillings et al., 1987, p. 1). There are a number of assumptions in this view (Stillings et al., 1987):

1. Information and information processes can be studied as patterns and the manipulation of patterns. (p. 1)

2. An organism or machine can produce meaningful behavior by performing formal operations on symbolic structures that bear a representational relationship to the world. (p. 4)

3. Information processes can and in part must be studied without reference to the physics or biology of the system carrying them out. (p. 4)

Thus, language and music, with their inherent patterns, rules, and various levels of abstraction, fit well into an information processing framework. This framework has been applied successfully to language, and is currently being applied to music.

\subsubsection{Grammars and Competence}

Researchers interested in cognitive science share a similar kind of questioning about competence. Concerning language, people ask: What does one know about one's language? What is the underlying system of rules for language $\mathrm{X}$ that a person knows and uses? Concerning music, people ask: What is it that makes a particular genre of music that genre? What constraints does it follow (Becker \& Becker, 1979)? What does a musician know in order to perform in a particular style (Levitt, 1993)? How does a person structure what she hears (Lerdahl \& Jackendoff, 1983)? What is the underlying system of rules for music X (Kippen \& Bel, 1992; Perlman \& Greenblatt, 1981)? 
As a grammar of a language is a "description of the ideal speaker-hearer's intrinsic competence" (Chomsky, 1965, p.4) a grammar of a musical idiom can be viewed as a description of an "experienced listener's" knowledge of that musical idiom (Lerdahl \& Jackendoff, 1983). To know a particular language or musical idiom is to know the rules (i.e., the grammar) of that system. Researchers interested in modeling music with grammars have focused on different aspects. Some focus on generating or producing a particular type of music (Kippen \& Bel, 1992; Sundberg \& Lindblom, 1976). Others focus on analyzing or assigning structure to a particular type of music (Lerdahl \& Jackendoff, 1983; Winograd, 1968). In either case, a musical grammar is a formal description, or specification of a particular musical idiom.

Radford (1988) discusses Chomsky's adequacies of grammars. A grammar is observationally adequate if it correctly specifies which sentences are well-formed in a language. A grammar is descriptively adequate if it not only is observationally adequate, but also gives a "principled account of the native speaker's intuitions" about the structure of sentences (p. 29). Musical grammars can also be viewed as being observationally adequate or descriptively adequate depending on their ability to describe structure. The notion "well-formed" has various interpretations in different musical grammar studies. For example, well-formed can mean with respect to a genre of music (Baroni et al., 1992), or with respect to a particular composer (Cope, 1993).

There are a number of advantages to specifying a musical system as a grammar. Winograd (1968) proposes that examining music with a linguistic framework enables us to see more clearly the object being studied and the linguistic method being used. After surveying a number of grammars and their contribution to representing music, Roads (1985) concludes that although grammars are not a perfect model for music, they have "clarified many issues involved in the representation of music structure" (p. 437). Lerdahl and Jackendoff (1983), Marsden and Pople (1992) and others point out that a grammar is 
a rigorous, precise, concise way of expressing the set of rules governing a particular musical idiom. Sundberg and Lindblom (1991) note that "once formulated a formalized algorithmic theory is independent of the intelligence and intuition of the user" (p. 269). Thus, for researchers interested in examining music in a computational manner and implementing musical systems on computers, formal musical grammars provide a base of algorithms. In addition, a grammar can be tested empirically (Camilleri, 1992; Lerdahl \& Jackendoff, 1983; Marsden \& Pople, 1992). A related advantage of using a grammar to describe music has to do with Chomsky's (1957) separation of the notions of "grammatical" and "meaningful." Musical semantics is problematic, but taking Chomsky's (1957) view lets one focus on the structure of musical lines without getting bogged down in meaning. Again, it should be noted that researchers have various interpretations of what "grammaticalness" means for music systems.

Thus, there are many analogies between language and music. A linguistics-based model of music, in particular, a grammar, is a method for exploring this relationship in a formal and rigorous manner.

\subsection{Balinese Kotekan}

Assuming that linguistic techniques are useful for analyzing at least some musical systems, and that grammars are a useful tool, what is it about Balinese kotekan that makes it a good choice for a linguistic type analysis? What is kotekan and its characteristics?

McPhee(1966), Capwell (1992), and others describe the Balinese gamelan (ensemble) as being made up of groups of instruments which have different functions in the ensemble. Some define colotomic structure (punctuate the melody). Others play the melody, and still others, a variant of the melody. Balinese gamelan music is by nature, hierarchical (Tenzer, 1991; Vitale, 1990). It is overtly layered; the lowest toned instruments play the slowest parts; each higher toned group of instruments plays 
progressively faster, usually by multiples of two. There is a "core" melody, pokok, that is played by the middle and lower registers of the ensemble. The other instruments of the ensemble play parts that are related in specific ways to the core melody. Kotekan is the "highly detailed elaboration" of the "slower core melody" (Vitale, 1990, p.3).

Kotekan is composed of two parts, called polos and sangsih by the Balinese (Vitale, 1990). Each part is an independent musical line that is composed so that it will interlock with the other part. Thus, when the parts are played together, they form a single musical line. The precision with which these parts are played is remarkable; although there are many instruments and musicians, the single musical line sounds seamless (McPhee, 1966; Tenzer, 1991; Vitale, 1990). The polos part is related to or derived from the core melody in specific ways (Tenzer, 1991; Vitale, 1990). In addition, the polos and sangsih are related to each other in specific ways (Vitale, 1990).

Vitale (1990; personal communication, 1993) observes that given a kotekan, a Balinese musician would usually be able to pick out the core melody or an outline of the core melody. Given one part of a kotekan, even one never heard previously, a Balinese musician would be able to come up with a second part quite easily, much in the same way that a Western musician would be able to spontaneously make up a harmony given a melody. So the question arises: what is it that a Balinese musician knows about kotekan that enables him to do this? Thus, it appears there are rules in Balinese gamelan music which relate the core melody to kotekan, and within kotekan, there are rules which relate the parts (polos and sangsih) to each other. A grammar of Balinese kotekan would explicitly describe these rules. 


\subsection{Research Questions}

The guiding questions for this study are:

What does a Balinese musician know about kotekan that enables him to spontaneously play a sangsih given a polos?

How can this competence be represented in a grammar?

\subsection{Method}

This study will be based on library research, scores, tapes, and communication with experts in Balinese music. No experiments will be performed.

A number of previously written grammars for musical systems will be examined, as well as literature concerning various types of formal grammars. Balinese kotekan data will be collected, in the form of literature, scores, and tapes. Portions of the data will be described in the form of a grammar. This grammar may or may not resemble other musical grammars in the literature.

The following are the major steps for this study:

1. Provide motivation for modeling music with grammars.

2. Read literature on types of formal grammars (e.g. Gonzalez \& Thomason, 1978) and examine previous grammars of music.

3. Collect Balinese kotekan data from libraries and from Wayne Vitale, director, Gamelan Sekar Jaya (a Balinese music ensemble based in California).

4. Analyze data and describe a portion of it in formal rules. A complete grammar of Balinese kotekan is beyond the scope of this study. However, examples of rules that would be part of a complete grammar will be given in this study.

5. Illustrate how the written rules apply to portions of Balinese pieces. 


\subsection{Limitations}

The limitations of this study are related to several categories. There are those related to debates within linguistic theory, those related to questions and debates in cognitive science, and those related to ethnomusicology.

In the debate over what should be included in the definition of linguistic competence and whether or not structure can be isolated from context, this study falls on the side of isolating structure. This analysis of Balinese kotekan will not be in its social context, but will focus on structure only. Furthermore, Balinese kotekan will be examined in isolation in order to make the task manageable; other aspects of Balinese music will not be included. Musical semantics is a problem for researchers as well (Gardner, 1993; Wiggins, Miranda, Smaill \& Harris, 1993) and is beyond the scope of this study.

A number of terms used in this study (and other studies) are problematic. However, their definitions in this study are given below.

\subsubsection{Music}

There are problems in defining what is music because it is culturally defined. Cross (1985) proposes that in any study there needs to be a working definition of music. In this study, the definition of music is confined to the definition of Balinese music used by Vitale (1990). Kotekan, polos, and sangsih are terms that Balinese musicians use. However, for readability and the understanding of the Western reader, the notation and vocabulary for talking about music will be based in the Western tradition.

\subsection{2 (Native) Intuition}

Precedence has been set by linguists on the use of intuition for languages. Lerdahl and Jackendoff (1983) explicitly state their attempt to model musical intuition and use their own intuition to make judgments for their grammar of western tonal music. They 
want to model not only the "conscious grasp of musical structure" (p. 3), but also (and largely) the "unconscious knowledge (musical intuition) that the listener brings to the hearing -- a knowledge that enables him to organize and make coherent the surface patterns of pitch, attack, duration ... and so forth" (p. 3). They propose a theory of music which is "explicitly psychological, in that it is concerned not with the organization of music in and of itself, but with the organization that the listener is capable of hearing" (p. 1).

West, Howell and Cross (1991) make a distinction between the rules of a musical idiom that are explicit in musical pedagogy and those that are not explicit. The former are taught to students "as a basis for their own composition" (p. 26). However, "it is suspected that there are also a great many grammatical rules governing the music of particular idioms, composers, etc. which are not explicit, the discovery of which represents a genuine advance in our understanding of musical structure" (p. 26). The rules of this study may fall into either of these categories. However, claims to what listeners are capable of hearing, as in Lerdahl and Jackendoff (1983), are beyond the scope of this study.

What does a Balinese musician hear? There are problems when Western ethnomusicologists analyze non-Western music (Blacking, 1981; Rahn, 1983). However, Blacking (1981) notes that in analyzing music of other cultures:

What a non-Venda hears in Venda music may be just those aspects that are universal: there are many ways in which an outsider can listen usefully to strange music. (p. 193)

The analysis in this study is based on research provided by western ethnomusicologists about what they observe Balinese musicians doing, what they observe in Balinese music, and what they observe themselves doing when they participate in Balinese music. This study assumes that just as a person can develop intuition for a language from a different culture, a person can develop intuition for a musical system from a different culture. 


\subsubsection{Experienced Listener}

What is meant by this term? There are degrees of experience. Lerdahl \& Jackendoff (1983) use this term as an idealization, just as Chomsky (1965) uses the ideal speaker-hearer as an idealization. "A listener without sufficient exposure to an idiom will not be able to organize in any rich way the sounds he perceives" (Lerdahl \& Jackendoff, 1983, p. 3). Other studies implicitly use this construct as well. In this study, an experienced listener refers to an experienced Balinese musician, or to a musician who is experienced with kotekan.

\subsection{Conclusion}

The relationship between music and language has been and still is a topic of interest to researchers in various disciplines. Modeling music and modeling language are also current research topics. Linguistic theory provides a framework for describing certain types of phenomena. Because of music's patterns and structures, it is useful to examine music with an information processing, linguistic frame of reference. Such an examination may help researchers understand more about the nature of music and of language, and may also give insight into cognitive processes. Musical grammars are a precise and formal way of describing regularities in musical systems, and of describing aspects of musical competence. 


\section{CHAPTER 2}

\section{REVIEW OF THE LITERATURE}

\subsection{Introduction}

Researchers address the study of musical grammars from a variety of perspectives. The content and organization of this chapter is designed to give an overview of issues concerning grammars and their applicability to music, a sense of the perspectives and approaches taken by researchers, exposure to the variety of musical grammar studies in the literature, and an examination of some of the similarities and differences between musical and linguistic grammars. The chapter discusses several aspects of musical grammars including: issues in evaluating musical grammars (Section 2.2), the applicability of formal grammars to musical systems (Section 2.3), and perspectives of analysis (Section 2.4). A listing of selected musical grammars is given in Section 2.4. Section 2.5 highlights selected features of musical grammars and compares aspects of musical and linguistic grammars.

\subsection{Considerations}

The definitions of well-formedness and grammaticality and the motivation behind the rules of a grammar are important considerations in interpreting and evaluating grammars.

\subsubsection{Well-formedness and Grammaticality}

Grammars for languages and music can be evaluated according to their observational or descriptive adequacy (Hughes, 1991; Radford, 1988). Adequacy is based on the notion of well-formedness. A grammar should generate all the well-formed 
utterances of a language, and exclude the ill-formed utterances; it should not over or under generate (Hughes, 1991; Johnson-Laird, 1991).

For language, Chomsky (1957) makes a distinction between a sentence being "grammatical" and being "meaningful." He illustrates this in the grammatical (i.e., syntactically well-formed) but meaningless sentence "Colorless green ideas sleep furiously" (p. 15). The definition of grammatical in this case is syntactically well-formed. However, the notion grammatical is also used in a broader sense. A linguistic grammar that is adequate specifies the sentences that are grammatical (and those that are not), i.e., semantically, phonologically, and morphologically well-formed, as well as syntactically well-formed (Radford, 1988). This broader notion of grammatical is not applied to music in most musical grammar studies. Researchers such as Lerdahl and Jackendoff (1983) and West, Howell and Cross (1985) propose that the reason this is so is that music has a different function from language.

In natural language, well-formedness is a basic prerequisite for conveying meaning... Music does not exist to convey meaning in the same way. (West et al., 1985, pp. 32-33)

... music is not tied down to specific meanings and functions, as language is. In a sense, music is pure structure, to be "played with" within certain bounds. (Lerdahl \& Jackendoff, 1983, p. 9)

The idea of grammaticality or well-formedness in music is perhaps closer to the definition of grammatical in Chomsky's 1957 sense; in most musical studies in the literature, grammatical means syntactically well-formed. Lerdahl and Jackendoff (1983) propose:

The closest analog to linguistic grammaticality in music theory is adherence to well-formedness rules. These rules resemble linguistic rules in that they either establish a branching or hierarchical structure (like phase-structure rules in syntax) or characterize permissible distortions of the branching structure (like transformations). (p. 308) 
Hughes (1991) notes, however, that the notion of grammaticality referring only to syntactically well-formed structures omits important cultural contextual factors in determining acceptability.

Well-formedness has various interpretations in different musical studies. For example, Cope (1993) defines the well-formedness of pieces generated by his grammar with respect to a particular composer's style. Baroni et al. (1992) define well-formedness with respect to particular repertoires: Lutheran chorales, 18th century French chansons, and arias by Giovanni Legrenzi. They make "a style-historical judgment concerning the possibility that a melody generated by [their] grammar could or could not belong to the particular repertoire" (p. 188). Lerdahl and Jackendoff (1983) use the notion of wellformedness to mean "possible structural descriptions" that a listener might assign to a piece of music (p. 9). These various interpretations of well-formedness determine the evaluation of a musical grammar's adequacy. ${ }^{2}$

\subsubsection{Motivation for Rules}

In grammars, rules that are "independently motivated and/or psychologically plausible" rather than arbitrary or ad hoc are desirable (Hughes, 1991, p. 344). Convincing rules give an explanation; ad hoc rules do not.

Baily (1985; 1989, cited in Hughes, 1991) and Johnson-Laird (1991) are examples of studies that use independently motivated rules. Baily proposes rules for plucking variations on the Afghani plucked lute, the rubab. These rules may be explained "not only by aesthetic criteria, but also by limitations of motor technique" (Hughes, 1991, p. 351). Johnson-Laird (1991) proposes rules for generating particular aspects of jazz based on the demands such rules would make on people's working memory. He uses "a set of simple,

\footnotetext{
${ }^{2}$ It should be noted, however, that a number of researchers, such as Lerdahl and Jackendoff (1983), and West, Howell, and Cross $(1985,1991)$ down-play the importance of well-formedness in musical grammars. See Section 2.5.4 on Preference Rules.
} 
but plausible" assumptions "to make a motivated choice of different sorts of grammar for characterizing what is computed by the different sorts of processes underlying musical improvisation" (p. 299). For example, Johnson-Laird conjectures that modern jazz rhythms "are generated by processes that place minimal load on working memory" (p. 305). If this is the case, one might expect that modern jazz rhythms could be described by certain types of simple rules as opposed to other types of rules that are more complex.

West et al. (1985) suggest that there are "global factors whose operation can account for much of the patterning of sound" (p. 47). For example, Gestalt features could be useful in explaining or motivating rules for structuring music (Lerdahl \& Jackendoff, 1983; West et al., 1985). Gestalt principles applied to music include (West et al., 1985):

Good continuation. People tend to group together notes that follow a common rule, such as repetition of a single note, or a continued ascent of a scale.

Proximity. People tend to group together notes that are closer together in time or in pitch.

Similarity. People tend to group together notes that are similar in characteristics, such as timbre.

Regularity. People "are more likely to group things into regular bundles than irregular ones" (p. 48).

Symmetry. "Symmetrical groups are preferred to asymmetrical groups" (p. 48).

Common fate. Repetition of a sequence of notes can make listeners hear those notes as a group. The repetition does not have to be exact. For example, the sequence might be transposed, or only the rhythm might be repeated.

Rules based on, or explained by, factors such as these are also independently motivated. 


\subsection{Formal Grammars Applied to Music}

Many researchers are interested in expressing aspects of music with formal grammars.

Given the multi-level nature of music, the importance of repetition and presence of a mixture of flexible choice of elements within an inflexible set of constraints, it has been considered by many that the structure of music can be adequately described only using grammars. (West et al., 1991, p. 24).

This section gives an overview of some of the issues involved with expressing music with formal grammars. Section 2.3.1 provides background information about formal grammars. Different types of formal grammars and their applicability to music are discussed in Sections 2.3.2 - 2.3.9.

\subsubsection{Background}

Grammars use productions, or re-write rules that have the form:

$$
\text { LHS --> RHS }
$$

Where

$$
\begin{aligned}
& \text { LHS = left hand side } \\
& \text { RHS = right hand side } \\
& -->=\text { becomes, is re-written as }
\end{aligned}
$$

A linguistic example is given in Figure 1.

$$
\begin{aligned}
& \text { S } \rightarrow \text { NP VP } \\
& \text { NP } \rightarrow \text { Det N } \\
& \text { VP } \rightarrow \text { V } \\
& \text { Det } \rightarrow \text { the } \\
& N \rightarrow \text { cat } \\
& \text { V } \rightarrow \text { purrs }
\end{aligned}
$$

Figure 1. A sample grammar.

This grammar could generate the sentence "The cat purrs." The symbols used in a grammar are classified as terminals and non-terminals. Terminals refer to items which 
cannot be broken down further; they never appear on the LHS of a rule. Non-terminals refer to items which can be broken down into other items; they do appear on the LHS of a rule. In Figure 1, the terminals are: the, cat, purrs. The non-terminals are: S, NP, VP, Det, N, V.

Grammars can be classified according to their power of expression and the restrictions on the form the rules (productions) can take. The "Chomsky hierarchy" defines four types of formal grammars (Chomsky, 1959; cited in Gonzalez \& Thomason, 1978). Depending on the grammar type, there are certain restrictions on the form of the LHS and RHS; thus, there are differences in what the grammars can describe. The more data a grammar can describe, the more powerful the grammar is considered to be. Table 1 gives the Chomsky hierarchy.

\section{TABLE 1}

Chomsky Hierarchy of Grammar Types

\begin{tabular}{|c|c|c|c|}
\hline $\begin{array}{c}\text { Grammar } \\
\text { Type }\end{array}$ & $\begin{array}{c}\text { Power of } \\
\text { Expression }\end{array}$ & Rule Form Restrictions & Example Rules \\
\hline $\begin{array}{l}\text { Type } 0 \\
\text { Unrestricted }\end{array}$ & $\begin{array}{l}\text { Most } \\
\text { powerful }\end{array}$ & No restrictions on rules. & -- \\
\hline $\begin{array}{l}\text { Type } 1 \\
\text { Context- } \\
\text { Sensitive }\end{array}$ & & $\begin{array}{l}\text { LHS can have terminals and } \\
\text { non-terminals. } \\
\text { RHS consists of LHS with a } \\
\text { single symbol expanded. }{ }^{3}\end{array}$ & $\begin{array}{l}\mathrm{aXb}->\mathrm{aYb} \\
\mathrm{X} \rightarrow \mathrm{Y} / \mathrm{a} \_\mathrm{b} \\
{[\text { vowel] }->} \\
{[\text { stress] /__(C)\# }}\end{array}$ \\
\hline $\begin{array}{l}\text { Type } 2 \\
\text { Context-Free }\end{array}$ & & LHS can have only one symbol. & $\begin{array}{l}\mathrm{S}->\text { NP VP } \\
\text { NP } \rightarrow \text { Det N }\end{array}$ \\
\hline $\begin{array}{l}\text { Type } 3 \\
\text { Regular }\end{array}$ & $\begin{array}{l}\text { Least } \\
\text { Powerful }\end{array}$ & $\begin{array}{l}\text { RHS consists of a single } \\
\text { terminal symbol or a terminal } \\
\text { symbol followed by a single } \\
\text { non-terminal symbol. }{ }^{4}\end{array}$ & $\begin{array}{l}\mathrm{S} \rightarrow>\text { the } \mathrm{N} \\
\mathrm{N} \rightarrow \text { cat }\end{array}$ \\
\hline
\end{tabular}

\footnotetext{
${ }^{3}$ (Winograd, 1983, p. 144)

${ }^{4}$ ibid.
} 
Each grammar, types $0-2$, can express whatever can be expressed by a grammar below it. For example, a context-sensitive grammar can describe data that a context-free (and regular grammar) can describe, but a context-free grammar will not necessarily be able to describe what a context-sensitive grammar can describe. Grammars that can express more are also more complicated to write and harder to implement. This has implications for the type of grammar researchers choose to write.

\subsubsection{Regular Grammar, Finite-State (Type 3)}

A regular grammar is the most restrictive type of grammar. Because of the restrictions on the form the rules can take, regular grammars cannot handle center embedding or recursion very well. Winograd (1983) gives examples of English sentences that would be a problem for type 3 grammars: (embedding) "The wallpaper the man your friend suggested put up is crooked" and (recursion) "This is the cat that bit the rat that..." (p. 145). A rule such as S -> NP VP would not be allowed in a regular grammar.

Similarly, Roads (1985) points out the limitations of type 3 grammars applied to music.

The ability of a type 3 rule to represent any kind of multilevel tree structure (such as a musical composition that exhibits a simple, hierarchical form) is extremely limited... A representation for music should have the power to generate at least nested phrases and motives, constructions technically excluded from type 3 grammars. (p. 413)

Thus, type 3 grammars are not powerful enough for expressing most musical systems.

Cases where type 3 grammars are used, however, appear in Johnson-Laird (1991). This study uses a regular grammar for portions of a grammar for jazz. Johnson-Laird suggests it is significant that certain musical constructs can be modeled in this way because the ability to use a particular type of grammar may have implications about the 
computational demands of the task on the mind. He proposes that computational demands may have an effect on musicians' abilities to instantaneously improvise.

\subsubsection{Context-Free Grammar (Type 2)}

In a context-free grammar there are no constraints on the application of the rewrite rule; a non-terminal will be re-written under any condition. Unlike the regular grammar, the RHS can have more than one non-terminal. Thus, rules such as S-> NP VP, which are common in linguistic grammars, are allowed. The previous example in Figure 1 is a context-free grammar.

Type 2 grammars are useful because they are relatively easy to implement and they are powerful enough to handle nested structures (Roads, 1985). Type 2 grammars can handle self-embedding and recursion. Thus, in music, nested motivic formations can be handled. An example of a context-free grammar for generating eight-bar tonal chord sequences is given below.

8-bars $->$ First-4 Second-4
First-4 -> Opening-cadence
First-4 -> Opening-cadence'
Second-4 -> Middle-cadence
Opening-cadence -> I I
Opening-cadence -> I V
Opening-cadence' -> I III
Opening-cadence' -> I IV
Middle-cadence -> I IV
Middle-cadence $->$ I V
Middle-cadence $\rightarrow$ IV I

(excerpted from Johnson-Laird, 1991, p. 310)

This grammar would generate sequences of chords such as:
(a) I IV I V IV I I V
(b) I III I V I IV I I
(c) I IV I V I IV I I 
(adapted from Johnson-Laird, 1991, p. 310)

Tree diagrams represent the hierarchical structure described by a grammar. Figure 2 shows the hierarchical structure of sequence (a).

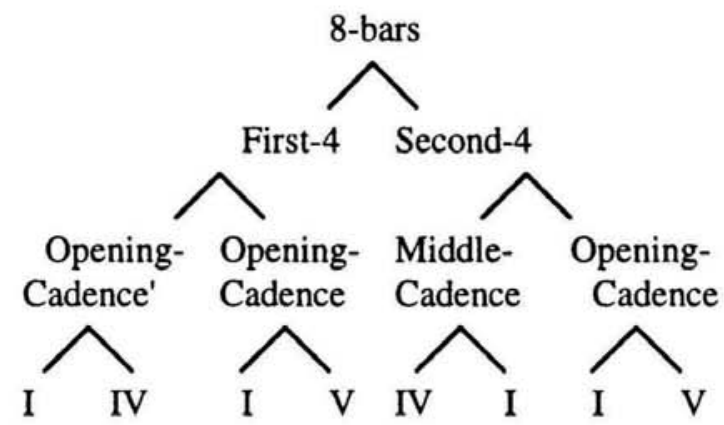

Figure 2. Tree diagram illustrating the hierarchical structure of sequence (a).

\subsubsection{Context-Sensitive Grammar (Type 1)}

A context-sensitive grammar has re-write rules that apply only in certain contexts or environments; a non-terminal will be re-written only under certain conditions.

Chomsky demonstrated that in order to describe natural languages adequately, that is, in a way that corresponds to our intuitions about language, type 1 and type 0 grammars are needed (Winograd, 1983). For example, the rule determining the form of a verb is context-sensitive; the form of the verb depends on the number (singular or plural) of the subject. Another context-sensitive example comes from phonology:

[vowel] $\rightarrow[$ stress] / _ (C)\#

(Kenstowicz \& Kisseberth, 1979, p. 41).

This rule states that a vowel is stressed when it occurs at the end of a word, or before a final consonant. If the environment is different, the sound may be realized differently.

Context-sensitivity also appears to be important in musical grammars.

"Particularly important is the influence of higher level structures on subordinate ones" (West et al., 1991, p. 25). For example, 
if a musical piece has the attribute 'tonal', or a $4 / 4$ metre, the subunits may be constrained to have these attributes also. A theme stated at the beginning of a movement constrains the melodic and harmonic structure of much of what follows. (p. 25)

Johnson-Laird (1991) gives an example of a context-sensitive rule for an interpolation in jazz:

I $->\operatorname{IIm} 7$ I _ V

(Johnson-Laird, 1991, p. 311)

This specifies that a IIm7 chord can be substituted for a I chord when a I chord occurs before a V chord.

In most cases of musical grammars, context-sensitive rules are needed to adequately describe the data. "A strong case can be made for the utility of including context sensitivity in musical grammars" (Roads, 1985, p. 412). Type 1 grammars are one way of doing this. However, type 1 grammars are also complicated and hard to implement.

Roads (1985) identifies two kinds of complications in applying type 1 grammars to music. First, in type 1 grammars, ambiguous rules are legal so there is no way of recovering a unique derivation from strings generated by type 1 grammars. Secondly, type 1 grammars are difficult to implement because rules would need to be written for every musical context. This could quickly become unruly. Roads observes that it is possible to use other kinds of grammars that are equivalent to context-sensitive grammars, but are easier to manage computationally. Transformations are one way to achieve context sensitivity without having to embed the context in the rules. (See Section 2.3.6.) 


\subsubsection{Unrestricted Grammars (Type 0)}

There are no constraints on the form re-write rules can take in an unrestricted grammar. This is the most powerful type of grammar; it is also the most difficult to deal with computationally.

Roads (1985) notes that type 0 grammars are not practical for describing music because "it is not possible to build a recognizer" for this type of grammar (p. 412). In other words, since there are no restrictions on the form of the re-write rules, any string of characters or notes could be parsed in many different ways. Thus, it would be very difficult to build a recognizer to handle all of the various parses. In addition, type 0 grammars allow "erasing rules" to be incorporated in the production rules. But keeping track of the output of such rules can be very confusing. There are instances where some kind of ability to delete is useful, however. For example, variations on a theme are often made by deleting notes from the original theme. Transformational grammars can handle this without incorporating erasure in the production rules (Roads, 1985).

\subsubsection{Transformational Grammars}

There are many different versions of transformational grammars (Winograd, 1983). However, the basic idea concerns the notions of deep and surface structures and transformations or rules that relate the deep to the surface. Transformational grammars were proposed by Chomsky (1957) in order to describe, for example,

1. the relationship between sentences such as:

John read the book.

The book was read by John.

2. the difference in structure between sentences such as:

John is easy to please.

John is eager to please. 
Roads (1985) observes that with transformations, it is possible to have a contextsensitive grammar without embedding the context-sensitivity in the phrase structure rules. Transformations increase the power and flexibility of a musical grammar. The output of abstract phrase structure rules can stay the same, and the transformation can change this output depending on a specific context. For example a phrase may be generated by an abstract rule. Then in that phrase, depending on the context, a transformational rule might change a quarter note into two eighth notes, or change a note into a rest, or add a rest, etc. (Roads, 1985).

The idea of deep and surface structure works well when applied to musical systems. Numerous musical grammars use this notion. (See Section 2.5.1 for a more detailed discussion.)

However, there are problems with transformational grammars. "There comes a point at which any string can be viewed as a transformation of any other string, and specifying the limits of valid transformations is difficult" (Roads, 1985, p. 414).

\subsubsection{Systemic Grammars}

Systemic grammar has its roots in anthropology and sociology. The approach to language is different from that used with transformational grammars. The emphasis is on language as a social activity, rather than on notions of syntactic grammaticality (Winograd, 1983). This model focuses on "language as doing, not knowing" and "emphasizes the importance of context and situation in the analysis of each utterance or text" (Winograd, 1983, p. 273).

The theoretical basis of systemic grammars rests on the observation that there is a high correlation between the context-dependent features of natural language and the semantic interpretation of the constituents that exhibit them. In practice, this means that symbols in the grammar can have additional features that may control their expansions. These features may include semantic tests for plausibility and meaningfulness. (Roads, 1985, p. 415) 
Thus, in systemic grammars, syntax and semantics can be "intermingled" in the rules (Roads, 1985). A musical grammar can make use of this, for example, in its interpretation of a E-G-C chord. This can be interpreted as the first inversion of the tonic of the key of C. However, if it is the last chord in a piece that has all along been in E minor, it is not meaningful to interpret the chord as related to $\mathrm{C}$ major (Roads, 1985). So although the chord has more than one possible interpretation, the systemic grammar chooses one interpretation to be meaningful in a particular context.

\subsubsection{Transition Networks}

A transition network is another method for representing a grammar. It consists of "a set of states, connected by arcs. Each arc represents a transition between two states" (Winograd, 1983, p. 55). For language, transition networks can be viewed as patterns for recognizing or generating sequences of words. "In both generating and recognizing, the process follows the form of the net in a step-by-step way -- each transition along an arc corresponds to a single word in the sequence" (p. 55). There are different types of transition networks; each is equivalent to a type of re-write grammar. The equivalencies are given in Table 2 .

TABLE 2

Equivalent Grammars and Transition Networks

\begin{tabular}{|l|l|}
\hline \multicolumn{1}{|c|}{ Grammar } & \multicolumn{1}{c|}{ Transition Network } \\
\hline \hline Type 1 - Context-sensitive & Augmented Transition Network \\
\hline Type 2 - Context-free & Recursive Transition Network \\
\hline Type 3 - Regular & Basic Transition Network \\
\hline
\end{tabular}


An example of a recursive transition network and its equivalent phrase structure rules is given in Table 3.

\section{TABLE 3}

\section{An Example of Equivalent Representations}

\begin{tabular}{|l|l|}
\hline \hline Context-free Phrase Structure Rules & Recursive Transition Network \\
\hline \hline S $\rightarrow$ NP VP & S \\
\hline NP $\rightarrow$ Det N & NP \\
\hline $\begin{array}{l}\text { VP } \rightarrow \text { V NP } \rightarrow \text { V } \\
\text { VP }\end{array}$ & VP \\
\hline
\end{tabular}

Transition networks, then, are another kind of representation of a grammar that can be used for recognizing and generating sequences of words.

Applied to musical systems, transition networks can be used for recognizing and generating sequences of notes. For example, Johnson-Laird (1991) uses a basic transition network for generating rhythms improvised by Charlie Parker, another for generating bass lines for jazz.

\subsubsection{Multidimensional Grammars}

In addition to the patterning of sounds over time, much of music "involves simultaneous or concurrent musical events. Therefore, it is necessary to model both horizontal and vertical structure" (West et al., 1985, pp. 46-47). A basic difference between linguistic and musical grammars is that musical grammars need to be able to handle these parallel, simultaneous musical events, while in language, generally, people do 
not speak in chorus (Powers, 1980). "The inherent parallelism in much music, for example, in chords and polyphony, requires appropriate representation mechanisms" (Roads, 1985, p. 417). Most musical grammars do not handle this aspect, but a complete grammar should. Roads (1985) proposes the use of multidimensional grammars (e.g., array, space, graph, plex grammars) to coordinate several musical aspects concurrently. A discussion of multidimensional grammars, and their use for music is a research topic that is beyond the scope of this study.

\subsection{Musical Grammars}

Musical grammars describe "classes of compositions" rather than individual compositions (Wiggins et al., 1993). For example, musical grammars give generalizations, rules, or principles that describe a particular genre or sub-genre of music, or the style of a composer.

West et al. (1985) identify basic elements that a model of music should include.

It is not practicable to model all perceptible facets of musical experience. One must decide the most important features to look at and define those sufficiently well understood to be included in a model. Patterning of music involves, at the very least, an identification of what elements go together, where disjunctions occur, and inclusion of elements and groups of elements in superordinate groups. It also requires identification of elements perceived as structurally important, as opposed to those that are, in some sense, embellishments. (p. 44)

A complete grammar of a musical system needs to include features such as rhythm and melody. Yet, because of the complexity of the subject most musical grammars focus on one particular aspect of music while omitting others (Hughes, 1991). For example, a grammar may describe the form of melodies in terms of tones, but omit descriptions of rhythm and harmony. In addition, researchers generally focus on one of two approaches: an analysis view or a synthesis view. 


\subsubsection{Approaches}

Although a grammar of music can be viewed as a description of a person's knowledge of a particular musical idiom, researchers modeling music with grammars generally make a distinction between analyzing (parsing) music (Lerdahl \& Jackendoff, 1983; Winograd, 1968) or synthesizing (generating) music (Johnson-Laird, 1991; Sundberg \& Lindblom, 1976). Those taking a synthesis or production view seek to generate music from abstract structures and underlying rules. Those taking an analysis or parsing view seek to arrive at an underlying structure from a given musical piece.

Hughes (1991) and others observe that the process of analyzing music is very different from composing or improvising music. Most people can listen to music and hear patterns and organization; relatively few people can compose or improvise music.

Therefore, in this view, separate grammars should be written for each of these processes. Perhaps part of this reasoning stems from the notion that "synthesizing" or "generating" music means only composing, playing, or improvising music.

Hughes (1991) writes:

Presumably an ideal musical grammar would describe what goes on in our brains when we create and interpret music. Unfortunately, in ... almost all other grammars of music, the rules are unidirectional (Clarke, 1988)... In creating a derivational tree (or its equivalent) for language or music, one generally starts with a single 'concept' -- a superordinate node such as Sentence or Gendhing Lampah' - and then traces one of various paths by which this concept is realized as sound... But surely in interpreting utterances we should start with a phonetic transcription at the top of our derivational tree and work downward to the meaning, via syntax... This interpretive, analytical process is unlikely to be simply a mirror of the generative, synthetic process which produced the original utterance; thus we probably need somewhat different sets of rules for encoding and decoding. Both are necessary in a complete grammar. (p. 346)

Lerdahl and Jackendoff (1983) argue for a view of generative grammar that focuses on analysis.

${ }^{5}$ Gendhing Lampah is the name of a genre of Javanese music. 
... what is really of interest in a generative grammar is the structure it assigns to sentences, not which strings of words are or are not grammatical sentences. The same holds for our theory of music. It is not intended to enumerate what pieces are possible, but to specify a structural description for any tonal piece; that is the structure that the experienced listener infers in his hearing of the piece. (p. 6)

On the other hand, Sundberg and Lindblom (1991) propose a view of a generative grammar of music that focuses on synthesis. They point out that one method for understanding or analyzing a system is by building a model that reproduces the data -analysis-by-synthesis.

Analysis-by synthesis is a research strategy which has proved very productive in the past. It implies that an aspect of reality is analyzed by first collecting data and then producing these same data by some kind of synthesis procedure. (p. 246)

Thus, a model of music that synthesizes or produces music in a particular style can tell us something about a person's knowledge of the underlying principles of that musical idiom. A model of music that analyzes or parses music in a particular style can also tell us something about that knowledge. So, while researchers take different approaches to musical grammars, in each case, a grammar is a description of competence -- knowledge of underlying principles (rules). A generative grammar does not only imply synthesis; it also includes analysis.

\subsubsection{A Listing of Selected Studies}

Table 4 gives a summary of a number of musical grammar studies. These studies are listed because they are well known or they illustrate the kinds of things people are interested in modeling. If the grammar is formalized in some way, the type of grammar is given. Grammars with rules that appear as sketchy verbal descriptions only are given the classification "Informal." It is interesting to note that most of these grammars are contextsensitive or equivalent to context sensitive grammars. 
TABLE 4

Selected Studies of Musical Grammars

\begin{tabular}{|c|c|c|c|}
\hline Study & Subject & $\begin{array}{l}\text { Form of } \\
\text { Grammar }\end{array}$ & Comments \\
\hline Winograd (1968) & $\begin{array}{l}\text { Western tonal } \\
\text { harmony }\end{array}$ & Systemic & Implemented in LISP. \\
\hline Blacking (1970) & $\begin{array}{l}\text { Venda } \\
\text { melodies }\end{array}$ & Informal & $\begin{array}{l}\text { Includes notions of deep } \\
\text { and surface structure, } \\
\text { transformations. }\end{array}$ \\
\hline $\begin{array}{l}\text { Sundberg \& } \\
\text { Lindblom (1976) }\end{array}$ & $\begin{array}{l}\text { Swedish } \\
\text { nursery and } \\
\text { folk tunes }\end{array}$ & $\begin{array}{l}\text { Trans- } \\
\text { formational }\end{array}$ & $\begin{array}{l}\text { Authors find similarities } \\
\text { between their rule system } \\
\text { and Chomsky \& Halle's } \\
\text { (1968) generative } \\
\text { phonology of English. }\end{array}$ \\
\hline $\begin{array}{l}\text { Becker \& Becker } \\
\text { (1979) }\end{array}$ & $\begin{array}{l}\text { Javanese } \\
\text { gamelan } \\
\text { genre }\end{array}$ & $\begin{array}{l}\text { Context- } \\
\text { Sensitive }\end{array}$ & A frequently cited study. \\
\hline $\begin{array}{l}\text { Perlman \& } \\
\text { Greenblatt (1981) }\end{array}$ & Jazz & $\begin{array}{l}\text { Sketch of } \\
\text { Trans- } \\
\text { formational }\end{array}$ & $\begin{array}{l}\text { Includes an intermediate } \\
\text { "shallow" level in between } \\
\text { deep and surface levels. }\end{array}$ \\
\hline $\begin{array}{l}\text { Lerdahl \& } \\
\text { Jackendoff (1983) }\end{array}$ & Western tonal & $\begin{array}{l}\text { Trans- } \\
\text { formational }\end{array}$ & $\begin{array}{l}\text { A frequently cited study. } \\
\text { Authors find similarities } \\
\text { between their analysis and } \\
\text { Liberman \& Prince's (1977) } \\
\text { stress analysis. }\end{array}$ \\
\hline Hughes (1988) & $\begin{array}{l}\text { Javanese } \\
\text { gamelan }\end{array}$ & $\begin{array}{l}\text { Trans- } \\
\text { formational }\end{array}$ & $\begin{array}{l}\text { Rules tested experimentally } \\
\text { with an Indonesian } \\
\text { musician. }\end{array}$ \\
\hline $\begin{array}{l}\text { Baily }(1985 ; 1989, \\
\text { cited in Hughes, } \\
1991)\end{array}$ & Afghani rubab & Informal & $\begin{array}{l}\text { Includes spatio-motor } \\
\text { considerations. }\end{array}$ \\
\hline
\end{tabular}




\section{TABLE 4 \\ Selected Studies of Musical Grammars \\ (continued)}

\begin{tabular}{|l|l|l|l|}
\hline $\begin{array}{l}\text { Johnson-Laird } \\
(1991)\end{array}$ & Jazz & $\begin{array}{l}\text { Regular, } \\
\text { Context-free \& } \\
\text { Context- } \\
\text { Sensitive }\end{array}$ & $\begin{array}{l}\text { Includes hypothesis about } \\
\text { complexity of grammar } \\
\text { required and the load on a } \\
\text { person's working memory. } \\
\text { Uses transition networks } \\
\text { also. }\end{array}$ \\
\hline $\begin{array}{l}\text { Baroni, Dalmonte \& } \\
\text { Jacoboni (1992) }\end{array}$ & $\begin{array}{l}\text { Western } \\
\text { chorales }\end{array}$ & $\begin{array}{l}\text { Trans- } \\
\text { formational }\end{array}$ & $\begin{array}{l}\text { Implemented in FORTRAN } \\
\text { and BASIC. }\end{array}$ \\
\hline $\begin{array}{l}\text { Kippen \& Bel } \\
\text { (1992) }\end{array}$ & $\begin{array}{l}\text { Indian Tabla } \\
\text { Drumming } \\
\text { Improvisation }\end{array}$ & $\begin{array}{l}\text { Context- } \\
\text { Sensitive }\end{array}$ & $\begin{array}{l}\text { Implemented on computer } \\
\text { and modified based on } \\
\text { musicians input. Available } \\
\text { in Binhex format. }\end{array}$ \\
\hline Cope (1993) & $\begin{array}{l}\text { Style } \\
\text { replication of } \\
\text { individual } \\
\text { composers }\end{array}$ & $\begin{array}{l}\text { Augmented } \\
\text { Transition } \\
\text { Network }\end{array}$ & $\begin{array}{l}\text { Implemented in Common } \\
\text { LISP. }\end{array}$ \\
\hline
\end{tabular}

\subsection{Selected Features of Musical Grammars}

Musical grammars exhibit interesting features that provide insight into the natures of both music and language. A number of characteristics of musical grammars are similar to those in linguistic grammars; others are not so similar. This section examines selected features of musical grammars. Not all musical grammars contain each of the following features. 


\subsubsection{Deep and Surface Structure}

As mentioned in Section 2.3.6, the idea of deep and surface structure is basic to transformational generative grammar. Sentences have an abstract deep structure from which the surface (the actual sentence) is derived by a set of rules. For example, sentences such as "She ate the pasta" and "The pasta was eaten by her," although different on the surface, have the same deep structure. Sentences such as "John is eager to please" and "John is easy to please," although similar on the surface, have different deep structures.

Relationships between deep structures and surface structures also appear in music analyses (Becker \& Becker, 1979; Blacking, 1973; Hughes, 1988; Lerdahl \& Jackendoff, 1983; Perlman \& Greenblatt, 1981). Lerdahl and Jackendoff (1983) note that their generative theory of tonal music and other work in the field of musical grammars are indebted to the work of Schenker (1935, cited in Lerdahl \& Jackendoff, 1983). "Schenker can be construed ... as having postulated a limited set of principles capable of recursively generating a potentially infinite set of tonal pieces" (Lerdahl \& Jackendoff, 1983, p. 337).

Schenker analysis proceeds by a recursive 'reduction' of a finished composition, eliminating subsidiary prolongations to reveal a harmonic and contrapuntal 'skeleton'. This skeleton is then further reduced by the very same methods over and again until the simplest and most fundamental structure is revealed. (Sloboda, 1985, p. 15)

Thus, Schenker's analysis of music reduced Western musical masterpieces (surface structure) to a (deep) core structure (Sloboda, 1985).

Blacking (1973) uses the notions of deep and surface structures in the analysis of a Venda children's song. This song has two different melodies that are actually sung. However, these melodies are described as "the same" by the Venda. Based on Vendas' intuitions about Venda music, Blacking proposes that the melodies are considered the same because "they are melodic transformations of the same deep structure" (p. 23). The 
deep structure is a "harmonic" sequence that has its rhythm and contour given by a string of words. "The tones of one melody are the harmonic equivalents of the other" (p. 23).

Deep and surface structures are frequently included in analyses of traditional jazz. Depending on the level of analysis, jazz chord sequences can be viewed as deep or surface structures. In one analysis, Perlman and Greenblatt (1981) consider the deep structure of a song to be its underlying harmony; the surface structure of a song is its improvised melody. "'Playing the changes,' that is, improvising on the predetermined harmonic pattern of a song, is the sine qua non of jazz competence" (p. 170). In addition, Perlman and Greenblatt note the ambiguity that exists in music, similar to the linguistic example, "Flying planes can be dangerous". The same melody can be played over a different set of chord progressions, creating a "different 'meaning' because it derives from a different harmonic deep structure" (p. 172).

In a different level of analysis, jazz chord sequences can be viewed as surface variations of underlying basic chord progressions. Perlman and Greenblatt (1981), Johnson-Laird (1991) and others note that jazz musicians routinely modify basic chord progressions to create more elaborate progressions. Steedman (1984, cited in JohnsonLaird, 1991) and Johnson-Laird (1991) develop a set of rules that generate variants of modern jazz chord sequences from basic chord sequences. In this case, then, chord sequences themselves are surface structures derived from basic, core chord sequences, such as basic twelve-bar blues. The repeated I-IV-II-V chord sequence of Gershwin's "I Got Rhythm" and "twelve-bar blues" are two examples of chord progressions (deep structures) from which hundreds of songs are derived (Perlman \& Greenblatt, 1981).

Deep and surface structures are constructs that work in non-Western music as well. Hughes $(1988,1991)$ finds deep and surface structures in Javanese music. In his analysis, three different sub-genres (Srepegan, Sampak, and Ayak-ayakan) of the genre 
Gendhing Lampah are derived from the same deep structure. Transformations applying in certain contexts cause the different surface manifestations (sub-genres).

\subsubsection{Structure and Variation}

Music is hierarchically structured; for example, there are multiple layers of phrasing. Rules act on this hierarchical structure of music. It is at structurally important points in music where there is the least variation (Hughes, 1991). For example, the first beat in a measure might be considered structurally more important than the second beat of a measure. Thus, the first beat might be more restricted in the choice of pitch; the second beat might have more choices of pitch.

The relationship between structure and variation is exhibited in Sundberg and Lindblom's (1976) grammars of nursery and folk tunes. For example, in the grammar of folk tunes, the "introduction of the opening and closing phrases and the beginning of the last subphrase give chord notes in the tonic. The end of each subphrase contains the fundamental of the tonic or the fifth of the dominant" (pp. 115-117). Thus, a note's position in the hierarchy can determine the choices of pitch. This is also the case in Lidov and Gabura's study (1973, cited in Sundberg and Lindblom, 1991) of eight bar melodies using the C major diatonic scale, in Baroni et al.'s (1991) study of French chansons, and in W. Vitale's (personal communication, 1993) observations about Balinese gamelan music.

Perlman and Greenblatt (1981) propose allo's and eme's $\mathrm{s}^{6}$ in jazz music and note at what points variation can occur. For example, "any seventh-chord may be replaced by a diminished chord built upon a tone that is a full step below the original" (p. 176). They note the importance of context; this variation can occur "only when the chord in question is a resolving chord, not a chord of rest" (p. 179).

\footnotetext{
${ }^{6}$ Allo's and eme's refer to the idea that items can be equivalent to each other (allo's) or distinct from each other (eme's). In linguistics, phonemes are distinct sounds, while allophones are variations of the same phoneme. Allophones are rule governed and can occur only in certain contexts.
} 


\subsubsection{Hierarchy of Rules -- Precedence, Conflicts, Variation}

Becker and Becker (1979) describe musical systems as a hierarchy of constraints. These constraints are the rules that a musical system follows. The constraints start out general and become more and more specific as one moves down the hierarchy. The highest level constraints apply to all the music of a given tradition. Lower level constraints distinguish the music of, for example, particular periods, styles, genres, composers, and individual pieces. It becomes increasingly more difficult to formalize music as one moves down the hierarchy. However, knowing these constraints, particularly the upper level ones, is crucial to being able to understand what makes a particular piece or performance interesting, innovative, or unique. One needs to know what the rules are in order to be able to appreciate how they are being manipulated or stretched.

Within levels and between levels, rules appear to have different strengths (Baroni et al., 1991; Becker \& Becker, 1979; Hughes, 1988). (See also Preference Rules Section 2.5.4, for another analysis of rule strength.) For example, metrical constraints may take precedence over pitch contour constraints; the constraints of a genre may take precedence over the constraints of a sub-genre. There is an assumption that in musical systems, variation takes place at the points where there are weaker or low-valued constraints (Becker \& Becker, 1979).

Becker and Becker (1979) observe that "in all present-day music systems and languages ... constraints are always shifting" (p. 32). Constraints higher up in the hierarchy may become more specific, and rules that are low may become more general. Rules may shift in their precedence. In English, the increasing acceptability of a sentence such as "there is a girl and two boys in the room" versus "there are a girl and two boys in the room" is due to a rule known as "the proximity principle" (Celce-Murcia \& Larsen- 
Freeman, 1983). Perhaps this is related to the idea of rules shifting. Although the traditional rule requires the latter sentence, the proximity principle seems to be gaining strength. Thus, the former sentence is becoming more acceptable.

Given levels and sets of constraints, the rules can re-enforce each other or conflict with each other. Johnson-Laird (1991) gives an example of cases where rules work together. His program generates jazz bass lines through sets of constraints concerning acceptable melodic contours, harmonic, and metrical considerations.

...on some occasions there is no choice about which note to play given all of these constraints. There is just one note that fits exactly the exigencies of the situation. On other occasions, there may be more than one feasible note, and so the program makes an arbitrary choice from amongst them. (p. 319)

At times, however, rules may come into conflict with each other. For example, one set of rules may require a particular sequence of notes, while an equally strong set of rules may require a different sequence of notes. Although an assumption is that variability occurs in places where there are low-level (weak) constraints (and therefore, room for more freedom), it is at the moments of conflicting strong constraints that music also shows variability. This is where musicians show their creativity in coming up with a solution to the conflict. Becker and Becker (1979) observe that in the genre srepegan, the greatest points of variability do not occur at the points of low level constraint. Rather, variability occurs because there are two different higher level constraints that are in conflict with each other.

The variability found at those points is occasioned by the different solutions to the problems of a conflict of constraints. The unexpected, the innovative, the irregularities of a srepegan can be understood as a kind of problem solving, a musical conflict resolution. In this genre, innovation comes not from freedom, but from too much control, too many constraints coinciding at a given point in the structure. (Becker \& Becker, 1979, pp. 3-4)

Becker and Becker (1979) and Hughes (1988) give examples of such situations in their analyses of Javanese music. However, while "a clash of strong constraints may result in 
the emergence of the most unique or exceptional forms," Hughes (1991) notes that there can be variation "even in the absence of strongly conflicting constraints" (p. 346).

Similar notions concerning conflicts of rules producing creative solutions or variations appear in linguistic theory. For example, Dieterich (1992) hypothesizes that syntactic changes in languages may be caused by conflicts between rules from different grammatical modules. He uses the rise and use of the word "do" in the English language, and the conflict between rules in Thematic Role Theory and Binding Theory as an example.

Breaking rules is often considered desirable, innovative, and creative in music (Becker \& Becker, 1979; Hughes, 1991; Johnson-Laird, 1991). However, Johnson-Laird (1991) points out that just breaking rules is not enough. Rules must be broken in certain ways if the music is to still be coherent and aesthetically pleasing. What the constraints are for breaking rules and the mental processes that underlie creativity are topics for further research.

\subsubsection{Preference Rules}

In addition to well-formedness rules, some musical grammars include preference rules. Preference rules are a type of rule that is not typically used in linguistic grammars. Unlike well-formedness rules, preference rules do not specify grammaticalness. Rather, they pick out a "preferred" structural description out of a set of well-formed structures. Lerdahl and Jackendoff (1983) use well-formedness rules to "specify the possible structural descriptions" a listener might assign to a musical piece (p. 9). Then out of the possible structural descriptions, preference rules designate the structural descriptions that "correspond to experienced listeners' hearings of any particular piece" (p. 9). The following is an example of a preference rule: 
Consider a sequence of four notes $\mathrm{n} 1, \mathrm{n} 2, \mathrm{n} 3, \mathrm{n} 4$. All else being equal, the transition n2-n 3 may be heard as a group boundary if the transition n2-n3 involves a greater intervalic distance than both n1-n2 and n3-n4.

(Lerdahl \& Jackendoff, 1983, p. 346)

West et al. (1985) note an advantage of using both well-formedness rules and preference rules. The well-formedness rules give an indication of what types of structures would never be found, and the preference rules give "a degree of flexibility to take account of individual differences in musical perception" (p. 38).

Lerdahl and Jackendoff (1983) explain the need for preference rules by differences in linguistic and music theory. In linguistic theory, grammaticality is considered the most important distinction; ambiguity (whether a string of words has more than one structure with different meanings) is a secondary distinction. However, as mentioned in Section 2.2.1, in music

grammaticality per se plays a far less important role, since almost any passage of music is potentially vastly ambiguous -- it is much easier to construe music in a multiplicity of ways. The reason for this is that music is not tied down to specific meanings and functions, as language is. In a sense, music is pure structure, to be played with within certain bounds. The interesting musical issues usually concern what is the most coherent or "preferred" way to hear a passage. Musical grammar must be able to express these preferences among interpretations ... A "preferred" structural description will tend to relate otherwise disparate intuitions and reveal regular structural patterns. (p. 9)

...whereas linguistic theory is highly concerned with grammaticality, music theory is much more concerned with preference among a considerable number of competing well-formed (grammatical) structures. (pp. 307-308)

Lerdahl and Jackendoff (1983) discuss whether there are a number of rule systems in linguistic theory that are comparable to preference rules in music. They find rules of pragmatics to be similar in nature to preference rules. For example, Grice's (1975) maxims of conversation are stated in terms of the speaker, but they can equally apply "to the process of interpretation by the hearer, where they appear as preferences on how to construe the speaker's intended meaning" (p. 310). So, for example, the maxim "be 
relevant" can be stated for the listener as "prefer to assume that the speaker is conveying something relevant" (p. 310).

Hughes (1991) suggests that analyses in which rules have varying strengths (Becker \& Becker, 1979) are other examples of preference rule systems operating. In a discussion concerning rules conflicting, Hughes proposes that preference rules similar to those of Lerdahl and Jackendoff's analysis may be used to resolve conflicts of rules by ranking rules' strength. Kippen and Bel's (1992) grammar of Indian tabla drumming includes weighted rules that give probabilities of occurrence of certain patterns. Hughes suggests this is another example of a type of preference rule system, and proposes "it is becoming increasingly apparent that musical grammars need to incorporate such probabilistic elements" (p. 349).

Preference rules may also be similar to variable rules in sociolinguistic studies. Variable rules are modified versions of the kinds of rules found in transformationalgenerative grammars (Wardhaugh, 1986). Variable rules include probabilities of

occurrence based on the presence or absence of certain factors. For example, depending on certain factors, such as social class, and level of formality, there are probabilities that a certain phoneme will be added or omitted from speech. This seems, then, to address preference, rather than well-formedness.

\subsubsection{Spatio-Motor Considerations}

An aspect of musical grammars that is generally not considered in linguistic grammars is spatio-motor considerations. There are characteristics of music that are constrained by physical factors, such as the construction of an instrument, or characteristics of human movement. Baily (1985) proposes the need "to consider the extent to which the creation of musical structures is shaped by sensorimotor factors" 
because there is a relationship between "sonic patterns of music and human movement" (pp. 237-238).

... the activity of music making involves patterned movement in relationship to the active surface of a musical instrument... Human movement is the process through which musical patterns are produced: Music is the sonic product of action. (Baily, 1985, p. 237)

As mentioned in Section 2.2.2, Baily suggests a partial grammar for plucking variations on the rubab. These plucking variations result in patterns that can be heard as distinct from the melodic pitch patterns. The following are examples of rules from this grammar:

Rule 3. $\wedge \wedge$ is an impossible combination.

Rule 4. The maximum number of $v$ 's in a row is 3 .

$(\vee=$ down stroke; $\wedge=$ upstroke)

(Baily, 1989, cited in Hughes, 1991, p. 351)

Rule 3 states that there will never be two upstrokes in a row. Rule 4 states that no more than 3 down strokes will occur in a row. Baily suggests that the patterns that occur might be explained by "limitations of motor technique" as well as aesthetic considerations (Hughes, 1991, p. 351). It is a difficult move to begin a matra (a unit of four plucks or less) with an upstroke. Virtuoso performers may deliberately begin a matra with an upstroke, but they may delay the playing of the note. The syncopation that results may be there for aesthetic reasons or it may be there for physical reasons.

The "... spatial properties of an instrument may influence the shape of the music played on it" (Baily, 1985, pp. 242-243). For example, in analyzing the music of Hector Berlioz, "it is useful to know that he often worked out harmonic procedures on a guitar, and that the structure of the instrument influenced many of his chord sequences" (Blacking, 1955, cited in Baily, 1985, p. 242).

Blacking (1973) gives an example of a musical system in Zambia that is determined by finger movement patterns, rather than by sonic patterns. Tunes (melodies) played on 
the kalimba mbiras (a kind of "thumb piano") are formed by "relationships between the patterns of the movement of the left and right thumbs, the patterns of rhythms with which [the keys are plucked], and the patterned arrangement of the 'keyboard' itself" (p. 12). This system is contrasted to the ndimba (another kind of thumb piano), in which the sonic patterns of the melody are the organizing factor; the physical thumb movements are "subordinate to the requirements of the song" (p. 12).

Baily (1985) concludes

If the study of music and cognition is to proceed from the culture specific to the universal, then a wider approach must be adopted, one that includes recognition of the possibility that music may be as much a motor event as a sonic event, as well as, of course, a social fact. (p. 258)

Thus, a complete musical grammar may need a spatio-motor dimension interacting with the sonic aspects of the music (Hughes, 1991).

\subsubsection{Extra-Musical Considerations}

Just as there are researchers who want to include social context (what might be considered extra-linguistic by some) in linguistic grammars, there are researchers who want to include what might be considered extra-musical context as a part of musical grammars. The social context might require, for example, a certain number or gender of participants or a certain time of year or day for performance (Hughes, 1991). Hughes (1988) includes such extra-musical contextual rules in his grammar of a genre of Javanese music; however, these rules are not formalized. The following is an example of an extramusical contextual rule:

Choose one of six pathet: SIM, SIS, SIN, PIM, PIN, PIB ${ }^{7}$

The choice is not free but is constrained by factors such as time of night, dramatic genre, etc. . At 1 a.m. in a wayang kulit performance, SIS must normally be chosen. (Hughes, 1988, p. 31)

\footnotetext{
${ }^{7}$ These refer to particular modes and tuning systems.
} 
West et al. (1985) also note that structure can be understood in part by reference to extra-musical or historical context. For example, in addition to the constraints of the instruments, there are also considerations such as music that is developed for dancing, or songs that require phrasing that takes into account breathing and makes linguistic sense. In addition, listeners may assign different structures depending upon how familiar they are with the music (West et al. 1985), or on the performance of a piece (Sundberg \& Lindblom, 1991).

\subsection{Conclusion}

Linguistic and musical grammars share some characteristics and differ in others. Similarities include the notions of deep and surface structure, rules acting on hierarchical structures, rule conflicts and solutions, variable rules, and the need, in general, for contextsensitive-rules. Because context-sensitive rules are difficult to manage, a number of musical grammars use transformations to make the computational task easier.

Differences between linguistic and musical grammars are the result of differences in the functions of language and music. Musical grammaticality is much more ambiguous than language grammaticality (West et al., 1985). The notion of well-formedness is perhaps more important in linguistic grammars than in musical grammars (Lerdahl \& Jackendoff, 1983; West et al., 1991). This is because linguistic grammars have to convey meaning. In music

the grammar serves to constrain the music so as to create expectation, to some extent to violate that expectation, enhance memorability and by these or other means provide listening satisfaction; meaning as embodied in a codified framework of signification does not seem to be intrinsic to music. (West et al., 1991, p. 26)

Researchers writing grammars for musical systems generally take either a synthetic or analytic approach. In either case, the grammar is a representation of musical knowledge or competence. Because of the complexity of the subject, most musical 
grammars focus on a single aspect of music, such as the pitch of the melody, and leave out others, such as harmony. Including social and other extra-musical contexts in musical grammars are topics for further research. 


\section{CHAPTER 3}

\section{A PARTIAL GRAMMAR FOR BALINESE KOTEKAN}

\subsection{Introduction}

This chapter addresses directly the questions concerning Balinese musicians' knowledge of kotekan and its structure, and the representation of this competence in the form of a grammar. As mentioned previously, kotekan is the elaboration of the core melody (pokok); the kotekan relates to the pokok in specific ways. Kotekan is composed of two individual parts: polos and sangsih. These separate parts interlock in specific ways to form a composite kotekan musical line. Given the polos part of a kotekan, even one not heard previously, a Balinese musician would usually be able to come up with a sangsih part quite easily and spontaneously. Thus, it appears there are rules that relate the parts to each other. A grammar of Balinese kotekan includes an explicit formalization of these rules.

Section 3.2 presents background information about Balinese gamelan music in order to provide context for the rules which are presented in Section 3.3.

\subsection{Balinese Gamelan Music - Background}

There are numerous styles of Balinese gamelan music. This study describes aspects of the modern gamelan gong kebyar style. The focus of this study is the gangsa, which is briefly described in Section 3.2.1. Section 3.2.2 describes the playing technique of kotekan on the gangsa. The general structure of Balinese gamelan music and its hierarchical nature is described in Section 3.2.3. 


\subsubsection{The Gangsa}

The gangsa is a bronze idiophone that is struck with a hard wooden mallet. The bronze keys are suspended on leather straps over bamboo resonating tubes. The keys range in size from approximately $13 / 4$ to 3 inches in width and 7 to 10 inches in length. The keys are beveled and musicians strike the middle portion; thus, the actual area for striking a key is about half the size of the key. The layout of the keyboard is given in Figure 3.

\begin{tabular}{|l|l|l|l|l|l|l|l|l|l|}
\hline D & E & G & A & C & D & E & G & A & C \\
\hline
\end{tabular}

Figure 3. Arrangement of keys on the gangsa.

The scale, then, consists of these notes: D, E, G, A, C. ${ }^{8}$ Moving from one of these tones to the next is considered one step, or conjunct motion. Tones next to each other in the scale are called adjacent. ${ }^{9}$ For example, $\mathrm{E}$ to $\mathrm{G}$ is conjunct motion or one step; $\mathrm{E}$ and $\mathrm{G}$ are adjacent. $\mathrm{E}$ to $\mathrm{A}$ is two steps, $\mathrm{E}$ to $\mathrm{C}$ is three steps, and so on.

In most gamelan gong kebyar, there are eight gangsa involved in playing the kotekan part of a piece (Vitale, 1990). They are divided into two groups: four pemade and four kantilan. The kantilan are tuned an octave above the pemade. In each group of four, two instruments are assigned to the polos part, two to the sangsih part. See Figure 4.

\footnotetext{
${ }^{8}$ The notes given are approximations. The tuning systems of Balinese music are different from that of Western tonal music. The system described in this study is pelog, a seven-note system from which fivetone (pentatonic) scales are extracted. The notes are often represented as D Eb G Ab C, or as D E G\# A C\#. In the text of this paper, sharps and flats are left out.
}

${ }^{9}$ Adjacent means tonally adjacent, as opposed to temporally adjacent, which means two notes occur sequentially in time without any rests in between. 


\section{PEMADE}

Sangsih

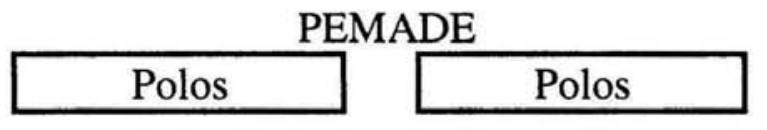

Sangsih

Sangsin
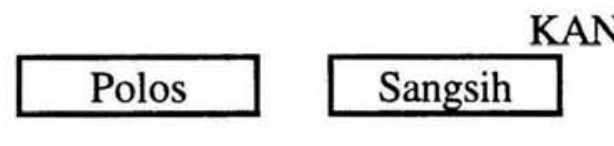

KANTILAN

Figure 4. Gangsas and assignments of polos and sangsih parts.

\subsubsection{Playing Technique}

An important factor in understanding the structure and rules of kotekan is the technique with which kotekan is performed. Vitale (1990) describes this technique:

The technique used to play the gangsa is critical in the execution of kotekan parts. The wooden mallet used to strike the keys is held in one hand, leaving the other hand free to damp the key's vibration after it is struck. The motion of the damping hand therefore mirrors that of the playing hand, following it along as its shadow. (p. 3)

The damping of keys is just as important as the striking of keys and must be precise. This is because where one sound ends, another often begins.

The note must be sharply defined both in its attack--the exact moment in which it is struck and thereby placed rhythmically--and in its disappearance as well, where another note or a rest will start. The reason is that the following note will often be in another part of the kotekan, performed by a different group of players. (p. 3)

\subsubsection{Structure}

As mentioned in Chapter 1, Balinese gamelan music is hierarchically structured, or divided into layers of phrases. Figure 5 illustrates the hierarchical phrasing structure, and marks structurally important points. 

A

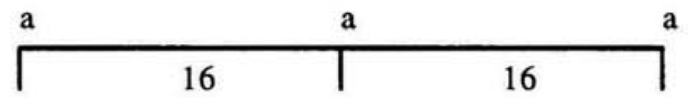
B

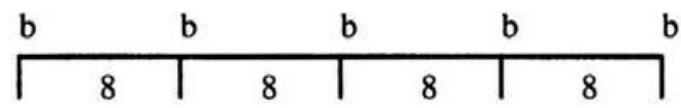

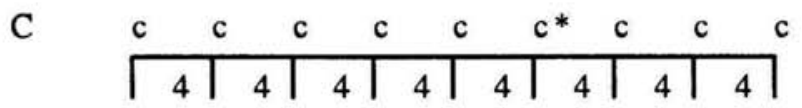

Figure 5. Hierarchical phrasing structure of Balinese gamelan music.

The numbers in Figure 5 correspond to the number of beats in a phrase. Points where $a, b$ and $c$ coincide are the most structurally important. Points where $b$ and $c$ coincide are also structurally important, but less so. Still less important are points $c$. Thus, what appears as structurally important at one level may not be important at a higher level. For example, in level C, point c* is structurally important, but at level B, it is not. The layers of phrases are punctuated by the colotomic instruments. The largest gong, known as gong ageng or simply gong, marks the longest phrases. In Figure 5, the largest gong would be marking the level A phrases, i.e., playing at the points marked $a$, which correspond to the 1 st beat of a 16 beat phrase. ${ }^{10}$

Figure 6 illustrates a typical layering of instruments and their parts in an 8-beat phrase.

\footnotetext{
${ }^{10}$ The idea that the gong marks the first beat of a phrase is how a Western musician feels the beats. Balinese musicians actually feel the gong on the last beat of a phrase. Because the music is cyclical, it can be described either way. Since this paper is written for readers familiar with Western tonal music, the structurally important points will be described as occurring at the beginning of phrases.
} 


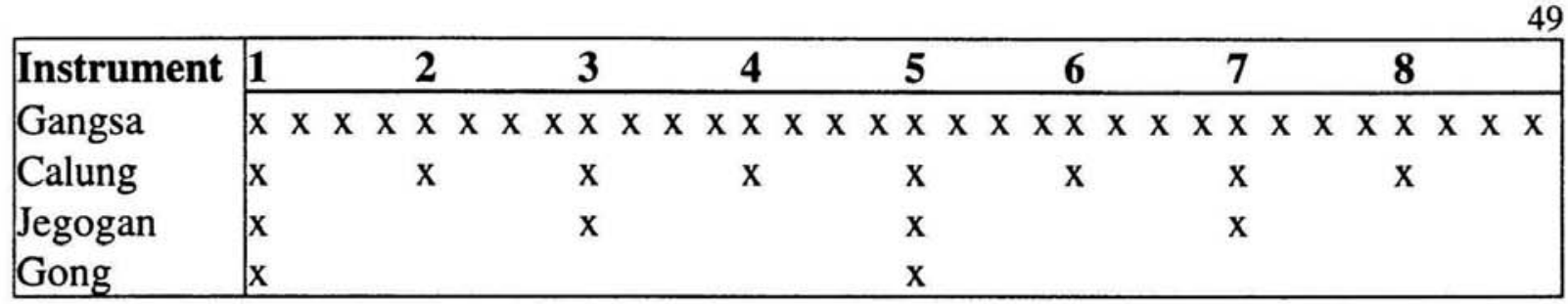

Figure 6. Display of a typical layering of instrumental parts in an 8-beat phrase.

In Figure 6, x's correspond to notes being played. The higher toned instruments are playing faster than lower toned instruments by even multiples. The gangsas, playing the kotekan, play the fastest. The calungs often play the core melody. The jegogan, a lower toned instrument than the calung, plays slower than the core melody. Balinese music is cyclical and metrical (i.e., has strong and weak beats). Structurally important points are at strong beats and are marked by layers of instruments coinciding. In this example, the structurally most important points are beats 1 and 5 . Beats 2,4 , and 6 are least important.

\subsection{Rules in Balinese Gamelan Music}

Rules in Balinese gamelan music fall into several categories ${ }^{11}$ (W. Vitale, personal communication, 1993). These categories can be considered to form a hierarchy:

1. Global Rules. General constraints on all musical (melodic) lines and general tendencies in the structure of the music overall.

2. Kotekan general rules. Includes the relationship of kotekan to the core melody.

3. Constraints on Polos and Sangsih as individual lines.

4. Rules for Polos and Sangsih interaction. Includes rules for deriving sangsih from polos.

\footnotetext{
${ }^{11}$ The categories presented here are those that directly affect kotekan. These are not necessarily the only categories of rules in Balinese music.
} 
Rules for upper levels apply to lower levels as well. Thus, a core melody is constrained by (1), while a sangsih part is constrained by levels (1) - (4).

The rules and generalizations in the next sections of this chapter are based on Vitale (1990; personal communication, 1993), and the scores ${ }^{12}$ in Appendix A.

Generalizations, although not formal rules, are presented for categories (1) and (2) above (Sections 3.3.1 and 3.3.2 respectively). The focus of this study is on the rules concerning categories (3) and (4) (Sections 3.3.3 and 3.3.4). A listing of all the rules and generalizations is given in Appendix B for easy reference.

\subsubsection{Global Rules}

The following are generalizations for Balinese gamelan music $(G R=$ Global Rule):

GR1. The parts of the ensemble coincide at structurally important points. These points are metrically strong points.

GR2. Musical lines are composed of tones that are repeated, adjacent or 2 steps away. ${ }^{13}$

\subsubsection{Kotekan Generalizations}

The general rules for kotekan as an elaboration of the pokok are as follows $(\mathrm{KG}=$ Kotekan Generalization):

KG1. At structurally important points in a piece, the kotekan meets up with (i.e., joins at the unison or octave with) the core. ${ }^{14}$ This rule is a specific case of GR1.

KG2. The kotekan should surround the notes of the core melody. For example, if the core makes a jump up, the kotekan movement is to follow it up. If the core movement is downward, the kotekan will follow it downward.

\footnotetext{
${ }^{12}$ The scores presented in this study are written in Western notation. Balinese musicians generally do not use a written notation system for Balinese music.

${ }^{13}$ Interval jumps greater than 2 steps do occur, but they are not common.

${ }^{14}$ The kotekan may meet up with the pokok at other points which are not structurally important as well.
} 
KG3. The polos is usually the part of the kotekan that meets up with (i.e., joins at the unison or octave with) the pokok at structurally important beats. This affects the polos-to-sangsih rules given in Section 3.3.4.

KG4. The kotekan as a line is continuous; i.e., there should not be breaks in sound.

The constraints on kotekan as a musical line follow GR2; that is, the intervals between sequential notes are one or two steps.

Figure 23 in Appendix A is an example of a kotekan line (top staff) and a pokok line (bottom staff). The polos part corresponds to the notes with the stems pointing down; the sangsih part corresponds to the notes with stems pointing up. The kotekan surrounds the pokok in that it hovers around the $\mathrm{E}$ and $\mathrm{A}$, which are also in the pokok (KG2). ${ }^{15}$ Both the pokok and kotekan lines are made up of conjunct and 2 step motion (GR2). The kotekan line does not have breaks in it (KG4).

In this example, at points marked $a$ and $b$, the kotekan matches up exactly with the pokok on every pokok note (KG1). At the points marked $a$, the polos matches up with the pokok (KG3). However, at the points marked $b$, the polos part does not match up; the sangsih part matches up. In these instances, KG1 is followed, although KG3 is not. W. Vitale (personal communication, 1993) stresses that these generalizations are tendencies in the music. In addition, when the kotekan (or polos) does not match up with the pokok at certain points, as mentioned previously, it may be the case that at a higher level in the hierarchy, the points in question are not structurally important. Thus what may appear as a violation of $\mathrm{KG} 1$ or $\mathrm{KG} 3$ at one level of phrasing may be, and in fact usually is, perfectly fine at a higher level.

As mentioned in Chapter 1, a Balinese musician, if given a kotekan, can usually extract the core melody or at least an outline of the core. This is because at structurally important points the kotekan and pokok play the same tone (KG1). Structurally important

\footnotetext{
${ }^{15}$ When an example illustrates particular rules, the rules are presented in parenthesis.
} 
points can be identified because they are metrically strong, the layers of phrases coincide, and the instrumental parts coincide (GR1). However, a given core may have various kotekan that will fit it. Formal rules that generate kotekan given a core are beyond the scope of this study.

\subsubsection{Rules for Polos and Sangsih as Individual Lines.}

Polos and sangsih as individual lines follow the same set of constraints (PSL $=$ Polos/Sangsih Line):

PSL1. Never more than 3 notes are played in a row; i.e., 1, 2 or 3 notes are played and then there must be a rest.

PSL2. Only single rests ${ }^{16}$ are allowed; i.e., there are never 2 or more rests in a row.

PSL3. Never 3 notes of the same pitch are played in a row. ( 2 of the same pitch in a row is also rare.)

PSL4. Pitches of the scale are adjacent when temporally adjacent. If there is a rest in between, then the tones do not have to be adjacent.

These rules can be formalized and succinctly expressed in the following phrase structure rules. Items appearing in ( )'s are optional.

Let: $\quad$ PSL $=$ polos or sangsih line

$\mathrm{NP}=$ note phrase

$\mathrm{R}=$ rest

$\mathrm{a}=$ note

$\mathrm{b}=$ adjacent note to $\mathrm{a}$

\footnotetext{
${ }^{16}$ Rests are not simply absences of sound. A rest is a period of silence with a specific length. Rests have a time value just as notes do.
} 
Phrase Structure Rules for Generating Polos and Sangsih Lines

$$
\begin{aligned}
& \text { PSL }->\text { (R) NP17 } \\
& N P \rightarrow \text { a (b) (a) R (NP) }
\end{aligned}
$$

These phrase structure rules can be expressed in a recursive transition network. Figure 7 illustrates a transition network that corresponds to the phrase structure rules above.

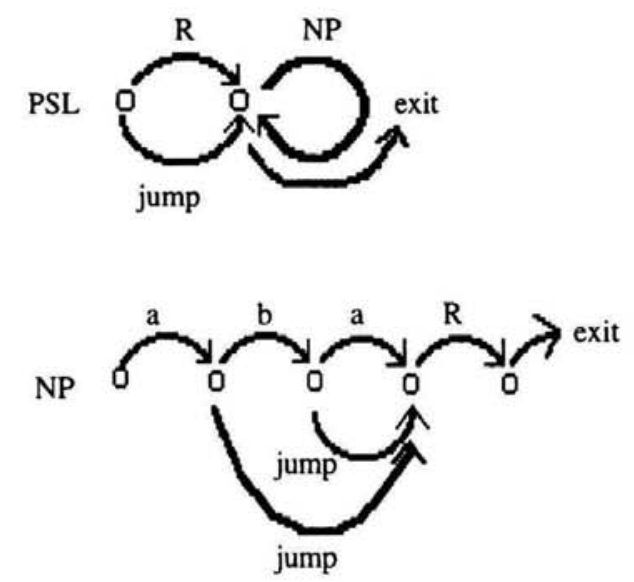

Figure 7. Transition network for generating polos and sangsih lines.

These rules apply to polos and sangsih lines at anytime. ${ }^{18}$ They are not dependent on the phrasing structure of the music. Figure 8 illustrates sample patterns that this grammar (specifically, the NP re-write rule) generates and corresponding note patterns. These basic note patterns are found throughout kotekan. In the figure, each column represents a beat; an empty box represents a rest. The rows represent adjacent tones. X's represent notes played.

\footnotetext{
${ }^{17}$ This rule makes it possible to begin a polos or sangsih line with a rest. This rule combined with the NP rule ensures that there will not be two rests in a row.

${ }^{18}$ The exception to these rules is a special form of kotekan known as norot. See Section 3.4.2.
} 


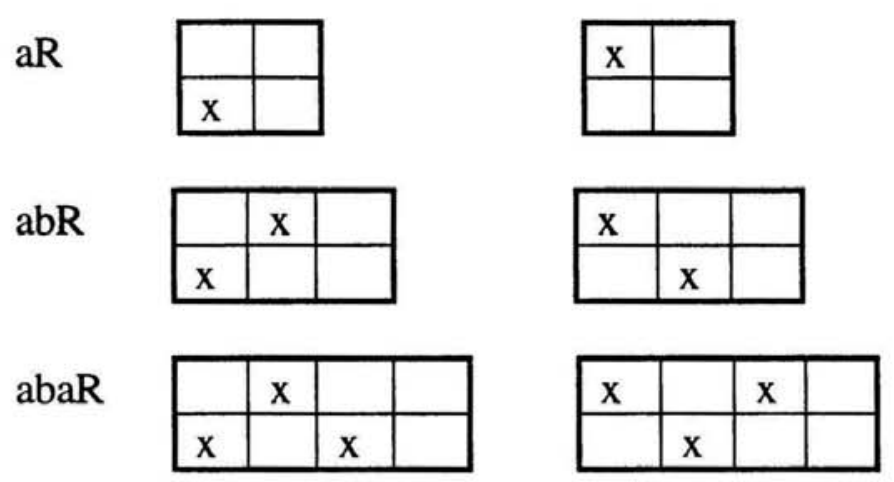

Figure 8. Patterns generated by the NP phrase structure rule and corresponding note patterns.

Because the NP rule is recursive, these patterns can be concatenated to form an infinite number of polos or sangsih lines. For example, by applying the rule recursively, a line such as the following can be generated:

(1) $a R$ abR aR abR abR aR aR

Spaces in line (1) above indicate an application of the NP re-write rule. An example of a graphical representation of line (1) is given in Figure 9 so that the pattern of adjacent notes and rests is more easily seen.

\begin{tabular}{|l|l|l|l|l|l|l|l|l|l|l|l|l|l|l|l|}
$\mathrm{a}$ & $\mathrm{R}$ & $\mathrm{a}$ & $\mathrm{b}$ & $\mathrm{R}$ & $\mathrm{a}$ & $\mathrm{R}$ & $\mathrm{a}$ & $\mathrm{b}$ & $\mathrm{R}$ & $\mathrm{a}$ & $\mathrm{b}$ & $\mathrm{R}$ & $\mathrm{a}$ & $\mathrm{R}$ & $\mathrm{a}$ \\
\hline & & & $\mathrm{x}$ & & & & $\mathrm{x}$ & & & & $\mathrm{x}$ & & & & $\mathrm{x}$ \\
\hline $\mathrm{x}$ & & $\mathrm{x}$ & & & $\mathrm{x}$ & & & $\mathrm{x}$ & & $\mathrm{x}$ & & & $\mathrm{x}$ & & \\
\hline
\end{tabular}

Figure 9. An example of a graphical representation of line (1).

Line (1) and Figure 9 correspond to the polos in Figure 23 in Appendix A. The correspondence is illustrated in the Table 5.

TABLE 5

Correspondence between Polos in Figure 23 and Line (1)

Line (1)

Polos

\begin{tabular}{|l|l|l|l|l|l|l|l|l|l|l|l|l|l|l|l|}
\hline $\mathrm{a}$ & $\mathrm{R}$ & $\mathrm{a}$ & $\mathrm{b}$ & $\mathrm{R}$ & $\mathrm{a}$ & $\mathrm{R}$ & $\mathrm{a}$ & $\mathrm{b}$ & $\mathrm{R}$ & $\mathrm{a}$ & $\mathrm{b}$ & $\mathrm{R}$ & $\mathrm{a}$ & $\mathrm{R}$ & $\mathrm{a}$ \\
\hline $\mathrm{E}$ & & $\mathrm{E}$ & $\mathrm{G}$ & & $\mathrm{E}$ & & $\mathrm{G}$ & $\mathrm{E}$ & & $\mathrm{E}$ & $\mathrm{G}$ & & $\mathrm{E}$ & & $\mathrm{G}$ \\
\hline
\end{tabular}


Note that once a rest occurs, the re-write rule starts over. So in one application of the rule, $a$ stands for E; in another application, it stands for G. When $a$ and $b$ appear temporally adjacent (i.e., no rests in between), they stand for adjacent tones. Thus, in this example, $a b$ stands for EG or GE. This means, then, that line (1) represents or describes many possibilities for actual notes. For example, line (1) describes the sequences of notes in Table 6 as well as many others.

TABLE 6

Example Sequences of Notes Described by Line (1)

$\begin{array}{llllllllllllllll}\mathbf{a} & \mathbf{R} & \mathbf{a} & \mathbf{b} & \mathbf{R} & \mathbf{a} & \mathbf{R} & \mathbf{a} & \mathbf{b} & \mathbf{R} & \mathbf{a} & \mathbf{b} & \mathbf{R} & \mathbf{a} & \mathbf{R} & \mathbf{a} \\ \mathrm{G} & & \mathrm{G} & \mathrm{E} & & \mathrm{E} & & \mathrm{E} & \mathrm{G} & & \mathrm{E} & \mathrm{G} & & \mathrm{G} & & \mathrm{E} \\ \mathrm{E} & & \mathrm{G} & \mathrm{E} & & \mathrm{G} & & \text { G } & \text { E } & & \text { E } & \text { G } & & \text { E } & & \text { G } \\ \text { C } & & \text { C } & \text { D } & & \text { D } & & \text { C } & \text { D } & & \text { D } & \text { C } & & \text { C } & & \text { D }\end{array}$

All of the polos and sangsih parts in the scores in Appendix A (except for Norot) follow the phrase structure rules for individual lines that were presented in this section.

\subsubsection{Rules for Generating Sangsih from Polos.}

There are a number of different types or forms of kotekan. These different types are often concatenated in a single composition to create very complex kotekan sections. Part of the definition of kotekan type depends on the number of notes that make up a unit or cell in the kotekan. A cell is made up of two, three, or four adjacent tones that surround or hover around the pokok tone. For example, in Figure 23, the kotekan is made up of a three note cell that consists of: E, G and A. The rules for generating a sangsih from a polos depend on the kotekan type and on the movement of the pokok. The types of kotekan examined in this study are:

Oncang-oncangan ( 2 note)

Norot (2 note)

Telu ( 3 note) 
Empat (4 note)

The following are rules describing the relationship between polos and sangsih in all types of kotekan (PSR $=$ Polos/Sangsih Relationship):

PSR1. The polos part is below the sangsih part; i.e., the sangsih is above the polos in pitch. ${ }^{19}$

PSR2. The polos is considered the "simple" part that tends to play on the beat. The sangsih is considered the "differing" part that tends to play off the beat. ${ }^{20}$

Most of the rules in the following sections are expressed as context-free re-write rules. However, the assignment of note values and the rules are actually context-sensitive because:

1. They assume that the kotekan matches up with the core according to general kotekan rules.

2. They depend on the movement of the pokok.

3. They apply within a given phrase of a piece; i.e., the scope of a rule extends over a phrase. Phrasing is assumed, although the rules given in this study do not do the segmenting.

\subsubsection{Oncang-Oncangan}

Oncang-oncangan is structurally one of the simplest kotekan. It is one of the most difficult to perform, however, because it usually occurs at the fastest tempos (Vitale, 1990). The basis of this kotekan is strictly rhythmical. There is a "straight forward alternation" between the polos and sangsih parts (p. 4). It is an example of PSR2 applying strictly. The rules for oncang-oncangan are $(\mathrm{O}=$ Oncang-oncangan Rule):

\footnotetext{
${ }^{19}$ There are times, however, when the polos is above the sangsih. This is explained in more detail in Section 3.4.3.

${ }^{20}$ Vitale (1990) notes that while this is generally true, the rhythmic relationship between the two parts is much more complex.
} 
O1. Polos is always on the beat.

O2. Sangsih is always off the beat.

The phrase structure rule for generating polos in oncang-oncangan is:

$$
\begin{aligned}
& \text { polos }->\mathrm{a} R \text { (polos) } \\
& \text { where } \begin{aligned}
\mathrm{a} & =\text { note } \\
\mathrm{R} & =\text { rest }
\end{aligned}
\end{aligned}
$$

This rule generates the following pattern:

a $R$ a $R$ a $R$ a $R$.....

This pattern is illustrated in Figure 24 in Appendix A. The polos is always on the beat and single notes are followed by single rests.

As mentioned previously, this rule is context-sensitive. The direction of the next $a$, i.e., higher or lower than the current $a$, is dependent on the motion of the core melody because the kotekan as a whole follows the core (KG2). It is often the case that the next note in the polos will be two steps away from the current note.

The sangsih can be generated from the polos in the following manner:

1. Wherever there is a note in the polos, play a rest.

2. Wherever there is a rest in the polos, play a note.

This can be expressed formally in the following transformation:

polos $\rightarrow$ sangsih $^{21}$

(1) $a->R$

(2) $R->b$

where $\mathrm{a}=$ polos note

$\mathrm{b}=$ sangsih note

$\mathrm{R}=$ rest

${ }^{21}$ The re-write rules are numbered for identification. They can be applied in any order to the polos line. 
The process of generating sangsih from polos is illustrated in Figure 10. Using the phrase structure rule for polos, a polos line is generated. Then the polos $->$ sangsih transformation is applied to generate the sangsih line. The numbers correspond to the rules applied.

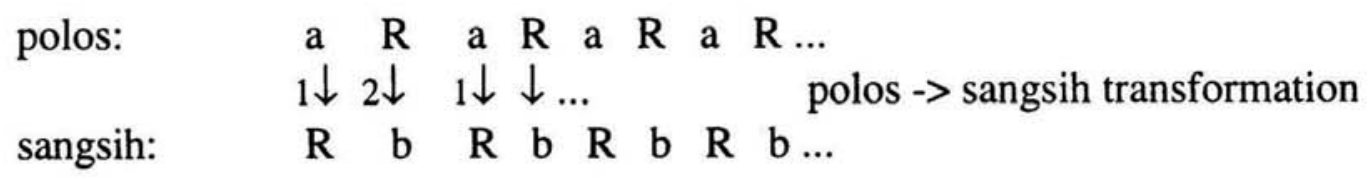

Figure 10. Process of generating sangsih from polos.

Figure 25 in Appendix A illustrates a sangsih generated from this process. It corresponds to the line: $R b R b R b$... The sangsih is always off the beat. Single notes are always followed by single rests.

The choice of $b$ depends on the motion of the core (KG2). In general, $b$ is adjacent to $a$ or the next $a$. Thus the kotekan line itself tends to follow the general tendency on lines, GR2 (sequential notes are repeated, one or two steps away), although not strictly. Figure 26 combines the polos in Figure 24 and the sangsih in Figure 25 and illustrates how the parts interlock to create a continuous kotekan line. There are no breaks in this line (KG4). At the points marked $a$ the polos meets up with the pokok (KG1, KG3). At the point marked $b$, there is an interval greater than 2 steps; GR2 is not being followed. It appears that this is a case where KG2 (surrounding the core melody) is stronger than GR2.

It is interesting to note that the requirement on polos and sangsih as individual lines, PSL4 (i.e., temporally adjacent notes are adjacent), is still followed. Because there is a rest after every note in each part, the next tone in that part does not have to be adjacent. In addition, the sangsih line occurs both above and below the polos; thus PSR1 is not followed. However, as mentioned previously, PSR2, concerning rhythm, is strictly 
followed. This is a case, then, where certain kotekan specific rules are more important than other global or general kotekan rules for defining what is well-formed.

\subsubsection{Kotekan Norot}

As mentioned previously, norot is a special 2-note case of kotekan. The rules for norot are $(\mathrm{N}=$ Norot Rule):

N1. Sangsih is always above polos.

N2. Sangsih is always adjacent to polos.

N3. Sangsih and polos anticipate the next core note -3 beats ahead of it.

This type of kotekan strictly follows PSR1, but does not strictly follow PSR2. It also strictly follows KG1, KG2 and KG3; i.e., the polos is on the core at structurally important points and the kotekan surrounds the core. The relationships between the polos, sangsih, and pokok are strictly defined in norot. Thus, both the polos and sangsih can be derived directly from the core melody. In addition, as usual, the sangsih can be derived from the polos.

These rules for norot are formalized as follows:

Let: $\quad a=$ core note

$\mathrm{b}=$ higher adjacent note to (a)

$\mathrm{c}=$ next core note

$\mathrm{d}=$ higher adjacent note to $(\mathrm{c})$

$\mathrm{R}=$ rest

The polos and sangsih are derived from the core using the following transformations:

$\begin{array}{ll}\frac{\text { core } \rightarrow \text { polos }}{a->\text { a RaRa }} & \frac{\text { core }>\text { sangsih }}{a->R b R b R} \\ c \rightarrow \text { c R } & c \rightarrow c c d\end{array}$

Figure 11 illustrates the tree structure these transforms generate. 
Core

Polos

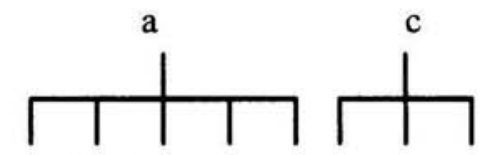

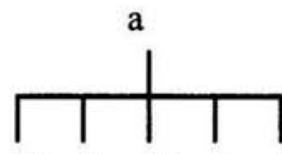

$\begin{array}{lllllllll}\mathbf{R} & \mathbf{b} & \mathbf{R} & \boldsymbol{b} & \mathbf{R} & \mathrm{c} & \mathbf{c} & \mathrm{d} & \text { Sangsih }\end{array}$

Figure 11. Tree structure illustrating the derivation of polos and sangsih from the core.

Thus, polos phrases always have the form: a R a R a c c R. Sangsih phrases always have the form: $\mathrm{R} \mathrm{b} \mathrm{R} \mathrm{b} \mathrm{R} \mathrm{c} \mathrm{c} \mathrm{d.} \mathrm{When} \mathrm{the} \mathrm{polos} \mathrm{and} \mathrm{sangsih} \mathrm{parts} \mathrm{are} \mathrm{played} \mathrm{together,} \mathrm{the}$ kotekan line is: $a b a b a c c d$.

Figure 27 in Appendix A, an example of the norot figuration, illustrates this ababaccd pattern. The polos matches the pokok tone at structurally important points (KG1, KG3). The kotekan forms a continuous line (KG4) that follows the pokok closely (KG2). The polos and sangsih parts follow the patterns given in this section.

An alternative way of approaching this figuration is to generate the sangsih from the polos, rather than directly from the core. The sangsih can be generated from the polos line using the following transformation:

$$
\begin{aligned}
& \text { polos }->\text { sangsih } \\
& \mathrm{a} \rightarrow \mathrm{R} \\
& \mathrm{R} \rightarrow \mathrm{b} / \mathrm{not} \text { _\# } \\
& \mathrm{R} \rightarrow \mathrm{d} / \text { /_\# } \\
& \mathrm{c} \rightarrow \mathrm{c}
\end{aligned}
$$

The re-write rules for transforming the rests into notes are context-sensitive in this analysis. The first says to change a polos rest into note $b$ when the rest is not phrase final. The second says to change a rest into note $d$ when the rest is phrase final. Figure 12 illustrates the process of generating the sangsih from the polos, which is ultimately dependent on the pokok. 


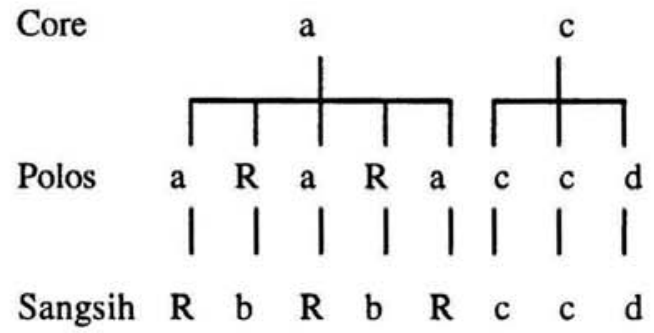

Figure 12. Generation of sangsih from the polos and ultimately, from the pokok.

\subsubsection{Kotekan Telu}

As mentioned previously, kotekan telu is based on a three note cell. Vitale (1990) describes kotekan telu:

Within this cell of three tones, the division into sangsih and polos always involves sharing the middle tone, which serves as a kind of pivot-point between the two parts. One of the parts will oscillate between the two higher tones, and the other between the two lower tones. (p. 6)

Thus, each tone of the cell has a relationship to the cell and to the part that plays it. A three note cell and these relationships are given in Figure 13.

\section{Kotekan Telu}

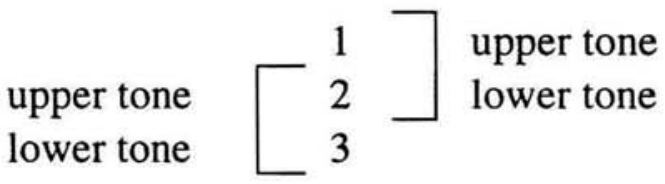

Figure 13. Tones and their relationship in a three note cell.

Tones 1 and 2 are played by one part; tones 2 and 3 by the other part. Tones 1 and 3 are called outer tones and tone 2, the inner tone.

Figures 14 and 15 show the relationships in the specific cases when the sangsih is above or below the polos. 


\section{Sangsih Above Polos}

\begin{tabular}{l|l|l} 
& & \multicolumn{1}{l}{ upper (outer) sangsih } \\
upper (inner) polos & 2 & $\begin{array}{l}\text { lower (inner) sangsih } \\
\text { lower (outer) polos }\end{array}$ \\
& &
\end{tabular}

Figure 14. Tone relationships when sangsih is above polos.

\begin{tabular}{|c|c|c|}
\hline \multicolumn{3}{|c|}{ Sangsih Below Polos } \\
\hline & 1 & upper (outer) pol \\
\hline per (inner) $\mathrm{s}$ & 2 & lower (inner) polos \\
\hline lower (outer) sangsih & 3 & \\
\hline
\end{tabular}

Figure 15. Tone relationships when sangsih is below polos.

The rules for generating sangsih from polos depend on whether the kotekan is stationary or moving. Whether the kotekan is stationary or moving ultimately depends on what the core melody is doing. The rules for stationary telu are presented below. The rules for moving telu are beyond the scope of this study.

The rules for fitting the polos and sangsih together, i.e., generating sangsih from polos, can be stated as follows ( $\mathrm{ST}=$ Stationary Telu Rule):

ST1. Every inner polos = inner sangsih; i.e., the middle (shared) note is played in unison.

ST2. Wherever there is a rest in polos, play the outer sangsih.

These rules are formalized in the following transformation:

Let: $\quad \mathrm{a}=$ outer polos

$\mathrm{b}=$ inner polos (middle note of 3 note cell)

$\mathrm{c}=$ adjacent to $\mathrm{b}$, not equal to $\mathrm{a}$

$\mathrm{R}=$ rest

polos $\rightarrow$ sangsih

(1) $a->R$

(2) $b->b$

(3) $\mathrm{R} \rightarrow \mathrm{c}$ 
In the case where the sangsih is above the polos the assignment of tones can be stated more specifically:

$$
\begin{aligned}
& \text { Sangsih Above Polos } \\
& \begin{array}{l}
\mathrm{a}=\text { lower polos } \\
\mathrm{b}=\text { upper polos } \\
\mathrm{c}=\text { upper adjacent to } \mathrm{b}
\end{array}
\end{aligned}
$$

Figures 23, 28, 29 and 30 in Appendix A are examples of kotekan telu in which the sangsih is above the polos. In each case, the kotekan is a continuous line (KG4) that meets up with the pokok at each beat of the pokok (KG1). In particular, the polos meets up with the pokok at the structurally more important beats (KG3). The polos and sangsih parts as individual lines follow the PSL rules. Figure 30 explicitly marks the points when the polos and sangsih share the middle tone.

Figure 28 is used in the following illustration of the application of the transformation to generate a sangsih given a polos. In Figure 28, the polos alternates between $\mathrm{E}$ and $\mathrm{G}$. The three note cell in this case is given in Figure 16.

$$
\begin{array}{|l|l|l} 
& =\mathrm{c} \text { (upper adjacent to } \mathrm{b}) \\
\cline { 1 - 1 } & =\mathrm{b} \text { (upper polos) } \\
\mathrm{y} & =\mathrm{a} \text { (lower polos) }
\end{array}
$$

Figure 16. Three note cell when polos alternates between E and G.

Figure 17 illustrates the application of the transform. The polos line of Figure 28 and the corresponding symbols are given. The transform is applied, resulting in the sangsih symbols and corresponding notes. The number of the re-write rule that applied is shown for the first three notes. The sangsih created is exactly the sangsih in Figure 28. 
$\underline{\text { Polos }}$

Note

Symbol

\begin{tabular}{|l|l|l|l|l|l|l|l|l|l|l|l|l|l|l|l|}
\hline E & & G & E & & E & G & & E & & G & E & & E & G & \\
\hline a & R & b & a & R & a & b & R & a & R & b & a & R & a & b & R \\
\hline
\end{tabular}

Polos $->$

Sangsih $1 \downarrow 3 \downarrow 2 \downarrow$

$\underline{\text { Sangsih }}$

Symbol

Note

\begin{tabular}{|l|l|l|l|l|l|l|l|l|l|l|l|l|l|l|l|}
\hline $\mathrm{R}$ & $\mathrm{c}$ & $\mathrm{b}$ & $\mathrm{R}$ & $\mathrm{c}$ & $\mathrm{R}$ & $\mathrm{b}$ & $\mathrm{c}$ & $\mathrm{R}$ & $\mathrm{c}$ & $\mathrm{b}$ & $\mathrm{R}$ & $\mathrm{c}$ & $\mathrm{R}$ & $\mathrm{b}$ & $\mathrm{c}$ \\
\hline & $\mathrm{A}$ & $\mathrm{G}$ & & $\mathrm{A}$ & & $\mathrm{G}$ & $\mathrm{A}$ & & $\mathrm{A}$ & $\mathrm{G}$ & & $\mathrm{A}$ & & $\mathrm{G}$ & $\mathrm{A}$ \\
\hline
\end{tabular}

Figure 17. Generation of sangsih from the polos in Appendix A - Figure 28.

As mentioned previously, the sangsih may occur below the polos due to kotekan general rules, such as having the kotekan follow the pokok (KG2) or preserving the relationship between the polos and the pokok (KG3). Figure 31 illustrates this phenomena. The shape of the pokok in this instance would make it impossible for the polos to both reside below the sangsih and coincide with the pokok at the important points. It is considered more important for the polos to match up with the pokok (KG3) than for the polos to be below the sangsih (PSR1). ${ }^{22}$ Thus, the polos ends up above the sangsih and matches up with the pokok at each pokok beat. In this case, then, the rules appear to be ranked in strength: KG3 is stronger than PSR1.

In the case where the sangsih is below the polos the assignment of tones can be stated specifically:

$\underline{\text { Sangsih Below Polos }}$

$$
\begin{aligned}
& \mathrm{a}=\text { upper polos } \\
& \mathrm{b}=\text { lower polos } \\
& \mathrm{c}=\text { lower adjacent to } \mathrm{b}
\end{aligned}
$$

\footnotetext{
${ }^{22} \mathrm{~W}$. Vitale (personal communication, 1994) notes this is caused by melodic contour considerations. These considerations are perhaps high in the hierarchy of constraints for Balinese gamelan music and they filter down to lower levels. An analysis of melodic contour considerations is beyond the scope of this study.
} 


\subsubsection{Kotekan Empat}

Kotekan empat is a four note kotekan in which the sangsih plays the upper two tones and the polos plays the lower two tones. The notes and their relationship to the cells is given below in Figure 18.

\section{Kotekan Empat}

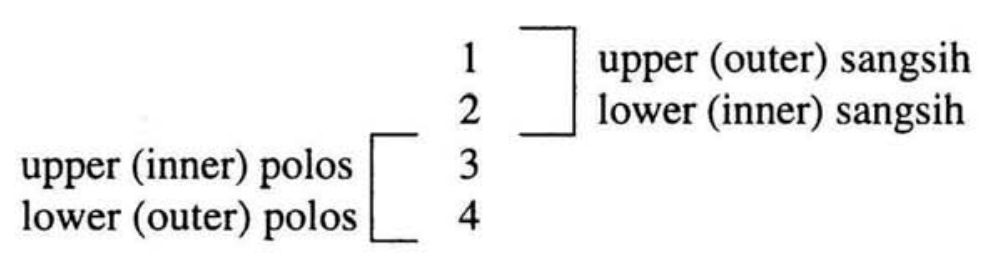

Figure 18. Relationship of tones to a 4 note cell and the kotekan parts.

In kotekan empat, the parts play simultaneously on the outer notes. The rules for generating sangsih from polos are given below $(\mathrm{E}=$ Empat Rule):

E1. Every lower polos is matched by upper sangsih.

E2. Wherever there is a rest in polos, play lower sangsih.

E3. Polos is always below sangsih.

These rules are formalized below:

Let: $\quad a=$ outer polos (lower)

$\mathrm{b}=$ inner polos (upper)

$\mathrm{c}=$ upper adjacent to $\mathrm{b}$

$\mathrm{d}=$ upper adjacent to $\mathrm{c}(2$ up from $\mathrm{a})$

$\mathrm{R}=$ rest

polos $\rightarrow$ sangsih

(1) $a \rightarrow d$

(2) $b \rightarrow R$

(3) $\mathrm{R} \rightarrow \mathrm{c}$

Figure 32 in Appendix A illustrates the polos part of a kotekan empat. In this case, the cell is defined as follows: 


$$
\begin{array}{|l|l|l}
\hline \mathrm{G} & =\mathrm{d} \text { (upper, adjacent to } \mathrm{c} \text { ) } \\
\cline { 1 - 1 } & =\mathrm{c} \text { (upper, adjacent to } \mathrm{b}) \\
\mathrm{y} & =\mathrm{b} \text { (inner, upper polos) } \\
\mathrm{y} & =\mathrm{a} \text { (outer, lower polos) }
\end{array}
$$

The polos matches up with the pokok at structurally important points (KG3) and follows the rules (PSL) for a well-formed polos line. Figure 33 illustrates the addition of notes with the application of the (3) R->c rule. Figure 34 illustrates the addition of applying the (2) b->R and (1) a->d rules, resulting in the completed figuration. Again, the kotekan forms a continuous line (KG4) and matches up with the pokok at structurally important points (KG1).

\subsection{Conclusion}

The musical system of Balinese kotekan can be described as a hierarchy of constraints from global tendencies to specific rules for various types of kotekan. Phrase structure rules can be used to describe individual polos and sangsih lines. The relationship between polos and sangsih can be expressed in the form of a grammar that uses phrase structure rules and transformations. These rules represent a portion of a complete grammar of Balinese kotekan.

An illustration of the application of these rules to new data and a discussion of the grammar's features are presented in Chapter 4. 


\section{CHAPTER 4}

\section{APPLICATION, EVALUATION, AND DISCUSSION}

\subsection{Introduction}

The generative method of writing grammars includes making hypotheses in the form of rules, and then testing the rules to see if their predictions apply to new data. In Section 4.2, the rules presented in Chapter 3 are applied to portions of Balinese pieces. An evaluation of the rules is presented in Section 4.3. Section 4.4 discusses features of the Balinese kotekan grammar with respect to the features of musical grammars given in Chapter 2.

\subsection{Application of Rules to New Data}

This section provides a number of examples that demonstrate the application of the rules presented in Chapter 3 to new data. The rules are applied to portions of three pieces. The first two pieces are classical. The last piece is a contemporary composition written in 1992.

\subsubsection{Excerpt from Baris}

This section applies the grammar to a portion of Baris, a traditional dance piece for a solo male performer. The score for this excerpt appears in Figure 35 in Appendix C. It is an example of kotekan empat. Section 4.2.1.1 analyzes the piece with respect to the informal rules (global rules, kotekan generalizations and polos/sangsih relationship generalizations) presented in Chapter 3. The phrase structure rules for polos and sangsih as individual lines are examined in Section 4.2.1.2. Finally, the application of the polos-tosangsih rules is demonstrated in Section 4.2.1.3. 


\subsubsection{Informal Rules}

A summary of the generalizations (informal rules) and their application to Baris is given in Table 7.

TABLE 7

Application of Informal Rules to Baris

\begin{tabular}{|l|l|l|}
\hline \hline Rule & Applies? & \multicolumn{1}{c|}{ Comment } \\
\hline \hline GR1 & Yes & See KG1 below. \\
\hline GR2 & Yes & Both pokok and kotekan consist of one and two step motion. \\
\hline KG1 & Yes & $\begin{array}{l}\text { Kotekan meets up with pokok at every pokok beat; therefore } \\
\text { it must meet at structurally important points. }\end{array}$ \\
\hline KG2 & Yes & Both kotekan and pokok use the same notes: C, D, E \\
\hline KG3 & Yes/No & $\begin{array}{l}\text { Polos matches up with the pokok in most cases, and at beat 1, } \\
\text { which is structurally most important. The sangsih matches up } \\
\text { at less structurally important points. }\end{array}$ \\
\hline KG4 & Yes & -- \\
\hline PSR1 & Yes & -- \\
\hline PSR2 & Yes/No & $\begin{array}{l}\text { There are instances when the polos is off the beat. This } \\
\text { creates a cross-rhythm or syncopated effect. }\end{array}$ \\
\hline
\end{tabular}

\subsubsection{Phrase Structure Rules for Polos and Sangsih as Individual Lines}

Figure 19 illustrates the correspondence between the score in Figure 35 and the lines generated by the phrase structure rules. In addition, it graphically illustrates the polos and sangsih lines. The pokok beats are given for reference. 


\section{POLOS}

\begin{tabular}{l|l|l|l|l|l|l|l|l|l|l|l|l|l|l|l|}
$\begin{array}{ll}1 \\
\mathrm{a}^{23}\end{array}$ & $\mathrm{R}$ & $\mathrm{a}$ & $\mathrm{b}$ & $\mathrm{R}$ & $\mathrm{a}$ & $\mathrm{b}$ & $\mathrm{R}$ & $\mathrm{a}$ & $\mathrm{b}$ & $\mathrm{R}$ & $\mathrm{a}$ & $\mathrm{b}$ & $\mathrm{R}$ & $\mathrm{a}$ & $\mathrm{b}$ \\
\hline & & & $\mathrm{D}$ & & & $\mathrm{D}$ & & & $\mathrm{D}$ & & & $\mathrm{D}$ & & & $\mathrm{D}$ \\
\hline $\mathrm{C}$ & & $\mathrm{C}$ & & & $\mathrm{C}$ & & & $\mathrm{C}$ & & & $\mathrm{C}$ & & & $\mathrm{C}$ & \\
\hline
\end{tabular}

\begin{tabular}{|c|c|c|c|c|c|c|c|c|c|c|c|c|c|c|c|}
\hline 5 & & & & 6 & & & & 7 & & & & 8 & & & \\
\hline $\mathrm{R}$ & a & $\mathrm{R}$ & a & b & $\mathrm{R}$ & $\mathrm{a}$ & b & $\mathrm{R}$ & a & b & $\mathrm{R}$ & $\mathrm{a}$ & b & $\mathbf{R}$ & $\mathrm{a}$ \\
\hline & & & D & & & D & & & D & & & D & & & $\mathrm{D}$ \\
\hline & C & & & $\bar{C}$ & & & C & & & $\bar{C}$ & & & C & & \\
\hline
\end{tabular}

\section{SANGSIH}

\begin{tabular}{|c|c|c|c|c|c|c|c|c|c|c|c|c|c|c|c|}
\hline 1 & & & & 2 & & & & 3 & & & & 4 & & & \\
\hline a & b & a & $\mathbf{R}$ & a & b & $\mathrm{R}$ & a & b & $\mathrm{R}$ & $\mathrm{a}$ & b & $\mathrm{R}$ & a & b & $\mathbf{R}$ \\
\hline$G$ & & G & & & $G$ & & & G & & & G & & & G & \\
\hline & $E$ & & & E & & & $\mathrm{E}$ & & & E & & & E & & \\
\hline
\end{tabular}

\begin{tabular}{|c|c|c|c|c|c|c|c|c|c|c|c|c|c|c|c|}
\hline 5 & & & & 6 & & & & 7 & & & & 8 & & & \\
\hline $\mathrm{a}$ & b & $\mathrm{a}$ & $\mathrm{R}$ & $\mathrm{a}$ & b & $\mathrm{R}$ & $\mathrm{a}$ & b & $\mathrm{R}$ & $\mathrm{a}$ & $\mathrm{b}$ & $\mathrm{R}$ & $\mathrm{a}$ & $\mathrm{b}$ & $R$ \\
\hline & $G$ & & & G & & & G & & & $\mathrm{G}$ & & & $G$ & & \\
\hline$E$ & & $\mathrm{E}$ & & & $E$ & & & $\mathrm{E}$ & & & $\mathrm{E}$ & & & $\mathrm{E}$ & \\
\hline
\end{tabular}

Figure 19. Correspondence between Baris and the lines generated by the phrase structure rules for polos and sangsih.

This figure demonstrates that the phrase structure rules apply: there are only single rests; there are no more than three consecutive notes before a rest; temporally adjacent tones are adjacent.

\footnotetext{
${ }^{23}$ This note is labeled $a$ at the beginning of the cycle. However, if the 8 beat phrase were repeated, the note would be labeled $b$, because the last note of the 8 beat cycle is $a$ and is adjacent to this first note. Thus the pattern would be $a b$ rather than $a a$.
} 


\subsubsection{Polos-to-Sangsih Transformational Rules (Kotekan Empat)}

The following is a demonstration of generating the sangsih from the polos using the polos-to-sangsih rules for kotekan empat. The cell in this phrase is defined:

$$
\begin{array}{|l|l|l}
\hline \mathrm{G} & =\mathrm{d} \text { (upper adjacent to } \mathrm{c}) \\
\mathrm{E} & =\mathrm{c} \text { (upper adjacent to } \mathrm{b}) \\
\mathrm{D} & =\mathrm{b} \text { (upper polos) } \\
\mathrm{y} & =\mathrm{a} \text { (lower polos) }
\end{array}
$$

Figure 20 illustrates the application of the polos-to-sangsih rules for empat. The pokok beats are given for reference.

\section{BEATS $1-4$}

Polos

Note

Symbol

\begin{tabular}{|c|c|c|c|c|c|c|c|c|c|c|c|c|c|c|c|}
\hline 1 & & & & 2 & & & & 3 & & & & 4 & & & \\
\hline $\mathrm{C}$ & & $\mathrm{C}$ & $\bar{D}$ & & $\mathrm{C}$ & $\bar{D}$ & & C & $\mathrm{D}$ & & $\mathrm{C}$ & D & & C & D \\
\hline $\mathrm{a}$ & $\mathrm{R}$ & $\mathrm{a}$ & b & $\mathrm{R}$ & $\mathrm{a}$ & b & $\mathrm{R}$ & a & b & $\mathrm{R}$ & $\mathrm{a}$ & b & $\mathrm{R}$ & $a$ & b \\
\hline
\end{tabular}

Polos $->$

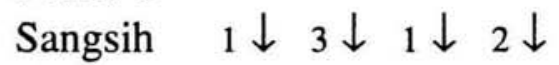

$\underline{\text { Sangsih }}$

Note

Symbol

\begin{tabular}{|l|l|l|l|l|l|l|l|l|l|l|l|l|l|l|l|}
\hline d & c & d & R & c & d & R & c & d & R & c & d & R & c & d & R \\
\hline G & E & G & & E & G & & E & G & & E & G & & E & G & \\
\hline
\end{tabular}

BEATS 5 - 8

$\underline{\text { Polos }}$

Note

Symbol

$5: 100$
\begin{tabular}{|l|l|l|l|l|l|l|l|l|l|l|l|l|l|l|l|}
\hline & $\mathrm{C}$ & & $\mathrm{D}$ & $\mathrm{C}$ & & $\mathrm{D}$ & $\mathrm{C}$ & & $\mathrm{D}$ & $\mathrm{C}$ & & $\mathrm{D}$ & $\mathrm{C}$ & & $\mathrm{D}$ \\
\hline $\mathrm{R}$ & $\mathrm{a}$ & $\mathrm{R}$ & $\mathrm{b}$ & $\mathrm{a}$ & $\mathrm{R}$ & $\mathrm{b}$ & $\mathrm{a}$ & $\mathrm{R}$ & $\mathrm{b}$ & $\mathrm{a}$ & $\mathrm{R}$ & $\mathrm{b}$ & $\mathrm{a}$ & $\mathrm{R}$ & $\mathrm{b}$ \\
\hline
\end{tabular}

Polos ->

Sangsih

$\underline{\text { Sangsih }}$

Note

Symbol

\begin{tabular}{|l|l|l|l|l|l|l|l|l|l|l|l|l|l|l|l|}
\hline c & d & c & R & d & c & R & d & c & R & d & c & R & d & c & R \\
\hline E & G & E & & G & E & & G & E & & G & E & & G & E & \\
\hline
\end{tabular}

Figure 20. Generation of sangsih from the polos in Baris.

The sangsih notes generated from this process correspond exactly with the sangsih notes in Figure 35. 


\subsubsection{Excerpt from Legong Keraton}

A portion of the score from Legong Keraton, a classical female dance piece appears in Figure 36 in Appendix C. The following is an analysis of the piece with respect to the grammar presented in Chapter 3. This portion is an example of kotekan empat.

\subsubsection{Informal Rules}

A summary of the generalizations (informal rules) and their application to this example is given in Table 8. Because the application of the rules is less straight forward than the Baris example, a discussion of the rules follows the table.

TABLE 8 Application of Informal Rules to Legong Keraton

\begin{tabular}{|l|l|}
\hline \multicolumn{1}{|c|}{ Rule } & \multicolumn{1}{c|}{ Applies? } \\
\hline \hline GR1 & Yes \\
\hline GR2 & Yes \\
\hline KG1 & Yes \\
\hline KG2 & Yes \\
\hline KG3 & No \\
\hline KG4 & Yes \\
\hline PSR1 & Yes \\
\hline PSR2 & No \\
\hline
\end{tabular}

In this example, the pokok appears in the bottom staff. The jegogans coincide with (i.e., play the unison or octave tone with) the pokok and the kotekan at the structurally most important points (GR1, KG1). These points are marked $a$, and appear every 4 beats of the pokok. The kotekan as a melodic line is continuous (KG4) and surrounds (anticipates) the pokok (KG2). For example, in the first 4 beats, the kotekan includes the notes D, E, G, A. The pokok uses the notes E, G, A and moves to D on the 
5th beat. In the second 4 beats, the pokok uses D, E, G, A. The kotekan uses D, E, G and C. The motion of each of the parts: jegogan, pokok, kotekan, is mostly conjunct or two steps (GR2).

The sangsih in this example meets up with the pokok in more instances than the polos does. Thus, it appears that KG3 is not as important in this case. Rather, because this is kotekan empat, the relationship of polos to sangsih, (i.e., sangsih above polos PSR1, E3) is more important. In order to preserve KG1 (kotekan matches up with pokok) and E3, the sangsih part plays the core note. As mentioned previously, the relationship between polos and sangsih is more complex than simply on-beat versus offbeat. This is another example where PSR2 does not apply.

At the point marked $c$, the sangsih is below the following polos note. At this point, however, the kotekan is moving to surround the core (KG2). The rules for empat do not apply in this instance.

\subsubsection{Phrase Structure Rules for Polos and Sangsih as Individual Lines}

Figure 21 illustrates the patterns of the polos and sangsih as individual lines graphically. It also shows the correspondence between the line generated by the phrase structure rules and the score in Figure 36.

\section{POLOS}

\begin{tabular}{|l|l|l|l|l|l|l|l|l|l|l|l|l|l|l|l|}
1 & \multicolumn{1}{c}{} & 2 & \multicolumn{1}{c}{3} & & & & \\
$\mathrm{R}$ & $\mathrm{a}$ & $\mathrm{b}$ & $\mathrm{R}$ & $\mathrm{a}$ & $\mathrm{b}$ & $\mathrm{R}$ & $\mathrm{a}$ & $\mathrm{R}$ & $\mathrm{a}$ & $\mathrm{b}$ & $\mathrm{R}$ & $\mathrm{a}$ & $\mathrm{b}$ & $\mathrm{R}$ & $\mathrm{a}$ \\
\hline & & $\mathrm{E}$ & & $\mathrm{E}$ & & & $\mathrm{E}$ & & & $\mathrm{E}$ & & $\mathrm{E}$ & & & $\mathrm{E}$ \\
\hline & $\mathrm{D}$ & & & & $\mathrm{D}$ & & & & $\mathrm{D}$ & & & & $\mathrm{D}$ & & \\
\hline
\end{tabular}

\begin{tabular}{|c|c|c|c|c|c|c|c|c|c|c|c|c|c|c|c|}
\hline 5 & & & & 6 & & & & 7 & & & & 8 & & & \\
\hline 0 & $\mathrm{R}$ & $\mathrm{a}$ & b & $\mathrm{R}$ & $\mathrm{a}$ & b & $\mathrm{R}$ & a & b & $\mathrm{R}$ & $\mathrm{a}$ & b & $\mathrm{R}$ & $\mathrm{a}$ & b \\
\hline & & & D & & & D & & D & & & D & & & & D \\
\hline D & & C & & & C & & & & $\mathrm{C}$ & & & $\mathrm{C}$ & & $\mathrm{C}$ & \\
\hline
\end{tabular}




\begin{tabular}{|c|c|c|c|c|c|c|c|c|c|c|c|c|c|c|c|}
\hline 9 & & & & 10 & & & & 11 & & & & 12 & & & \\
\hline $\mathrm{R}$ & a & b & $\mathrm{R}$ & a & b & $\mathrm{R}$ & a & $\mathrm{R}$ & $\mathrm{a}$ & $\mathrm{R}$ & a & b & $\mathrm{R}$ & $\mathrm{a}$ & b \\
\hline & & $\bar{D}$ & & $\mathrm{D}$ & & & $\mathrm{D}$ & & $G$ & & & $\overline{\mathrm{G}}$ & & & $\bar{G}$ \\
\hline & $\mathrm{C}$ & & & & $\mathrm{C}$ & & & & & & $E$ & & & $\mathrm{E}$ & \\
\hline
\end{tabular}

\begin{tabular}{|c|c|c|c|c|c|c|c|c|c|c|c|c|c|c|c|}
\hline 13 & & & & 14 & & & & 15 & & & & 16 & & & \\
\hline $\mathrm{R}$ & $\mathrm{a}$ & $\mathrm{R}$ & a & $\mathrm{R}$ & a & b & $\mathrm{R}$ & a & b & $\mathrm{R}$ & a & b & $\mathrm{R}$ & a & b \\
\hline & & & & & & $E$ & & $E$ & & & $\bar{E}$ & & & & $\mathrm{E}$ \\
\hline & $E$ & & $E$ & & D & & & & $D$ & & & D & & $\mathrm{D}$ & \\
\hline
\end{tabular}

\section{SANGSIH}

\begin{tabular}{|c|c|c|c|c|c|c|c|c|c|c|c|c|c|c|c|}
\hline 1 & & & & 2 & & & & 3 & & & & 4 & & & \\
\hline $\mathrm{a}$ & b & $\mathrm{R}$ & $\mathrm{a}$ & $\mathrm{R}$ & $\mathrm{a}$ & $\mathrm{b}$ & $\mathrm{R}$ & $\mathrm{a}$ & b & $\mathrm{R}$ & $\mathrm{a}$ & $\mathrm{R}$ & $\mathrm{a}$ & $\mathrm{b}$ & $*$ \\
\hline & $\bar{A}$ & & & & A & & & & $\bar{A}$ & & & & $\bar{A}$ & & \\
\hline $\bar{G}$ & & & $\mathrm{G}$ & & & $\mathrm{G}$ & & $\mathrm{G}$ & & & $\mathrm{G}$ & & & $\mathrm{G}$ & $\mathrm{E}^{*}$ \\
\hline
\end{tabular}

\begin{tabular}{|c|c|c|c|c|c|c|c|c|c|c|c|c|c|c|c|}
\hline 5 & & & & 6 & & & & 7 & & & & 8 & & & \\
\hline $\mathrm{R}$ & $\mathrm{a}$ & b & $\mathrm{R}$ & a & b & $\mathrm{R}$ & $\mathrm{a}$ & $\mathrm{R}$ & a & $\mathrm{b}$ & $\mathbf{R}$ & $\mathrm{a}$ & b & a & $\mathrm{R}$ \\
\hline & & $\bar{G}$ & & & $\bar{G}$ & & & & $\mathrm{G}$ & & & $G$ & & $\mathrm{G}$ & \\
\hline & $E$ & & & $E$ & & & $\mathrm{E}$ & & & $\mathrm{E}$ & & & $E$ & & \\
\hline
\end{tabular}

\begin{tabular}{|c|c|c|c|c|c|c|c|c|c|c|c|c|c|c|c|}
\hline 9 & & & & 10 & & & & 11 & & & & 12 & & & \\
\hline a & b & $\mathrm{R}$ & a & $\mathbf{R}$ & a & b & $\mathrm{R}$ & a & $\mathrm{R}$ & a & b & $\mathrm{R}$ & a & b & $\mathrm{R}$ \\
\hline & G & & & & G & & & & & & C & & & C & \\
\hline$E$ & & & E & & & E & & E & & A & & & A & & \\
\hline
\end{tabular}

\begin{tabular}{ll|l|l|l|l|l|l|l|l|l|l|l|l|l|l|}
13 & \multicolumn{1}{c}{14} & \multicolumn{1}{c}{15} & \multicolumn{1}{c}{16} \\
$\mathrm{a}$ & $\mathrm{R}$ & $\mathrm{a}$ & $\mathrm{R}$ & $\mathrm{a}$ & $\mathrm{b}$ & $\mathrm{R}$ & $\mathrm{a}$ & $\mathrm{R}$ & $\mathrm{a}$ & $\mathrm{b}$ & $\mathrm{R}$ & $\mathrm{a}$ & $\mathrm{b}$ & $\mathrm{a}$ & $\mathrm{R}$ \\
\hline $\mathrm{A}$ & & & & & $\mathrm{A}$ & & & & $\mathrm{A}$ & & & $\mathrm{A}$ & & $\mathrm{A}$ & \\
\hline & & $\mathrm{G}$ & & $\mathrm{G}$ & & & $\mathrm{G}$ & & & $\mathrm{G}$ & & & $\mathrm{G}$ & & \\
\hline
\end{tabular}

Figure 21. Correspondence between Legong Keraton and lines generated by phrase structure rules for polos and sangsih.

There are only single rests, temporally adjacent tones are adjacent, and at most there are three notes played before there is a rest. Thus these lines are described by the phrase 
structure rules of chapter 3. At the point marked $b$ in the score, and * in Figure 21, the sangsih does not follow the $a b a$ pattern of the phrase structure rules. This is because the kotekan is moving to follow the core (KG2). Rules for moving kotekan would be more appropriate in this instance.

\subsubsection{Polos-to-Sangsih Transformational Rules (Kotekan Empat)}

The following is a demonstration of generating the sangsih from the polos using the polos-to-sangsih rules for kotekan empat.

BEATS 1 - 4. The cell in this phrase is defined:

$$
\begin{array}{|l|l|l}
\hline \mathrm{A} & =\mathrm{d} \text { (upper, adjacent to } \mathrm{c}) \\
\cline { 1 - 1 } & =\mathrm{c} \text { (upper, adjacent to } \mathrm{b}) \\
\mathrm{y} & =\mathrm{b} \text { (inner, upper polos) } \\
\cline { 1 - 1 } & =\mathrm{a} \text { (outer, lower polos) }
\end{array}
$$

$\underline{\text { Polos }}$

Note

Symbol

Polos ->

Sangsih $3 \downarrow \quad 1 \downarrow 2 \downarrow$

$\underline{\text { Sangsih }}$

Symbol

Note

1
\begin{tabular}{|l|l|l|l|l|l|l|l|l|l|l|l|l|l|l|l|}
\hline & $\mathrm{D}$ & $\mathrm{E}$ & & $\mathrm{E}$ & $\mathrm{D}$ & & $\mathrm{E}$ & & $\mathrm{D}$ & $\mathrm{E}$ & & $\mathrm{E}$ & $\mathrm{D}$ & & $\mathrm{E}$ \\
\hline $\mathrm{R}$ & $\mathrm{a}$ & $\mathrm{b}$ & $\mathrm{R}$ & $\mathrm{b}$ & $\mathrm{a}$ & $\mathrm{R}$ & $\mathrm{b}$ & $\mathrm{R}$ & $\mathrm{a}$ & $\mathrm{b}$ & $\mathrm{R}$ & $\mathrm{b}$ & $\mathrm{a}$ & $\mathrm{R}$ & $\mathrm{b}$ \\
\hline
\end{tabular}

\begin{tabular}{|l|l|l|l|l|l|l|l|l|l|l|l|l|l|l|l|}
\hline c & d & R & c & R & d & c & R & c & d & R & c & R & d & c & R \\
\hline G & A & & G & & A & G & & G & A & & G & & A & G & $*$ \\
\hline
\end{tabular}

\section{BEATS 5 - 8}

The cell in this phrase is defined:

$$
\begin{array}{|l|l|}
\hline \mathrm{G} & =\mathrm{d} \text { (upper, adjacent to } \mathrm{c} \text { ) } \\
\cline { 1 - 1 } & =\mathrm{c} \text { (upper, adjacent to } \mathrm{b} \text { ) } \\
\mathrm{y} & =\mathrm{b} \text { (inner, upper polos) } \\
\cline { 1 - 1 } & =\mathrm{a} \text { (outer, lower polos) }
\end{array}
$$


$\underline{\text { Polos }}$

Note

Symbol

5
\begin{tabular}{|l|l|l|l|l|l|l|l|l|l|l|l|l|l|l|l|}
\hline D & & C & D & & C & D & & D & C & & D & C & & C & D \\
\hline b & R & a & b & R & a & b & R & b & a & R & b & a & R & a & b \\
\hline
\end{tabular}

Polos ->

Sangsih

$\underline{\text { Sangsih }}$

Symbol

Note

\begin{tabular}{|l|l|l|l|l|l|l|l|l|l|l|l|l|l|l|l|}
\hline R & c & d & R & c & d & R & c & R & d & c & R & d & c & d & R \\
\hline & E & G & & E & G & & E & & G & E & & G & E & G & \\
\hline
\end{tabular}

BEATS $9-10$

The cell in this phrase is defined:

$$
\begin{array}{|l|l|l}
\hline \mathrm{G} & =\mathrm{d} \text { (upper, adjacent to } \mathrm{c} \text { ) } \\
\cline { 1 - 1 } & =\mathrm{c} \text { (upper, adjacent to } \mathrm{b}) \\
\mathrm{y} & =\mathrm{b} \text { (inner, upper polos) } \\
\cline { 1 - 1 } & =\mathrm{a} \text { (outer, lower polos) }
\end{array}
$$

$\underline{\text { Polos }}$

Note

Symbol

9
\begin{tabular}{|l|l|l|l|l|l|l|l|}
\hline & C & D & & D & C & & D \\
\hline R & a & b & R & b & a & R & b \\
\hline
\end{tabular}

Polos ->

Sangsih

$\underline{\text { Sangsih }}$

Symbol

Note

\begin{tabular}{|l|l|l|l|l|l|l|l|}
\hline c & d & R & c & R & d & c & R \\
\hline E & G & & E & & G & E & \\
\hline
\end{tabular}

BEATS $11-13$

The cell in this phrase is defined:

$$
\begin{array}{|l|l|l}
\hline \mathrm{C} & =\mathrm{d} \text { (upper, adjacent to } \mathrm{c} \text { ) } \\
\mathrm{A} & =\mathrm{c} \text { (upper, adjacent to } \mathrm{b}) \\
\mathrm{y} & =\mathrm{b} \text { (inner, upper polos) } \\
\mathrm{y} & =\mathrm{a} \text { (outer, lower polos) }
\end{array}
$$




\begin{tabular}{|c|c|c|c|c|c|c|c|c|c|c|c|c|}
\hline \multirow{2}{*}{$\frac{\text { Polos }}{\text { Note }}$} & & \multicolumn{4}{|c|}{12} & \multicolumn{4}{|c|}{13} \\
\hline & & $\mathrm{G}$ & & $E$ & $\mathrm{G}$ & & $\mathrm{E}$ & $\bar{G}$ & & $\mathrm{E}^{*}$ & & $\mathrm{E}^{*}$ \\
\hline & $\mathrm{R}$ & $\mathrm{b}$ & $\mathrm{R}$ & $a$ & $\mathrm{~b}$ & $\mathbf{K}$ & $a$ & $\mathrm{~b}$ & 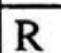 & $*$ & $\pi$ & $*$ \\
\hline
\end{tabular}

Polos ->

Sangsih

$\underline{\text { Sangsih }}$

Symbol

Note

\begin{tabular}{|l|l|l|l|l|l|l|l|l|l|l|l|}
\hline $\mathrm{c}$ & $\mathrm{R}$ & $\mathrm{c}$ & $\mathrm{d}$ & $\mathrm{R}$ & $\mathrm{c}$ & $\mathrm{d}$ & $\mathrm{R}$ & $\mathrm{c}$ & $*$ & $*$ & $*$ \\
\hline $\mathrm{A}^{*}$ & & $\mathrm{~A}$ & $\mathrm{C}$ & & $\mathrm{A}$ & $\mathrm{C}$ & & $\mathrm{A}$ & & & \\
\hline
\end{tabular}

\section{*BEAT 13}

*As mentioned previously, different types of kotekan can appear in succession in a piece.

The phrase here appears to be an example of oncang-oncangan. So the empat rules for generating sangsih do not work in this instance.

BEATS $14-16$

The cell in this phrase is defined:

$$
\begin{array}{|l|l|}
\hline \mathrm{A} & =\mathrm{d} \text { (upper, adjacent to } \mathrm{c} \text { ) } \\
\mathrm{G} & =\mathrm{c} \text { (upper, adjacent to } \mathrm{b}) \\
\mathrm{E} & =\mathrm{b} \text { (inner, upper polos) } \\
\mathrm{y} & =\mathrm{a} \text { (outer, lower polos) }
\end{array}
$$

\begin{tabular}{|c|c|c|c|c|c|c|c|c|c|c|c|c|}
\hline Polos & 14 & & & & 15 & & & & 16 & & & \\
\hline Note & & D & E & & $E$ & D & & E & D & & D & E \\
\hline Symbol & $\mathrm{R}$ & $a$ & $b$ & $\mathbf{R}$ & $b$ & $a$ & R & $\mathrm{b}$ & $a$ & $R$ & $a$ & $b$ \\
\hline $\begin{array}{l}\text { Polos -> } \\
\text { Sangsih } \\
\text { Sangsih }\end{array}$ & & & & & & & & & & & & \\
\hline Symbol & c & $\mathrm{d}$ & $\mathrm{R}$ & c & $\mathrm{R}$ & $\mathrm{d}$ & c & $\mathrm{R}$ & $d$ & $\mathrm{c}$ & $\mathrm{d}$ & $\mathrm{R}$ \\
\hline Note & G & A & & G & & A & G & & A & G & A & \\
\hline
\end{tabular}

Figure 22. Generation of sangsih from the polos in Legong Keraton. 


\subsubsection{Excerpt from Gora Merdawa}

Figure 37 in Appendix C contains a portion of a kotekan from a contemporary piece, Gora Merdawa, by I Nyoman Windha (1992). This music is included as an example of contemporary pieces stretching the standard techniques of kotekan. In a number of places in the piece, the rules presented in Chapter 3 are not followed. However, enough rules are followed so that the kotekan is recognizable as being mainly empat.

In general, the lines mainly consist of units of single, two or three adjacent tones (PSL1, PSL3). The kotekan line itself consists of mainly one and two step motion (GR2). There are only single rests (PSL2). The sangsih is above the polos (E3) and the lower polos is generally matched by an upper sangsih. The first two pokok beats of the excerpt are straight forward empat; they exactly follow the empat rules presented.

Table 9 describes some of the places where rules are violated. The PSL rules are those that were formalized in the phrase structure rules of polos and sangsih as individual lines. The $\mathrm{E}$ rules were incorporated in the polos-to-sangsih transformational rules for empat.

TABLE 9

Descriptions of Broken Rules in Gora Merdawa

\begin{tabular}{|l|l|l|}
\hline \hline Point & \multicolumn{1}{|c|}{ Description } & Rule Violated \\
\hline a & Temporally adjacent notes are not adjacent in polos. & PSL4 \\
\hline b & Kotekan line has breaks. & KG4 \\
\hline b & A polos rest is not matched with a sangsih note. & E2 \\
\hline c & The same note is repeated. This is rare. & PSL4, PSL3? \\
\hline d & The same note is played 3 times in a row. & PSL3 \\
\hline e & Polos plays four notes in a row. & PSL1 \\
\hline f & Polos plays sangsih note or sangsih plays polos note. & E3 \\
\hline g & $\begin{array}{l}\text { Although a lower polos is matched by an upper } \\
\text { sangsih, the outer tones of the empat are 4 steps away, } \\
\text { rather than the usual 3 steps away. This is a very } \\
\text { unusual combination of tones to play together. }\end{array}$ & E1 \\
\hline
\end{tabular}


It is interesting to note the ways in which rules are stretched or broken. For example, E1 is followed in that the lower polos is matched by an upper sangsih. However, this rule is stretched by making the upper sangsih an unexpected note that is 4 steps away rather than 3 steps away. In a stretch of E3 and PSR1, the sangsih never goes below the polos, but the two parts share the same notes in a number of places. This is an interesting stretch of E3 and PSR1 because by sharing the note, the sangsih is not below or above the polos. At point $b$ two rules are violated. Because a polos rest is not matched with a sangsih note (violating E2), a break occurs in the kotekan line (violating KG4).

\subsection{Evaluation of Rules}

The partial grammar presented in this study can be evaluated according to its ability to generate musical lines that would be acceptable in the gong kebyar style and according to the motivation behind the rules.

\subsubsection{Well-formedness}

Well-formedness in this study is defined with respect to the gamelan gong kebyar style of kotekan. The informal rules (global and kotekan generalizations) describe wellformed (i.e., syntactically acceptable) musical lines and relationships between the parts of the ensemble. The context-free phrase structure rules for polos and sangsih individual lines specify well-formed polos or sangsih lines in isolation. The rules, however, do not specify what a "good" polos or sangsih line is with respect to the pokok; this would be context-sensitive.

The transformational rules for generating sangsih from polos describe well-formed sangsih lines given well-formed polos lines; the rules explicitly describe the relationship between polos and sangsih. However, while the rules exclude ill-formed musical lines, they do not include all the well-formed lines. Variation exists, particularly at the 
structurally weaker points in the music. These acceptable variations have not been included in the formalized rules of this study. Thus, although the transformational rules in this study have not been tested extensively, they would probably tend to under generate.

As in other musical grammar studies, well-formedness and grammaticality in this study are not completely analogous to language. Because, as mentioned previously, music is not tied down to meaning in the same way language is, well-formedness in music is perhaps not as important as preferences. Furthermore, in music, rules are broken on purpose. Musicians can play pieces with broken or stretched rules and listeners generally are still receptive to the music. But as Becker and Becker (1979) point out, the rules have to be there in order to be exploited; people have to know what the rules, or expectations are, so that they can appreciate how they are being stretched. It is not clear, then, whether a composition such as Windha (1992) that stretches rules should be considered ungrammatical. The rules given in this study are tendencies. At times they are followed; other times they are not. Perhaps, then, they function more like preference rules rather than well-formedness rules.

As in other musical grammars, the rules needed to adequately describe Balinese kotekan are context-sensitive. For example, the choice of a note depends on its place in the phrasing structure, the notes around it, and the motion of the core melody.

\subsubsection{Motivation for Rules}

Spatio-motor considerations are a motivating factor behind the splitting of the kotekan into the polos and sangsih parts and the phrase structure rules for polos and sangsih as individual lines. The layout of the gangsa and the playing technique have an affect on the structure of kotekan. Because of the construction of the instrument and the technique with which it is played, there are limitations to what is physically possible.

The splitting of the parts may be a result of the speed at which the kotekan is 
performed. For example, Vitale (1990) notes that norot configuration, when played at slower tempos, is not split up; each part plays the whole configuration.

Kotekan may well have evolved out of the desire to play this figuration at faster and faster tempos, until a single player could no longer execute all of the notes...The players split the figuration into kotekan at the point where it becomes too fast to play alone, usually done so smoothly that the listener is unaware of the division. (p. 6)

Concerning the $a R, a b R, a b a R$ patterns of the phrase structure rules, Vitale writes:

One reason for the prevalence of these simple units, clear to any performer of kotekan, is that they yield the most easily playable pattern, which can be combined to form any kind of figuration. For example, four successive tones in one part would become exceedingly difficult to play at a fast tempo (three already taxes the upper tempo limit of most players). Two successive non-adjacent tones would create a difficult leap, and likewise two successive rests would put an awkward pause in the part. Either of these would interrupt the fluid motion of the arm which is so critical in playing kotekan. (p. 6)

The perception of the interlocking parts as a single line appears to be based on Gestalt principles, particularly good continuation, proximity, similarity and common fate. Vitale (1990) observes the use of Gestalt principles in the playing of the parts. Balinese players do not sense the sangsih part with the rhythmic tension that Western musicians feel with upbeats. Rather, the sangsih part is thought to "fill in the gaps in the wave motion of the figuration" (p. 5).

In order to do so accurately, the player must concentrate exclusively on the resultant pattern. That is, he must be as aware of the other part as of his own, perceiving the downbeats as if he were producing them himself. The sangsih player is simply placing his notes in between. (p. 5).

The players must make slight adjustments in speed in order to synchronize the parts. "When all the players in the gangsa section achieve this ... the sound of the individual instruments disappears into the complete web of the figuration, and all the players sound as one" (p. 5). 


\subsection{Features of a Grammar for Balinese Kotekan}

The partial grammar written for Balinese kotekan exhibits a number of the features of musical grammars that were discussed in Section 2.5. This section examines some of these features.

\subsubsection{Deep and Surface Structure}

Balinese music can be described as having deep and surface structure. As mentioned previously, every piece of music has a core melody from which all the other parts are derived. The pokok can be thought of as the deep underlying structure to a piece of music; the kotekan is one of many possible surface manifestations. However, in Balinese music, the deep structure is overt, and is heard along with the "surface" elaboration. An underlying pokok may have many different kotekan manifestations, just as, in jazz, a deep chord structure has many surface improvisations.

At a different level of analysis, the polos acts as a kind of deep structure from which the sangsih is derived. The use of transformations works well in this study because they not only give a well-formed sangsih line, but they illustrate the relationship between the polos and sangsih parts. For example, it would be possible to specify a phrase structure rule for the sangsih part in oncang-oncangan as:

$$
\text { sangsih } \rightarrow \mathrm{R} \text { a (sangsih). }
$$

This would generate the $R a R a$ pattern that specifies the off-beat part. However, describing the sangsih in terms of a transformation of the polos explicitly illustrates the interlocking relationship between the parts.

\subsubsection{Structure and Variation}

Hughes' (1991) observation that it is at structurally important points in music where there is the least variation is very apparent in Balinese music, as exhibited by rules 
GR1 and KG1. At the structurally important points the parts must coincide; the kotekan note should match the core note. At structurally weaker points, there is room for variation. As mentioned previously, the rules presented in this study do not handle the variation that exists. This is mainly because it is easier to specify what happens when the kotekan is stable; the rules apply to these situations. Variation is more likely on the weaker beats or when the kotekan is moving. A complete grammar of kotekan would specify this variation as well.

\subsubsection{Hierarchy of Rules and Preferences}

Becker and Becker's (1979) description of musical systems as a hierarchy of constraints works very well for Balinese music. The analysis of Balinese music in this study uses a hierarchy of constraints from global rules to kotekan specific rules. The higher level global rules affect the lower level rules. For example, the kotekan general rule for polos generally matching up with the pokok (KG3) affects the polos-to-sangsih rules for specific kotekan types. As discussed in Section 3.4.3.1, this rule determines whether the sangsih is above or below the polos.

As mentioned in Chapter 2, rules can reinforce one another or conflict with each other. Examples of both of these situations appear in Balinese music. For example, rules from a lower level can reinforce those at a higher level. The polos-to-sangsih transformation re-write rules that change a polos rest into a sangsih note reinforce the kotekan general rule that there are no breaks in the kotekan line (KG4). The polos/sangsih phrase structure rules (PSL) contribute to the general motion of lines being one or two step (GR2).

An example of rules conflicting was given in Section 3.4.3.1. The requirement of the polos being below the sangsih clashed with the requirement of the polos coinciding 
with the pokok. In this case, the resolution of the conflict took the form of one rule being preferred over another rule.

Thus, ranked rules or preference rules are apparent in this grammar. In addition, it appears that different types of kotekan put different emphasis on the importance of certain rules. For example, for oncang-oncangan the important and defining rule is the one specifying rhythmic alternation (PSR2). The oncang-oncangan specific rules, $\mathrm{O} 1$ and $\mathrm{O} 2$, reinforce PSR2. Whether the sangsih is above or below the polos (PSR1) is not important in this type of kotekan. So the kotekan specific rules, $\mathrm{O} 1$ and $\mathrm{O} 2$, are sufficient for defining what is well-formed; the more general rule, PSR1, is not part of the definition. As mentioned in Chapter 2, Becker and Becker (1979) note that rules may shift in strength.

\subsubsection{Spatio-Motor Considerations}

In addition to the spatio-motor considerations discussed in Section 4.3.2, there are others in a grammar for kotekan. For example, kotekan telu can be played only on the gangsas. Because the polos and sangsih parts are played on paired instruments, the shared middle tone in the kotekan telu figuration is possible. It is not possible to play kotekan telu on, for example, the reong ${ }^{24}$ because the parts could not share the middle tone. It is possible, however, to play kotekan empat on the reong.

Another example of spatio-motor considerations can be seen in the effect of tempo on the rules. The phrase structure rules are followed more strictly at faster tempos due to technical physical limitations. Rules may be broken at slower tempos, because, for example, playing consecutive notes that are far apart from each other, or playing four

\footnotetext{
${ }^{24}$ The reong is a "row of small tuned gongs played by four musicians" (Vitale, 1990, p. 2). Two players cannot play the same note (i.e., gong) at the same time.
} 
consecutive notes, is possible at a slow enough tempo. Rules may be broken at faster tempos as a way of pushing or displaying the virtuosity of the ensemble.

\subsection{Conclusion}

The partial grammar for Balinese kotekan presented in this study describes wellformed musical lines. However, it probably under generates because there is more variation in Balinese music than was described by the rules. The rules apply mainly to the kotekan when it is stable. Rules are needed to describe moving kotekan. The rules presented in this study are a starting point for a complete grammar of Balinese kotekan.

The grammar exhibits features similar to other musical grammars. There are deep and surface structures, variation related to structure, a hierarchy of constraints, ranked or preference rules, and spatio-motor considerations. In addition, the rules needed to adequately describe the musical system are context-sensitive. 


\section{CHAPTER 5}

\section{CONCLUSION}

\subsection{Introduction}

This chapter concludes the thesis by presenting some topics for further research (Section 5.2), possible implications (Section 5.3) and a summary of the study (Section 5.4).

\subsection{Some Open Issues}

There are many open issues in music cognition, ethnomusicology, artificial intelligence and linguistics for the study of musical grammars. A small number of topics for further research are mentioned in the following sections.

\subsubsection{Performance Considerations}

An interesting point in the literature is the number of researchers who think it is necessary to model musical performance, and think that a grammar of music should model musical performance. For example, Kippen and Bel (1992) try to model the irregularities in actual performances of tabla drumming. Sundberg, Friberg and Fryden (1991) observe that in performance, musicians regularly deviate from the score; this seems to produce performances that "sound musically more acceptable" (p. 194). They propose context dependent rules that describe these deviations. Sundberg and Lindblom (1991) note that there is "evidence that structure is manifested in performance. For instance, phrase endings are marked by final lengthening in music performance, just as in speech" (p. 253). Nord et al. (1990) observe this lengthening in their timing studies of prose, poetry and music. 
The notion that a grammar should model performance is very different from the traditional view of grammars, which is that a grammar does not predict performance. "A grammar can describe the background knowledge of the musician, but it can never predict what he will do in a given musical situation" (Becker \& Becker, 1979, p. 32).

Thus, researchers have various ideas about the goals of musical grammars. This is similar to theoretical linguistics, in which there are researchers who completely separate performance from grammar, and those who attempt to model aspects of performance in the form of variable rules. Modeling performance in musical grammars is a topic for further research.

\subsubsection{Bottom-up Models}

As mentioned in Chapter 1, the analysis of Balinese music in this study was from a top-down information processing perspective. A basic premise of this approach is that knowledge can be expressed in the form of explicit rules. It should be noted that there are studies that approach the analysis of music from a bottom-up information processing perspective. Some systems that use this approach are referred to as neural networks or connectionist models. In these studies, knowledge does not take the form of explicit rules; rather, it is inferred. The goal is to model the structure and functioning of the brain and model learning. Leman (1992) provides an overview of neural networks applied to music. Bharucha (1993) is an example of a connectionist model applied to Western harmony. The use of bottom-up models for music is a topic for further research.

\subsubsection{Rule Conflicts and Variation in Balinese Music}

In this study it was proposed that variation occurs in Balinese music at structurally less important points. However, as Becker and Becker (1979) and Hughes (1991) point out, variation can also occur at points where rules are in conflict. In Balinese music, there 
are different levels of rules which interact with each other; they may reinforce or conflict with each other. In the examples given in this study, when rules conflicted, they were generally resolved by one rule taking precedence over another. This study was limited in the number of examples used. A topic for further research is to analyze more examples where rules are in conflict, to see if the conflicts are always resolved in the same manner, or if these are points of variation, as Becker and Becker and Hughes suggest. It is possible, for example, that in the places where the kotekan is moving because the core is moving, that there might be tension between wanting the polos below the sangsih or on the core.

\subsubsection{Lexical Phrases}

A topic for further research is the definition and use of musical lexical phrases. In linguistic theory, Nattinger and DeCarrico (1992) describe lexical phrases as prefabricated chunks of language, varying in length, that "exist somewhere between the traditional poles of lexicon and syntax" (p. 1). These chunks are familiar, conventionalized expressions that have particular functions and occur with high frequency. These set phrases have a fixed form which may or may not have slots to be filled in. Examples of lexical phrases include expressions such as "by the way" or "a _ ago" or "the _ er X, the _ er Y" (p. 1).

A characteristic of lexical phrases is that they are used in (unanalyzed) chunks; however, they can be analyzed for syntactic content.

...while lexical phrases are prefabricated lexical chunks that are readily accessible as completely or partially assembled units, they are also for the most part analyzable by regular rules of grammar. (Nattinger \& DeCarrico, 1992, p. 8).

Music also appears to have the equivalent of lexical phrases. Musical lexical phrases might include motifs such as jazz licks, riffs, and set figurations of kotekan, such as norot or a version of kotekan telu. These are also high frequency composites occurring in unanalyzed chunks that can be broken down. For example, W. Vitale (personal 
communication, 1993) observes that the patterns that occur in kotekan are very common and so well known that they require no thought or effort to perform. Yet, given a new and strange polos, a Balinese musician could come up with a sangsih by going back to the rules he knows about how sangsih is related to polos. Thus, at least parts of kotekan consist of unanalyzed, conventionalized chunks that can be broken down.

The ability to use lexical phrases contributes to a person's fluency in a language. Because the chunks are very familiar and "ready-made", they do not take a lot of processing effort for the speaker or the hearer. This promotes fluency.

It is our ability to use lexical phrases... that helps us speak with fluency. This prefabricated speech has both the advantage of more efficient retrieval and of permitting speakers (and hearers) to direct their attention to the larger structure of the discourse, rather than keeping it focused narrowly on individual words as they are produced. (Nattinger \& DeCarrico, 1992, p. 32)

Similarly, in music, processing effort affects fluency. This is one of the ideas behind Johnson-Laird's (1991) analysis of jazz and the computational effort involved.

In a musical improvisation, a musician has to generate notes in real time, and has no opportunity to go back to revise them. Hence, an optimal system will be one that operates highly efficiently and without the need for complex intermediate computations... It will place a minimal demand on the processing capacity of working memory. (p. 301)

Knowledge of and the ability to use (put together) musical figurations contribute to a musician's fluency, i.e., the ability to improvise with ease or come up with a sangsih part with ease. In other words, knowledge of the repertoire of riffs or telu patterns, and the ability to use them, for example, help musicians play fluently. Perlman and Greenblatt (1981) suggest

the musician accomplishes his/her aims through mastery of and spontaneous resort to a basic vocabulary of musical figures, interspersed with quotes and connected by scales and arpeggios. (pp. 175-176)

Perlman and Greenblatt note that "scales and arpeggios are the intermediate or transitional devices that hold the improvised line together and bridge the gap between individual licks" 
(p. 183). Thus, scales and arpeggios may also be thought of as kinds of musical lexical phrases.

Competence in language includes different kinds of knowledge. Nattinger and DeCarrico (1992) suggest

One's knowledge of language and one's ability to use it... include knowledge of how to create sentences 'from scratch' and knowledge of prefabricated patterns... and knowing how to select and retrieve ready-made form/function composites... for appropriate situations or contexts... (p. 13)

Thus, in language, creativity is expressed in the ability to form new sentences from scratch or from putting together prefabricated chunks.

Similarly, competence in music includes different kinds of knowledge. For example, Perlman and Greenblatt suggest that knowledge of the structure of jazz, the jazz licks, and knowing how to use licks are part of what a musician needs to know in order to be able to improvise. Improvisations are "facilitated by [musicians'] knowledge of the available harmonic and melodic possibilities and by their technical skill and imagination in combining and recombining these possibilities in novel ways" (p. 182).

creativity consists not in executing the prefabricated unit, but in producing it at exactly the right moment, so that it fits with unmistakable appropriateness at that point in the ... musical discourse. (p. 176)

The degree to which the lexical phrase / musical lexical phrase analogy holds is a topic for further research. What a musical lexical phrase is needs to be defined more precisely. The use of musical lexical phrases in the acquisition of a musical idiom is also a topic for further research.

\subsubsection{Extra-musical factors}

In this study extra-musical factors were not considered. A topic for further research then is to take into account some of these factors, although how to formalize them is unclear. For example, W. Vitale (personal communication, 1993) notes that in 
Balinese culture, the idea of ramai $^{25}$ is important in aesthetics. This is reflected in art, architecture and in the music. Some of the rules (e.g., KG2, KG4), and even the idea of interlocking parts are perhaps motivated by this concept.

\subsection{Implications}

This study fits into larger studies concerning how people organize and process information in their brains, and how machines can model human intelligence. The place of this study is given in the following hierarchy:

Cognitive Science (including linguistics, psychology, AI, music cognition)

Knowledge Representation \& Information Processing

Music Representation \& Models

Top Down Models

Linguistic Models of Music

Grammatical Models of Music

Non-Western Music

Balinese Music

Grammar of Kotekan

Just as linguistic grammars might provide insight into the organization of language in speakers' and hearers' minds, musical grammars might tell something about the organization of music in musicians' and listeners' minds. The similarities and differences between linguistic and musical grammars might also reveal something about human minds. This is an open field for research.

\footnotetext{
${ }^{25}$ Ramai, literally translated as "busy," refers to a Balinese concept in which ornate, intricate and balanced patterns are very desirable.
} 
As another example of a musical grammar, this study adds to the body of knowledge concerning musical grammars and possible universals. It is perhaps significant that the grammar in this study shares features with other musical grammars.

Linguistic grammars are useful for facilitating the recognition and parsing of language on computers. Similarly, musical grammars might be useful for facilitating the automatic transcription of music played, for example, on a keyboard with a MIDI interface. Musical grammars might also be used for generating music. For example, composers might use musical grammars to automatically generate a first pass for a harmony or a sangsih part.

This study contributes to the theoretical basis for further research on the use of music in the classroom for language teaching. For example, it gives insight for research concerning teaching techniques that exploit the parallels between the rhythmic and phrasal structures of music and language. In addition, this study might be a small piece of a theoretical basis for more teaching techniques utilizing aspects of cognition which are common to both music and language.

\subsection{Conclusion}

The natures of and the relationship between music and language can be examined more closely through the use of an information processing, linguistic framework. In particular, the use of this framework helps to clarify aspects of linguistic methodology and to test how far music and language analogies can be pushed.

Grammars are a precise and formal way of describing structure and regularities in linguistic and musical systems, and of describing aspects of competence. Linguistic and musical grammars share some features and differ in others. Similarities include the notions of deep and surface structure, variation related to structure, hierarchies of rules, rule conflicts and solutions, and the need, in general, for context sensitive rules. Because of 
the differences in the functions of language and music, the degree of importance of wellformedness versus preference in musical grammars is a topic for further research.

The grammar for Balinese kotekan presented in this study exhibits features that are similar to other musical grammars. The system can be described as a hierarchy of constraints from global tendencies to specific rules for various types of kotekan. In addition, there are deep and surface structures, variation related to structure, ranked or preference rules, spatio-motor considerations, and the need for context-sensitive rules. The structure of polos and sangsih parts as individual lines can be described by contextfree phrase structure rules. The relationship between polos and sangsih is described by transformations. The rules presented apply to kotekan when it is stable. Rules are needed to describe kotekan when it is moving and to describe other aspects of variation. The grammar presented, then, is a starting point for a complete grammar of Balinese kotekan. 


\section{REFERENCES}

Baily, J. (1985). Music Structure and Human Movement. In P. Howell, I. Cross, \& R. West (Eds.), Musical Structure and Cognition (pp. 237-258). London \& Orlando, FL: Academic Press Inc.

Baroni, M., Dalmonte, R., \& Jacoboni, D. (1992). Theory and Analysis of European Melody. In A. Marsden \& A. Pople (Eds.), Computer Representations and Models in Music (pp. 187-206). San Diego, CA: Academic Press Inc.

Becker, J. \& Becker, A. (1979). A Grammar of the Musical Genre Srepegan. Journal of Music Theory, 23(1), 1-43.

Becker, J. \& Becker, A. (1981). A Musical Icon: Power and Meaning in Javanese Gamelan Music. In W. Steiner (Ed.), The Sign in Music and Literature (pp. 203215). Austin: University of Texas Press.

Bernstein, L. (1976). The Unanswered Question. Cambridge, MA: Harvard University Press.

Bharucha, J. (1993). MUSACT: A Connectionist Model of Musical Harmony. In Schwanauer, S.M. \& Levitt, D.A. (Eds.) Machine Models of Music (pp. 496-509). Cambridge, MA: The MIT Press.

Blacking, J. (1970). Tonal organization in the music of two Venda initiation schools. Ethnomusicology, 14, 1-56.

Blacking, J. (1973). How musical is man? Seattle, WA: University of Washington Press.

Blacking, J. (1981). The Problem of "Ethnic" Perceptions in the Semiotics of Music. In W. Steiner (Ed.), The Sign in Music and Literature (pp. 184-194). Austin: University of Texas Press.

Camilleri, L. (1992). Computational Theories of Music: Theoretical and Applicative Issues. In A. Marsden \& A. Pople (Eds.), Computer Representations and Models in Music (pp. 171-186). San Diego, CA: Academic Press Inc.

Capwell, C. (1992). The Music of Indonesia. In B. Nettl, C. Capwell, I. Wong, T. Turino, P. Bohlman (Eds.), Excursions in World Music (pp. 134-164). Englewood Cliffs, NJ: Prentice-Hall Inc.

Celce-Murcia, M. \& Larsen-Freeman, D. (1983). The Grammar Book. Cambridge, MA: Newbury House. 
Chomsky, N. (1957). Syntactic Structures. The Hague: Mouton.

Chomsky, N. (1959). On Certain Formal Properties of Grammars. Information and Control, 2, 137-167.

Chomsky, N. (1965). Aspects of the Theory of Syntax. Cambridge, MA: MIT Press.

Chomsky, N. \& Halle, M. (1968). The Sound Pattern of English. New York: Harper \& Row.

Cope, D. (1993). A Computer Model of Music Composition. In Schwanauer, S.M. \& Levitt, D.A. (Eds.) Machine Models of Music (pp. 402-425). Cambridge, MA: The MIT Press.

Cross, I. (1985). Music and Change: On the Establishment of Rules. In P. Howell, I. Cross, \& R. West (Eds.), Musical Structure and Cognition (pp. 1-19). Orlando: Academic Press, Inc.

Dannenberg, R. B., (1993). Music Representation Issues, Techniques, and Systems. Computer Music Journal, 17(3), 20-30.

Dieterich, T. (1992, May). The Origin of Auxiliary Do. Paper presented at the meeting of the Natural Language Working Group, Portland State University, Portland, OR.

Dowling, W. J. \& Harwood, D, L. (1986). Music Cognition. Orlando FL: Academic Press Inc.

Feld, S. (1974). Linguistic Models in Ethnomusicology. Ethnomusicology, 18, 179-217.

Fromkin, V. \& Rodman, R. (1988). An Introduction to Language (4th ed.). Orlando, FL: Holt, Rinehart and Winston, Inc.

Gardner, H. (1993). Frames of mind (Tenth-Anniversary Edition). New York: Basic Books (A division of Harper Collins Publishers).

Giauque, G. S. (1985). Foreign Language Acquisition and the Study of Music. (ERIC Document Reproduction Service No. ED 264 738).

Gonzalez, R. C. \& Thomason, M. G. (1978). Syntactic Pattern Recognition. Reading, MA: Addison-Wesley Publishing Co.

Grice, P. (1975). Logic and Conversation. In P. Cole \& J. Morgan (Eds.), Syntax and Semantics (pp. 22-40). New York: Academic Press, Inc. 
Howell, P., Cross, I., \& West, R. (Eds.). (1985). Musical Structure and Cognition. Orlando, FL: Academic Press, Inc.

Hughes, D. W. (1988). Deep Structure and Surface Structure in Javanese Music: A Grammar of Gendhing Lampah. Ethnomusicology, 23, 23-74.

Hughes, D. W. (1991). Grammars of Non-Western Musics: A Selective Survey. In P. Howell, I. Cross, \& R. West (Eds.), Representing Musical Structure (pp. 327362). San Diego: Academic Press.

Johnson-Laird, P. N. (1991). Jazz Improvisation: A Theory at the Computational Level. In P. Howell, I. Cross, \& R. West (Eds.), Representing Musical Structure (pp. 291325). San Diego: Academic Press.

Keiler, A. R. (1978). Bernstein's The Unanswered Question and the Problem of Musical Competence. Musical Quarterly, 64(2), 195-222.

$\checkmark$ Keiler, A. R. (1981). Two Views of Musical Semiotics. In W. Steiner (Ed.), The Sign in Music and Literature (pp. 138-168). Austin: University of Texas Press.

Kenstowicz, M. \& Kisseberth, C. (1979). Generative Phonology. New York: Academic Press, Inc.

Kippen, J. \& Bel, B. (1992). Modelling Music with Grammars: Formal Language Representation in the Bol Processor. In A. Marsden \& A. Pople (Eds.), Computer Representations and Models in Music (pp. 207-237). San Diego, CA: Academic Press Inc.

Leman, M. (1992). Artificial Neural Networks in Music Research. In A. Marsden \& A. Pople (Eds.), Computer Representations and Models in Music (pp. 265-301). San Diego, CA: Academic Press Inc.

Levman, B. (1992). The Genesis of Music and Language. Ethnomusicology, 36, 147-70.

Lerdahl, F., \& Jackendoff, R. (1983). A Generative Theory of Tonal Music. Cambridge, MA: The MIT Press.

Levitt, D. (1993). A Representation for Musical Dialects. In S. Schwanauer \& D. Levitt (Eds.), Machine Models of Music, (pp. 455-469). Cambridge, MA: The MIT Press.

Liberman, M. \& Prince, A. (1977). On Stress and Linguistic Rhythm. Linguistic Inquiry 8(2), 249-336. 
Longuet-Higgins, H.C. (1993). The Perception of Melodies. In S. Schwanauer \& D. Levitt (Eds.), Machine Models of Music, (pp. 470-495). Cambridge, MA: The MIT Press.

Lyons, J. (1968). Introduction to Theoretical Linguistics. New York: Cambridge University Press.

Marsden, A. \& Pople, A. (1992). Introduction: Music, Computers and Abstraction. In A. Marsden \& A. Pople (Eds.), Computer Representations and Models in Music (pp. 1-4). San Diego, CA: Academic Press Inc.

McPhee, C. (1966). Music in Bali. New Haven, CT: Yale University Press.

Nattinger, J. \& DeCarrico, J. (1992). Lexical Phrases and Language Teaching. Oxford: Oxford University Press.

Nettl, B. (1992). Introduction: Studying Musics of the World's Cultures. In B. Nettl, C. Capwell, I. Wong, T. Turino, P. Bohlman (Eds.), Excursions in World Music (pp. 1-13). Englewood Cliffs, NJ: Prentice-Hall Inc.

Nord, L., Kruckenberg, A., \& Fant G. (1990). Some Timing Studies of Prose, Poetry and Music. Speech Communication, 9, 477-483.

Perlman, A. M., \& Greenblatt, D. (1981). Miles Davis Meets Noam Chomsky: Some Observations on Jazz Improvisation and Language Structure. In W. Steiner (Ed.), The Sign in Music and Literature (pp. 169-183). Austin: University of Texas Press.

- Powers, H. S. (1980). Language models and musical analysis. Ethnomusicology, 24, 1-61.

Radford, A. (1988). Transformational Grammar: A First Course. New York: Cambridge University Press.

Rahn, J. (1983). A Theory for All Music: Problems and Solutions in the Analysis of NonWestern Forms. Toronto: University of Toronto Press.

Roads, C. (1985). Grammars as Representations for Music. In C. Roads \& J. Strawn (Eds.), Foundations of Computer Music, (pp. 403-442). Cambridge, MA: The MIT Press.

Sagi, M., \& Vitanyi, I. (1988). Experimental research into musical generative ability. In J. Sloboda (Ed.), Generative Processes in Music, (pp. 179-194). Oxford: Clarendon Press. 
Sloboda, J. A. (1985). The Musical Mind: The cognitive psychology of music. New York: Oxford University Press.

Stillings, N., Feinstein, M., Garfield, J.L., Rissland, E.L., Rosenbaum, D.A., Weisler, S.E., \& Baker-Ward, L.(1987). Cognitive Science An Introduction. Cambridge, MA: The MIT Press.

Sundberg, J., Friberg, A. \& Fryden, L. (1991). Common Secrets of Musicians and Listeners: An Analysis-by-synthesis Study of Musical Performance. In P. Howell, I. Cross, \& R. West (Eds.), Representing Musical Structure (pp. 161-197). San Diego: Academic Press.

Sundberg, J., \& Lindblom, B. (1976). Generative theories in language and music descriptions. Cognition, 4, 99-122.

Sundberg, J., \& Lindblom, B. (1991). Generative Theories for Describing Musical Structure. In P. Howell, I. Cross, \& R. West (Eds.), Representing Musical Structure (pp. 245-272). San Diego: Academic Press.

Tenzer, M. (1991). Balinese Music. Seattle, WA: University of Washington Press.

Vitale, W. (1990). Kotekan: the technique of interlocking parts in Balinese music. Balungan, 4(2), 2-15.

Wardhaugh, R. (1986). An Introduction to Sociolinguistics. Cambridge, MA: Basil Blackwell.

West, R., Howell, P., \& Cross, I. (1985). Modelling Perceived Musical Structure. In P. Howell, I. Cross, \& R. West (Eds.), Musical Structure and Cognition (pp. 21-52). London \& Orlando, FL: Academic Press Inc.

West, R., Howell, P. \& Cross, I. (1991). Musical Structure and Knowledge Representation. In P. Howell, I. Cross, \& R. West (Eds.), Representing Musical Structure (pp. 1-30). San Diego: Academic Press.

Wiggins, G., Miranda, E., Smaill, A., \& Harris, M. (1993). A Framework for the Evaluation of Music Representation Systems. Computer Music Journal, 17(3), 3142.

Winograd, T. (1968). Linguistics and the computer analysis of tonal harmony. Journal of Music Theory, 12(1), 2-49.

Winograd, T. (1983). Language as a Cognitive Process. Reading, MA: Addison-Wesley Publishing Co. 


\section{APPENDIX A ${ }^{1}$}

For all scores:

Bottom staff $=$ pokok Top staff $=$ kotekan $\quad$ Stem down $=$ polos $\quad$ Stem up $=$ sangsih

(a)

(b)

(a)

(b)

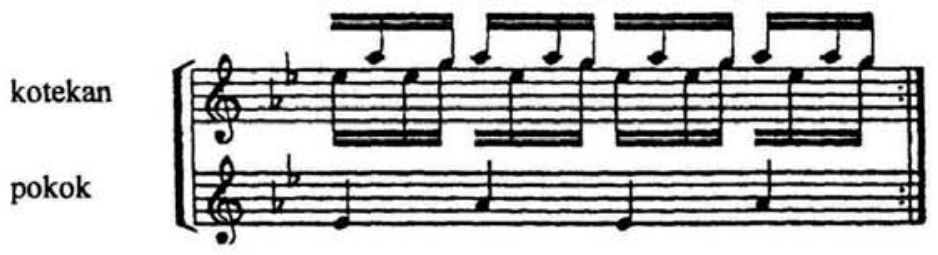

Figure 23. Example of kotekan and pokok.

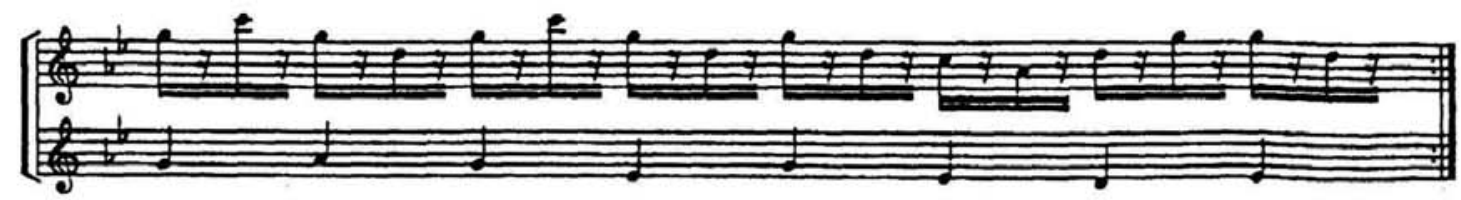

Figure 24. Polos part of oncang-oncangan.

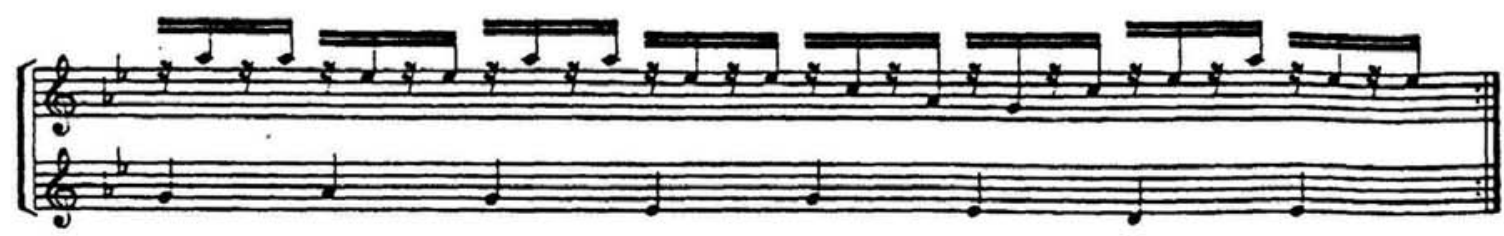

Figure 25. Sangsih part of oncang-oncangan.

(a)

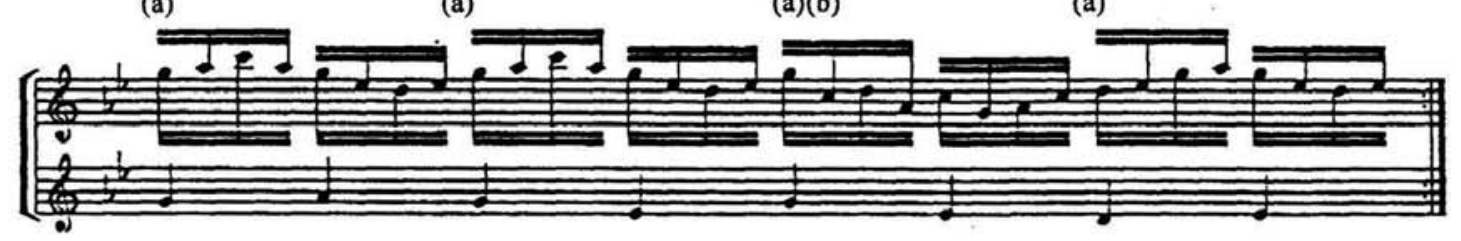

Figure 26. Composite of polos and sangsih in oncang-oncangan.

\footnotetext{
${ }^{1}$ Source: Vitale (1990)
} 


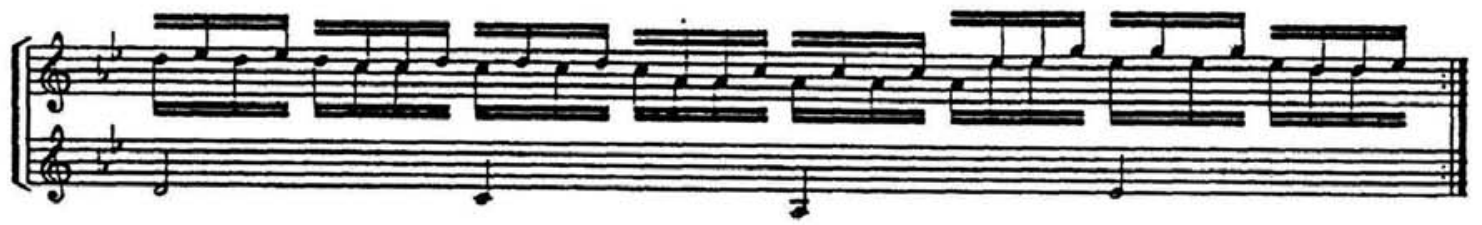

Figure 27. Norot figuration.

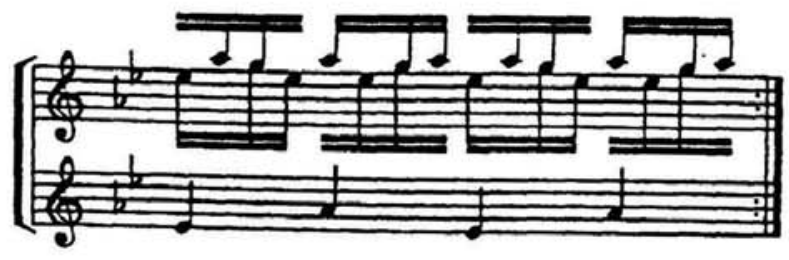

Figure 28. Kotekan telu.

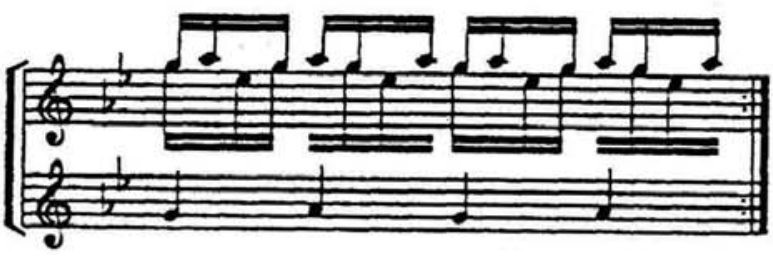

Figure 29. Kotekan telu.

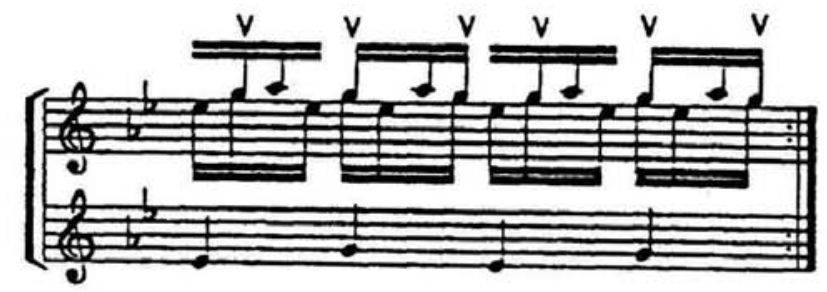

Figure 30. Kotekan telu. Shared notes are marked. 


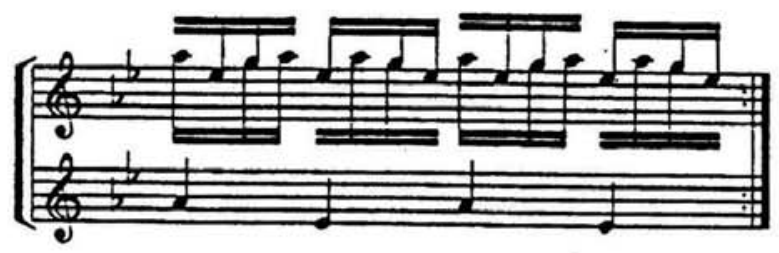

Figure 31. Kotekan telu with sangsih below polos.

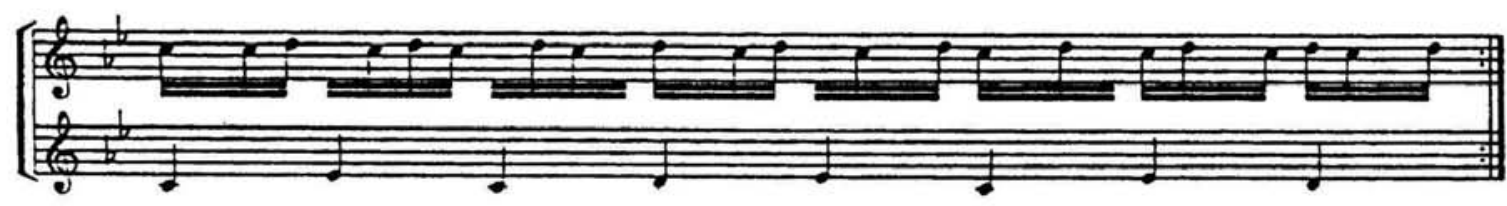

Figure 32. Kotekan empat: polos.

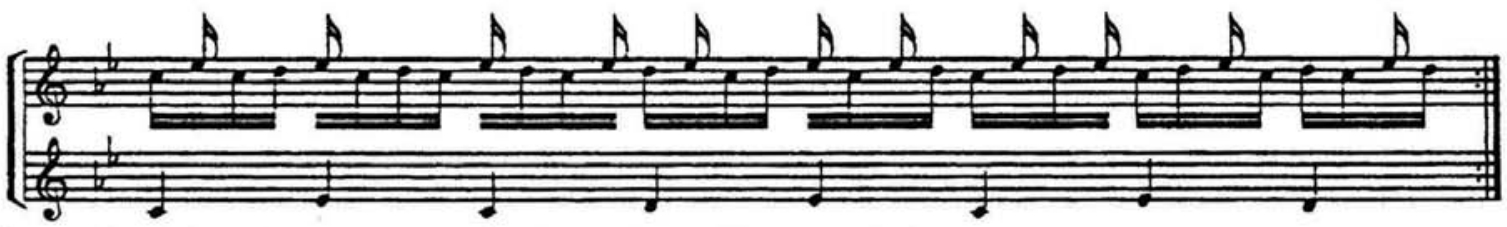

Figure 33. Kotekan empat: Application of R->c rule for generating sangsih from polos.

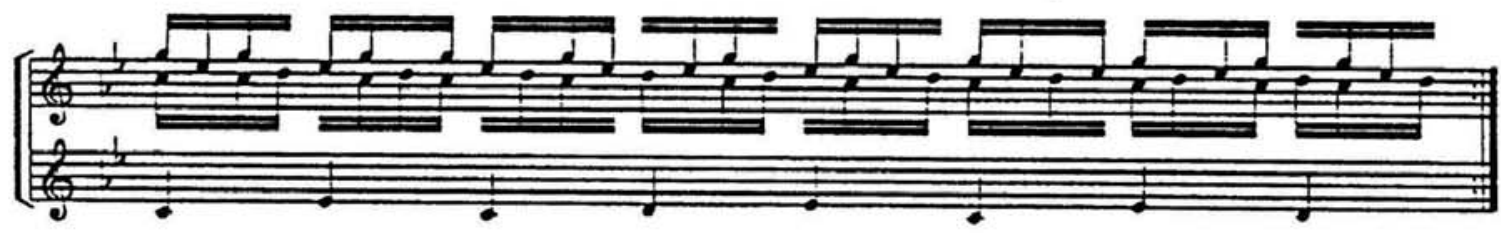

Figure 34. Kotekan empat: Complete figuration that results by applying $b->R$ and $a->d$ rules to Figure 33. 


\section{APPENDIX B}

\section{Global Rules}

GR1. The parts of the ensemble coincide at structurally important points. These points are metrically strong points.

GR2. Musical lines are composed of tones that are repeated, adjacent or 2 steps away.

\section{Kotekan Generalizations}

KG1. At structurally important points in a piece, the kotekan meets up with (i.e., joins at the unison or octave with) the core. This rule is a specific case of GR1.

KG2. The kotekan should surround the notes of the core melody. For example, if the core makes a jump up, the kotekan movement is to follow it up. If the core movement is downward, the kotekan will follow it downward.

KG3. The polos is usually the part of the kotekan that meets up with (i.e., joins at the unison or octave with) the pokok at structurally important beats. This affects the polos-to-sangsih rules given in Section 3.3.4.

KG4. The kotekan as a line is continuous; i.e., there should not be breaks in sound.

\section{Rules for Polos and Sangsih as Individual Lines.}

PSL1. Never more than 3 notes are played in a row; i.e., 1, 2 or 3 notes are played and then there must be a rest.

PSL2. Only single rests are allowed; i.e., there are never 2 or more rests in a row.

PSL3. Never 3 notes of the same pitch are played in a row. (2 of the same pitch in a row is also rare.)

PSL4. Pitches of the scale are adjacent when temporally adjacent. If there is a rest in between, then the tones do not have to be adjacent. 
Let: $\quad$ PSL $=$ polos or sangsih line $\quad \mathrm{R}=$ rest

$$
\begin{array}{ll}
\mathrm{NP}=\text { note phrase } & \mathrm{a}=\text { note } \\
\mathrm{b}=\text { adjacent note to } \mathrm{a}
\end{array}
$$

Phrase Structure Rules for Generating Polos and Sangsih Lines

PSL $\rightarrow$ (R) NP

$\mathrm{NP} \rightarrow \mathrm{a}$ (b) (a) R (NP)

\section{Polos/Sangsih Relationship}

PSR1. The polos part is below the sangsih part; i.e., the sangsih is above the polos in pitch.

PSR2. The polos is considered the "simple" part that tends to play on the beat. The sangsih is considered the "differing" part that tends to play off the beat.

\section{Oncang-oncangan}

O1. Polos is always on the beat.

O2. Sangsih is always off the beat.

Let: $\quad a=$ polos note

$\mathrm{b}=$ sangsih note

$\mathrm{R}=$ rest

polos $\rightarrow$ sangsih

(1) $a->R$

(2) $\mathrm{R}->\mathrm{b}$

\section{Norot}

N1. Sangsih is always above polos.

N2. Sangsih is always adjacent to polos.

N3. Sangsih and polos anticipate the next core note -3 beats ahead of it.

Let: $\quad a=$ core note

$\mathrm{b}=$ higher adjacent note to (a)

$\mathrm{c}=$ next core note

$\mathrm{d}=$ higher adjacent note to (c)

$\mathrm{R}=$ rest 
core $\rightarrow$ polos

a $\rightarrow$ a R a R a

c $\rightarrow$ c c R core $\rightarrow$ sangsih

a $\rightarrow$ R b R b R

$c \rightarrow c$ d

polos $\rightarrow$ sangsih

a $\rightarrow$ R

$\mathrm{R}->\mathrm{b} /$ not_\#

$\mathrm{R} \rightarrow \mathrm{d} /{ }_{-} \#$

$c->c$

\section{Stationary Telu}

ST1. Every inner polos = inner sangsih; i.e., the middle (shared) note is played in unison.

ST2. Wherever there is a rest in polos, play the outer sangsih.

Let $\quad \mathrm{a}=$ outer polos

$\mathrm{b}=$ inner polos (middle note of 3 note cell)

$\mathrm{c}=$ adjacent to $\mathrm{b}$, not equal to $\mathrm{a}$

$\mathrm{R}=$ rest

polos $\rightarrow$ sangsih

(1) $a->R$

(2) $b->b$

(3) $\mathrm{R} \rightarrow \mathrm{c}$

\section{Empat}

E1. Every lower polos is matched by upper sangsih.

E2. Wherever there is a rest in polos, play lower sangsih.

E3. Polos is always below sangsih.

Let: $\quad \mathrm{a}=$ outer polos (lower)

$\mathrm{b}=$ inner polos (upper)

$\mathrm{c}=$ upper adjacent to $\mathrm{b}$

$\mathrm{d}=$ upper adjacent to $\mathrm{c}$ ( 2 up from a)

$\mathrm{R}=$ rest

polos $\rightarrow$ sangsih
(1) $a->d$
(2) $b \rightarrow r$
(3) $R->c$ 


\section{APPENDIX C}

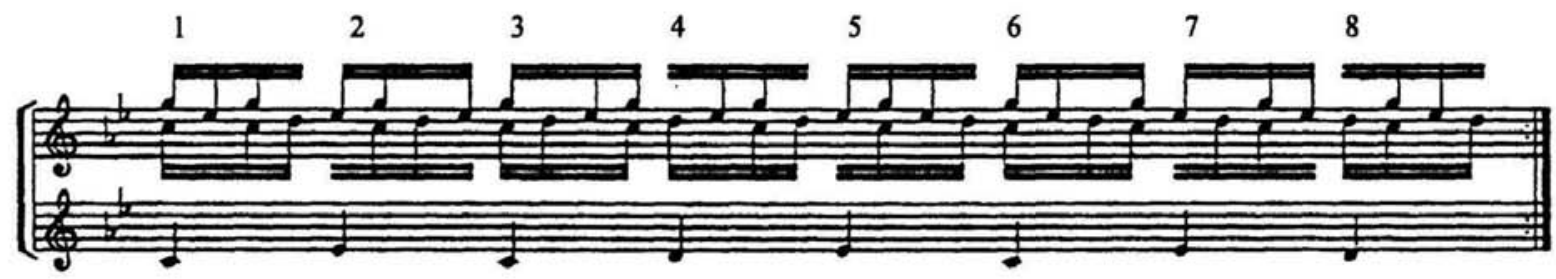

Figure 35. Excerpt from Baris. ${ }^{2}$

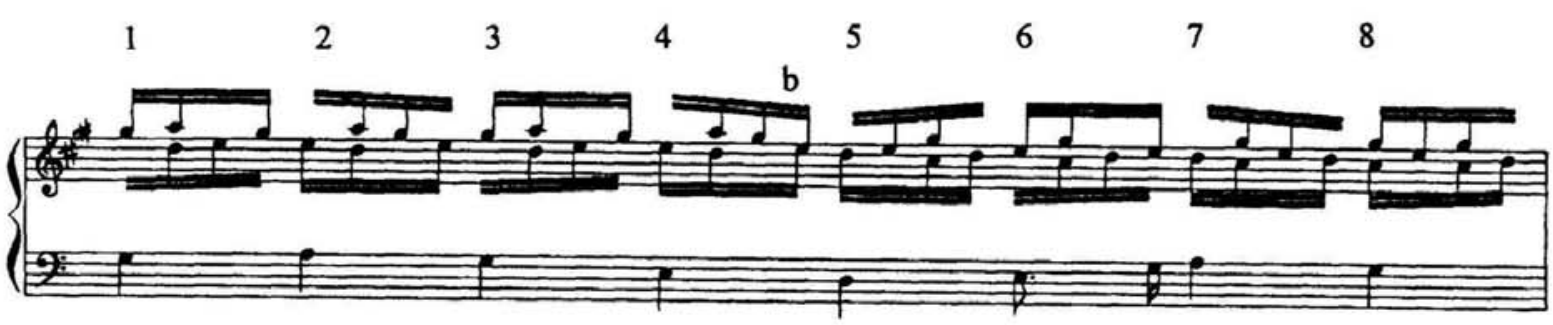

a

a

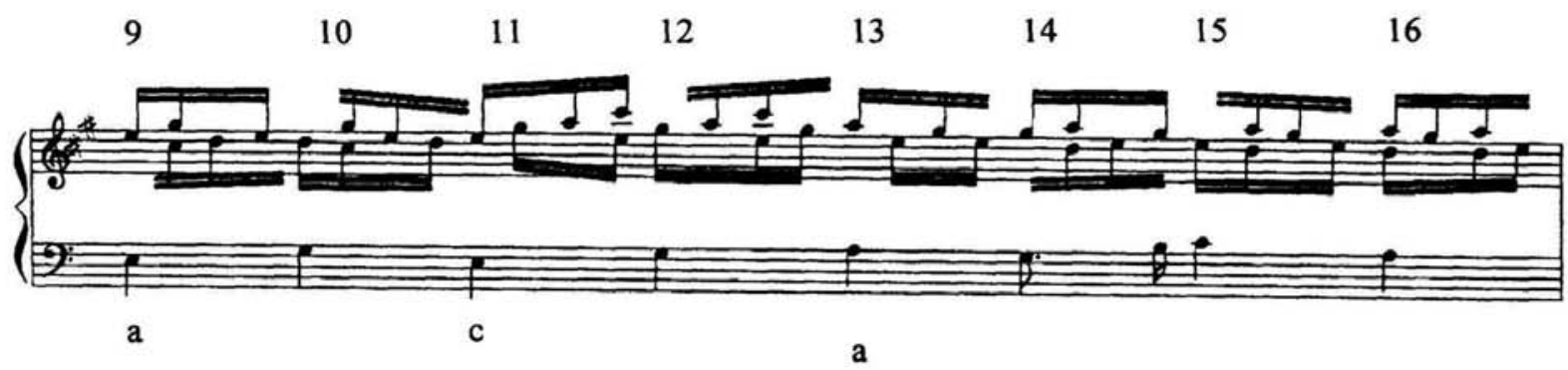

Figure 36. Excerpt from Legong Keraton. ${ }^{3}$

${ }^{2}$ Source $=$ Vitale $(1990)$.

${ }^{3}$ Source $=W$. Vitale (personal communication, 1994). 

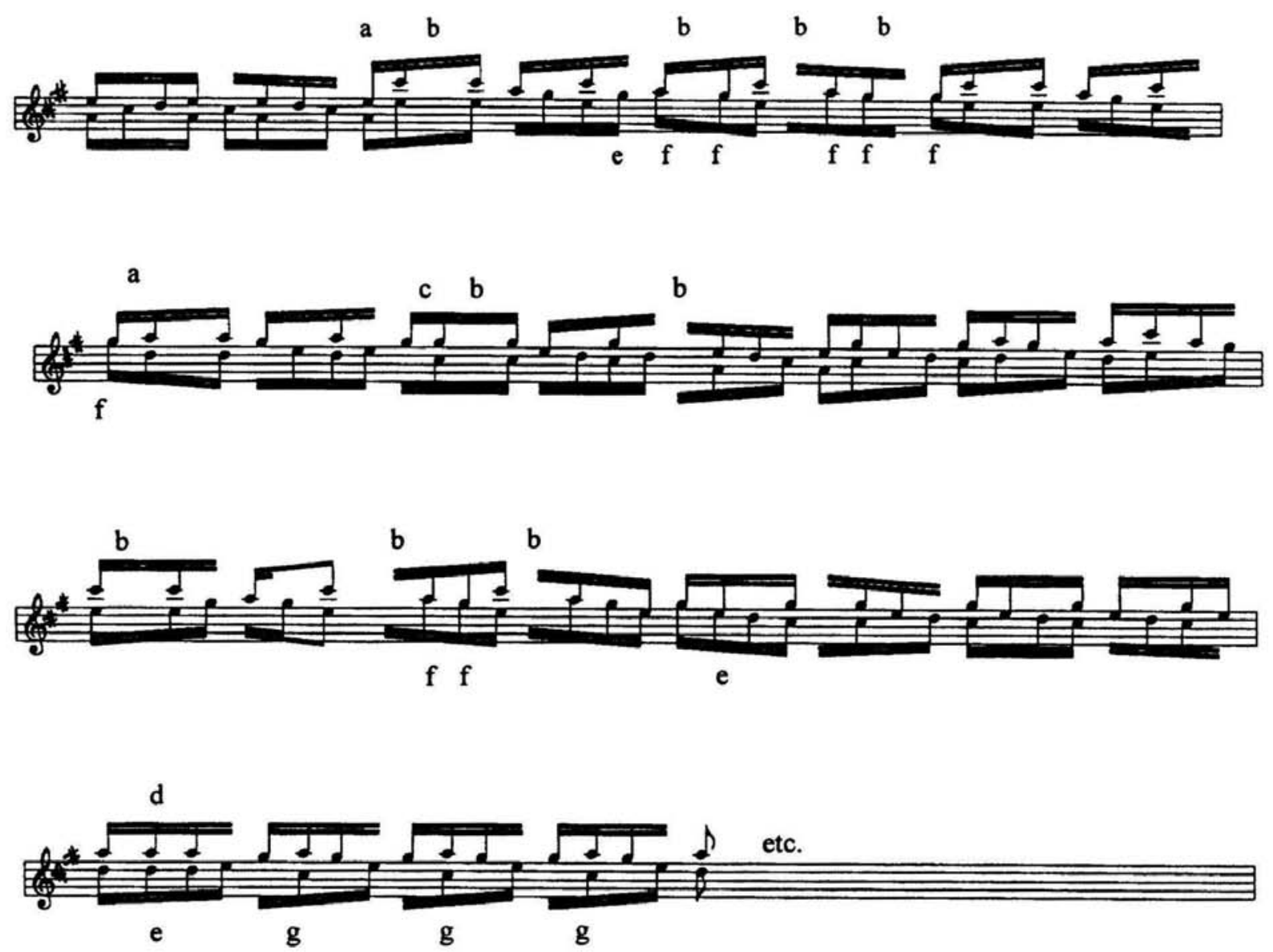

Figure 37. Excerpt from Gora Merdawa. ${ }^{4}$

${ }^{4}$ Source $=\mathrm{W}$. Vitale (personal communication, 1994) 